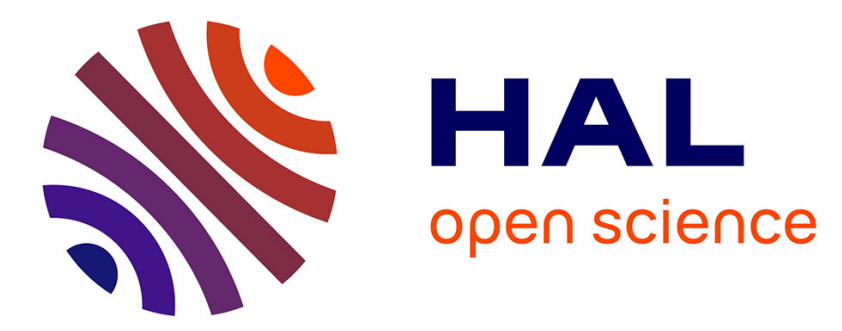

\title{
La dynamique de création, réplication et déclin des lieux de pèlerinage: le nouveau pèlerinage de Shikoku à Sasaguri
}

Kazuhisa Nakayama, Anne Bouchy

\section{- To cite this version:}

Kazuhisa Nakayama, Anne Bouchy. La dynamique de création, réplication et déclin des lieux de pèlerinage: le nouveau pèlerinage de Shikoku à Sasaguri. Cahiers d'Extrême-Asie, 2013, no. 22, p. 269-350. halshs-03134699

\section{HAL Id: halshs-03134699 \\ https://shs.hal.science/halshs-03134699}

Submitted on 8 Feb 2021

HAL is a multi-disciplinary open access archive for the deposit and dissemination of scientific research documents, whether they are published or not. The documents may come from teaching and research institutions in France or abroad, or from public or private research centers.
L'archive ouverte pluridisciplinaire HAL, est destinée au dépôt et à la diffusion de documents scientifiques de niveau recherche, publiés ou non, émanant des établissements d'enseignement et de recherche français ou étrangers, des laboratoires publics ou privés. 


\title{
La dynamique de création, réplication et déclin des lieux de pèlerinage : le nouveau pèlerinage de Shikoku à Sasaguri
} Kazuhisa Nakayama, Anne Bouchy

\begin{abstract}
The present article examines the dynamics between inside and outside of pilgrimage in studying the case of Sasaguri New Shikoku Holy Places (Sasaguri Shin-Shikoku reijō). As a result, it became possible to distinguish four facets of these dynamics: 1. dynamics by which the pilgrimage places are generated (dynamics of generation), 2. dynamics by which pilgrims going to visit these places are generated (dynamics of reception), 3. dynamics by which pilgrimage places change pilgrims (dynamics of action), and 4. dynamics by which pilgrims change pilgrimage places (dynamics of re-creation). The first and the fourth are dynamics that concern the pilgrimage places (creation and changes of the pilgrimage places), and the second and the third are dynamics concerning the pilgrims (use of pilgrimage places by pilgrims). What becomes evident in these dynamics is the power sustained on the notion of utsushi, that is "to copy", or "to transfer", or "to shift", or "to reflect". By imitating the resource of subtle power (reiryoku) and authority (iryoku) of the outside, it is possible to create inside a new culture of pilgrimage by using little resources of effort and knowledge. The appropriation of patterns is a creative method, and is the driving power of changing society and culture.

Pilgrimage can change humans, but in Sasaguri' s pilgrimage places, it is not only the pilgrims, but also the object of pilgrimage, that is those people who manage and control the holy places and who take care of pilgrims, who are changed: their identity consciousness and economic situation are drastically transformed. It is the pilgrimage places and those living there that are the object of ceaseless change.
\end{abstract}

\section{Citer ce document / Cite this document :}

Nakayama Kazuhisa, Bouchy Anne. La dynamique de création, réplication et déclin des lieux de pèlerinage : le nouveau pèlerinage de Shikoku à Sasaguri. In: Cahiers d'Extrême-Asie, vol. 22, 2013. Le vivre ensemble à Sasaguri, une communauté de Kyūshū. Dans l'entrelacs des dynamiques du dedans et du dehors. pp. 269-350;

doi : https://doi.org/10.3406/asie.2013.1420

https://www.persee.fr/doc/asie_0766-1177_2013_num_22_1_1420

Fichier pdf généré le 06/02/2019 


\title{
LA DYNAMIQUE DE CRÉATION, RÉPLICATION ET DÉCLIN DES LIEUX DE PÈlerinAGE : LE NOUVEAU PÈlerinage de SHIKOKU À SASAgURI
}

NaKayama Kazuhisa 中山和久

\begin{abstract}
The present article examines the dynamics between inside and outside of pilgrimage in studying the case of Sasaguri New Sbikoku Holy Places (Sasaguri Shin-Sbikoku reijo 篠栗新四国需場). As a result, it became possible to distinguish four facets of these dynamics: 1. dynamics by which the pilgrimage places are generated (dynamics of generation), 2. dynamics by which pilgrims going to visit these places are generated (dynamics of reception), 3. dynamics by which pilgrimage places change pilgrims (dynamics of action), and 4. dynamics by which pilgrims change pilgrimage places (dynamics of re-creation). The first and the fourth are dynamics that concern the pilgrimage places (creation and changes of the pilgrimage places), and the second and the third are dynamics concerning the pilgrims (use of pilgrimage places by pilgrims). What becomes evident in these dynamics is the power sustained on the notion of utsushi ウツシ, that is 写 or “to copy," 移 or “to transfer,"要 or “to shift," and 映 or "to reflect." By imitating the resource of subtle power (reiryoku 霊力) and authority (iryoku 威力) of the outside, it is possible to create inside a new culture of pilgrimage by using little resources of effort and knowledge. The appropriation of patterns is a creative method, and is the driving power of changing society and culture.

Pilgrimage can change bumans, but in Sasaguri's pilgrimage places, it is not only the pilgrims, but also the object of pilgrimage, that is those people who manage and control the boly places and who take care of pilgrims, who are changed: their identity consciousness and economic situation are drastically transformed. It is the pilgrimage places and those living there that are the object of ceaseless change.
\end{abstract}

Faisant voyager dans le monde extérieur par-delà les frontières de l'univers intérieur, le pèlerinage (junrei 巡礼) est la source d'expériences marquantes pour celui qui l'entreprend et il transforme souvent sa vie. Combinaison complexe de multiples dimensions idéelles, rituelles, spatiales et organisationnelles, le pèlerinage peut être regardé comme un dispositif culturel performant, capable de modifier l'intériorité par le biais de son organisation et de sa réalisation. À ce titre, on peut dire que c'est une technique laborieusement et hautement élaborée par l'humanité en vue de manipuler l'esprit.

Mais le pèlerinage contribue aussi à changer le monde extérieur. De nombreux exemples montrent que les éléments culturels rapportés de l'extérieur par les pèlerins ont transformé les sociétés locales. On peut évoquer l'importance de l'impact qu'eurent les pèlerins de Saint-Jacques-de-Compostelle dans la Reconquista ou encore celui du pèlerinage de Jérusalem sur les Croisades. Ainsi, par le biais des 
dynamiques du debors et du dedans, les pèlerinages n'ont cessé de représenter une importante force de transformation culturelle et sociale à l'échelle de la planète. Et c'est le cas au Japon.

Sur le sol japonais s'est répandue la pratique pérégrine consistant à relier les uns à la suite des autres plusieurs dizaines de sites de pèlerinage dont le chiffre consacré est de 33 ou de 88 . On peut penser qu'il s'agit là d'un efficace dispositif symbolique susceptible d'apporter des modifications dans l'esprit et le comportement du pèlerin.

Je voudrais ici examiner cette action du pèlerinage sous les quatre angles différents des dynamiques de transformation produites par les lieux de pèlerinage, par les pèlerins, par les lieux de pèlerinage sur les pèlerins et par les pèlerins sur les lieux de pèlerinage, en partant de l'analyse de ces influences réciproques qui se développent entre l'intérieur et l'extérieur dans le cas concret du pèlerinage de Shikoku à Sasaguri 篠栗.

\section{Arrière-plan de cette étude}

\section{Les recherches japonaises sur le pèlerinage}

C'est au début du $\mathrm{Xx}^{\mathrm{e}}$ siècle que commencèrent véritablement les recherches sur les pèlerinages au Japon. Les articles de Fujita Akira 藤田明 ( (Origine des trentetrois lieux de la région occidentale et de leur pèlerinage $»)^{1}$ en 1907 et de Hara Hideshirō 原秀四郎 ( $\mathrm{A}$ propos des recherches sur les quatre-vingt-huit lieux [de pèlerinage] $")^{2}$ en 1909 furent les premier à traiter du pèlerinage en tant qu'objet d'étude des sciences humaines et sociales contemporaines. Ces travaux d'histoire avaient pour objectif de mettre en lumière la formation et le développement historique de deux pèlerinages célèbres : celui des trente-trois temples du Kansai 関西 dédiés au bodhisattva Kannon 観音菩薩 et celui des quatre-vingt-huit temples de Shikoku, légendairement fondé par Kūkai 空海 (774-835). Et si l'on excepte les recherches de détail, les travaux sur les lieux saints arrivèrent à maturité vers 1975 . L'aboutissement en fut l'ouvrage de Shinjō Tsunezō 新城常三 ( Nouvelle étude d'histoire socioéconomique des pèlerinages aux temples et sanctuaires ») en 1982. À partir des années 1970, s'engagèrent des approches du pèlerinage autres que celle des historiens, comme celles des spécialistes d'ethnologie du Japon, de sociologie ou de géographie qui, s'intéressant majoritairement au point de vue de l'acteur du pèlerinage, développèrent une ligne de travaux sur le pèlerin à partir de l'analyse de ses appartenances sociales, de ses mobiles, des réalités de ses pratiques,

I. Fujita Akira 滕田明, “Saigoku sanjū san-sho reijō to junrei no ken.yo 》 西国三十三所

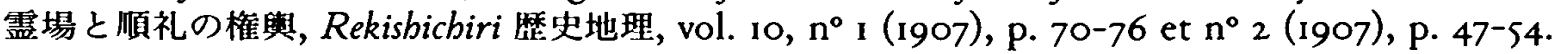

2. Hara Hideshirō 原秀四郎, «Hachijū hakka-sho no kenkyū ni tsuite 》八十八ヶ所の研究 について, Yüsei 有声, $\mathrm{n}^{\circ} 32$ (1909).

3. Shinjō Tsunezō 新城常三, Shinkō Shaji sankei no shakai keizaishi teki kenkyū 新稿社寺参 詣の社会経済史的研究, 1982 . 
de ses coutumes, organisations, rites et référentiels conceptuels ou spirituels ${ }^{4}$. Et plus particulièrement, à la suite de l'introduction par Hoshino Eiki 星野英紀 de la théorie de la communitas de Victor Turner, qui concorda avec l'essor du structuralisme et de la phénoménologie, se développèrent de brillantes recherches sur la question, tant dans les sciences religieuses qu'en anthropologie culturelle. Ceci fut à l'origine de micro-approches s'intéressant à des cas particuliers et concrets de pèlerins, ou encore d'études portant sur le point de vue de ce qui est objet de pèlerinage, qui mirent en lumière les pratiques d'accueil des pèlerins (settai 接待), l'industrie du pèlerinage, les organisations locales gérant les lieux saints, etc.

Mais bien qu'il y ait aujourd'hui une importante masse de travaux sur le pèlerinage, ceux-ci se sont pour l'essentiel focalisés sur les grands pèlerinages du Kansai et de Shikoku, alors qu'est encore très bref l'historique des études traitant, comme la présente contribution, du pèlerinage de Shikoku à Sasaguri, c'est-à-dire des petits pèlerinages régionaux que l'on trouve dans tout le pays, et des sites secondaires ou des réplications locales des grands pèlerinages. Le premier chercheur à avoir travaillé sur cette question dès 1959 est Gorai Shigeru 五来重 ${ }^{5}$, qui en signala très tôt les interrelations avec le bouddhisme coutumier fortement implanté dans les pratiques locales de tout le pays. Pourtant, ce n'est qu'à partir du milieu des années i980 que cette approche fut approfondie, après n'avoir d'abord donné lieu qu'à des rapports fragmentaires.

En 1984, dans son article sur les origines du pèlerinage de Shikoku dans l'île de Shōdo 小豆島 (dans la mer intérieure de Seto 瀬戸内海) ${ }^{6}$, Oda Masayasu 小田匡保 analysa spatialement et socialement les conditions du pèlerinage répliqué (utsushi junrei ウツシ巡礼); en 1985, partant de l'étude du pèlerinage de Shikoku dans la basse région du fleuve Tone 利根川 (département de Chiba 千葉県) ${ }^{7}$, en tenant scrupuleusement compte de la dimcnsion historique, Kojima Hiromi 小嶋博巳 examina la façon dont l'usage des lieux de pèlerinage se modifie dans le temps en fonction des conditions socioéconomiques de chaque époque; et en 1986, dans un article portant sur les pèlerinages locaux de la région du Kansai, Tanaka Tomohiko 田中 智彦 théorisa la réflexion sur la propagation, la diffusion et le développement des

4. Takeda Akira 武田明, Junrei to minzoku 巡礼の民俗, 1969. Gorai Shigeru 五来重, «Shinkō. Henro, junrei, yugyō hijiri » 信仰一遍路 - 巡礼 - 遊行聖, Dentō to gendai 伝統と現代, vol. $2, \mathrm{n}^{\circ} 3$ (1969), p. 70-75. Maeda Takashi 前田卓, Junrei no shakaigaku 巡礼の社会学, 1971. Shinno Toshikazu 真野俊和, “Shikoku henro e no michi. Junrei no shisō 》四国遍路への道 : 巡礼の思想, Kikan gendai sbükyō 季刊現代宗教, vol. I, n ${ }^{\circ} 3$ (1975), p. 106-122. Hoshino Eiki 星野英紀, «Hikaku junrei ron no kokoromi »比較巡礼論の試み, dans Bukkyō minzoku gakkai 仏教民俗学会, éd., Bukkyō to girei 仏教と儀礼, 1977, P. 239-256. Tanaka Hiroshi 田中博, Junreichi no sekai 巡礼地の世界, 1983. Aoki Tamotsu 青木保, Ontake junrei 御岳巡礼, 1985. Kojima Hiromi 小嶋博巳, éd., Saigoku junrei sanjü san-do gyōja no kenkȳ̄ 西国巡礼三十三度行者の研究, 1993.

5. Gorai Shigeru 五来重, Bukkyō to minzoku 仏教と民俗, dans Shinkō to minzoku 信仰と民俗, Nihon minzokugaku taikei 日本民俗学大系, vol. 8 (1959) p. 323-34I.

6. Oda Masayasu 小田匡保, «Shōdo shima ni okeru utsushi reijō no seiritsu » 小豆島にお ける写し霊場の成立, Jinbun chiri 人文地理, vol. 36, $\mathrm{n}^{\circ} 4$ (1984), p. 347-36r.

7. Kojima Hiromi 小鴄博巳, “Tonegawa karyū.iki no shin Shikoku junrei 》利根川下流域 の新四国巡礼, Seijo bungei 成城文芸, $\mathrm{n}^{\circ} 113 / 114$ (1985), p. 128-164. 
pèlerinages. Il proposa un modèle théorique de leur développement : " lieux de pèlerinages nationaux $\rightarrow$ lieux de pèlerinages régionaux (provinciaux) $\rightarrow$ lieux de pèlerinages urbains $\rightarrow$ lieux de pèlerinages cantonaux ${ }^{8} »$. Depuis cette date, c'est autour de ces trois chercheurs que se sont organisés les travaux sur les pèlerinages de petite dimension'.

Prenant ces résultats pour fondement et pour thématique principale de mes recherches, les pèlerinages locaux, j'ai moi-même travaillé sur la question des lieux saints d'une part, et sur celle du pèlerin d'autre part ${ }^{10}$. Ici, tout en revisitant les études et les théories sur les fluctuations et les dynamiques des pèlerinages vus sous l'angle de la fondation et de l'utilisation des lieux qui en font l'objet, je voudrais tenter d'en faire la synthèse. Je prendrai pour matériaux principaux les données historiques et ethnographiques : mon objectif est de saisir le développement historique de l'action réciproque que produisent, les uns sur les autres, lieux de pèlerinage et pèlerins, ainsi que les variations des structures pérégrines, afin de renouveler l'approche du pèlerinage sous l'angle de ses dynamiques ${ }^{11}$. Ma problématique s'organise autour de quatre axes qui correspondent au développement du pèlerinage, c'est-à-dire : pourquoi fonde-t-on des lieux de pèlerinage (dynamique de création des pèlerinages); pourquoi se rend-on en pèlerinage sur des lieux ainsi créés (dynamique de la genèse du pèlerin) ; qu'acquiert-on par le pèlerinage (dynamique de transformation du pèlerin par les lieux de pèlerinage) ; en quoi est transformé un lieu devenu objet de pèlerinage (dynamique de transformation des lieux de pèlerinage par les pèlerins).

8. Tanaka Tomohiko 田中智彦, « Kinki-chihō ni okeru chiikiteki junrei-chi »近畿地方にお ける地域的巡礼地, Köbe daigaku shigaku nenpō 神戸大学史学年報, $\mathrm{n}^{\circ}$ I (1986), p. 45-63.

9. Le bilan des recherches à été dressé par Shinno Toshikazu 真野俊和 dans les trois volumes suivants : Kōza Nibon no junrei 講座:日本の巡礼 (Séminaires. Les pèlerinages au Japon), vol. I : Honzon junrei 本被巡礼, vol. 2 : Seiseki junrei 聖躓巡礼, vol. 3 : Junrei no kōzō to chibō junrei 巡礼 の構造と地方巡礼, 1996.

10. Voir les différents travaux de Nakayama Kazuhisa 中山和久 : sur les trente-six lieux saints de Fudō 不動 dans le Kantō (Kantō sanjū san Fudō reijō 関東三十六不動慧場), "Junrei to gendai »巡礼と現代, Nibon minzokugaku 日本民俗学, n² 21 (1997), p. 32-65; sur le pèlerinage de Shikoku à Sasaguri, “Junrei to gyöba no kankei » 巡礼と行場の関係, Sangaku sbugen 山岳修験, $n^{\circ} 25$ (2000), p. 58-71 ; sur les pèlerinages dans le département de Yamanashi 山梨県, « Junrei ni yoru idō no taiken " 巡礼による移動の体験, Chiiki kenkyū 地域研究, no 4 (2005), p. 33-47; sur les pèlerinages dans la région de Shōnai 庄内 du département de Yamagata 山形県, "Yusa no “omairi” bunka 》遊佐の $\mathbf{r}_{j} ま い り 」$ 文化, dans Kanda Yoriko 神田より子, éd., Chōkai sanroku Yusa no minzoku 鳥海山簏遊佐の民俗, 2006, vol. I, p. 374-501.

II. J'ai adopté cet angle d'approche à la suite de la proposition faite par Anne Bouchy d'analyser les faits culturels avec le point de vue de la dynamique (rikigaku 力学). Or aborder cette question par le biais de la dynamique des pelerinages implique de tenir compte des fluctuations que connurent les lieux saints et de la diversité des pèlerins : ceci permet d'espérer des résultats qui n'ont pas pu être obtenus jusqu'à présent par les recherches antérieures, lesquelles étaient linéaires et essentialistes. 


\section{Topiques des recherches sur les pèlerinages de petite taille}

Pour étudier la fondation de lieux de pèlerinage, il faut pouvoir accéder à des documents qui permettent d'en connaître le processus. Or, comme presque tous les petits pèlerinages existant aujourd'hui ont été fondés à partir du $\mathrm{XIX}^{e}$ siècle, les archives et les traditions orales qui en relatent la création sont relativement abondantes, ce qui est un atout favorable.

À cause des restrictions induites par les pèlerinages choisis et les archives, les travaux antérieurs sur les lieux saints ont eu tendance à réduire la naissance des objets de pèlerinage à des événements historiques particuliers, ou à y voir un phénomène « naturel » qui résulte des conditions topographiques singulières, les définissant ainsi comme des lieux saints relevant de l'ordre des données fixes. Mais les études sur les pèlerinages de petite envergure ont déjà fait apparaître des réalités très différentes, en présentant de très nombreux cas de transferts d'objets de pèlerinage. Ces « petits » pèlerinages sont parfois dépréciés comme étant de «simples imitations ». Pourtant, comme en témoigne la conception d'une voie (dó 道) qui part de l'assimilation de modèles fixes (kata カ夕/型) pour aboutir à la créativité dans le jūdō, l'art du thé (sadō 茶道) ou le shugendō, ou encore la technique du mitate 見立て («support de vue »), c'est-à-dire du substitut, dans l'art des jardins, de la poésie ou des estampes, on sait que la réplication est une notion importante, qui est au fondement même de la tradition. C'est pourquoi, faire l'analyse des faits de réplique et de reproduction, ainsi que des conceptions qui les sous-tendent, est loin d'être dénué de sens.

Au sujet des pèlerinages de petite taille, est très répandue l'opinion selon laquelle, dans la diffusion de ce type de cultes, jouerait un rôle déterminant le désir de ceux qui auraient créé, "faute de mieux », les substituts locaux des grands pèlerinages comme ceux du Kansai ou de Shikoku, dont ils sc trouvaient éloignés. Or il s'avère que nombreux sont les ensembles qui ne semblent pas avoir été créés dans le but de constituer des pèlerinages. En outre, on a pu repérer un grand nombre d'usages locaux particularisés. Aussi un réexamen est-il nécessaire.

Par ailleurs, les petits pèlerinages qui sont bien intégrés territorialement, et très fréquentés, conviennent tout particulièrement à une approche cherchant à mettre en évidence de façon fine la manière dont on tire parti de tels lieux. Comme il existe aujourd'hui de nombreux parcours intensivement empruntés, il est possible de faire apparaître assez précisément les processus de leur recomposition. Et il faut bien avoir à l'esprit de prime abord que ce n'est pas parce qu'un objet de pèlerinage $a$ été créé que cela génère nécessairement des pratiques pérégrines.

Pour ce qui regarde le pèlerin, on a tendance à proposer une analyse conventionnelle assimilant sa démarche à celle d'un rite de passage qui conduit à faire une expérience de type "anti-structure », dans des conditions de liminarité qui sortent de l'ordinaire. Ou bien, nombreuses sont les explications toutes faites émanant des organisations religieuses qui le donnent comme recherchant aide, efficace subtile (reigen 霊験), guérison, transformation intérieure ou manifestation de bienfaits. Et ce, alors même que les activités du pèlerin sur les lieux de pèlerinage sont extrêmement diverses, comprenant également celles de la vie quotidienne ou encore des loisirs. Ceci aussi nécessite d'être réexaminé. 
Des circuits de pèlerinages de trente-trois ou de quatre-vingt-huit étapes, d'une envergure plus ou moins grande, ont été créés dans tout le Japon. Leur nombre est évalué à dix mille pour le moins. Presque tous sont de petits parcours situés sur des territoires relativement étroits, où sont déployés les lieux saints du pèlerinage. Pour ceux qui les fréquentent, ils représentent une existence proche qui ne nécessite ni beaucoup de frais ni beaucoup de temps, et dont on peut faire le tour en quelques jours de congé, en fin de semaine.

La commodité de leur fréquentation fait qu'ils deviennent, pour certains, des lieux de dévotion régulière, où il est possible de se changer les idées pour dissiper les petits soucis ordinaires ou une déprime passagère. Par ailleurs, la société locale les utilise largement de façon communautaire pour les rites annuels. Là où existent notamment des pratiques de pèlerinage printanières associées au plaisir de goûter les joies du printemps, le caractère ludique est fortement marqué. Ces petits pèlerinages, où l'on peut recycler commodément l'énergie morale et physique épuisée dans la vie quotidienne, peuvent être regardés comme des systèmes coutumiers de régénération des forces humaines et locales. Bien sûr, ceux dont la fréquentation est très élevée valent particulièrement la peine d'être étudiés.

Mais cette approche de la fondation, du développement et de l'usage réel des lieux de pèlerinage ne doit pas prendre appui sur des idées préconçues. C'est bien en partant d'une analyse exacte et renouvelée des processus concrets qui sous-tendent ces réalités que je voudrais ici tenter d'en faire émerger une autre vision.

\section{Présentation du nouveau pèlerinage de Shikoku à Sasaguri}

La plupart des petits pèlerinages existant aujourd'hui ont été conçus comme des répliques du circuit des trente-trois temples du Kansai ou de celui des quatre-vingt-huit temples de Shikoku. Ces deux derniers ayant été organisés au XIr siècle, la naissance de leurs « copies » est donc ultérieure à cette date. Mais on peut supposer qu'à l'arrière-plan de ce phénomène de réplication, dans toutes les régions préexistaient des pratiques originelles de circumambulation fortement ancrées au niveau local. Les premières réplications de pèlerinages sont attestées dès la première moitié du XII ${ }^{\mathrm{e}}$ siècle, et au $\mathrm{XVIII}^{\mathrm{e}}$ siècle, des répliques du circuit du Kansai existaient partout dans le pays. Mais au XIX ${ }^{\circ}$ siècle, avec la large diffusion du culte du Grand Maître Kōbō (Kōbō daishi 弘法大師, c'est-à-dire Kūkai 空海 ${ }^{12}$ ), fondateur légendaire du pèlerinage de Shikoku, les copies de ce circuit des quatre-vingt-huit temples de Shikoku (Shikoku Hachijū hakka-sho reijō 四国八十八ヶ所需場) naquirent comme bambous après la pluie. Pour les distinguer de ce dernier, auquel fut donné le nom de « vrai Shikoku » ou «Shikoku originel» (Hon-Shikoku 本四国), ces reproductions furent appelées « nouveaux Shikoku » (Shin Shikoku 新四国). À leur nombre, on compte le pèlerinage de Sasaguri, qui est dénommé "Quatre-vingt-huit lieux saints de Shikoku à Sasaguri » (Sasaguri Shikoku reijō hachijū hakka-sho 篠栗四国霊場八十八ヶ所) ou «Quatre-vingt-huit lieux de Shikoku à Sasaguri » (Sasaguri Shikoku hachijū hakka-sho 篠栗四国八十八ヶ所),

12. Fondateur de l’École Shingon 真言宗 du bouddhisme ésotérique japonais. (N.D.T.) 


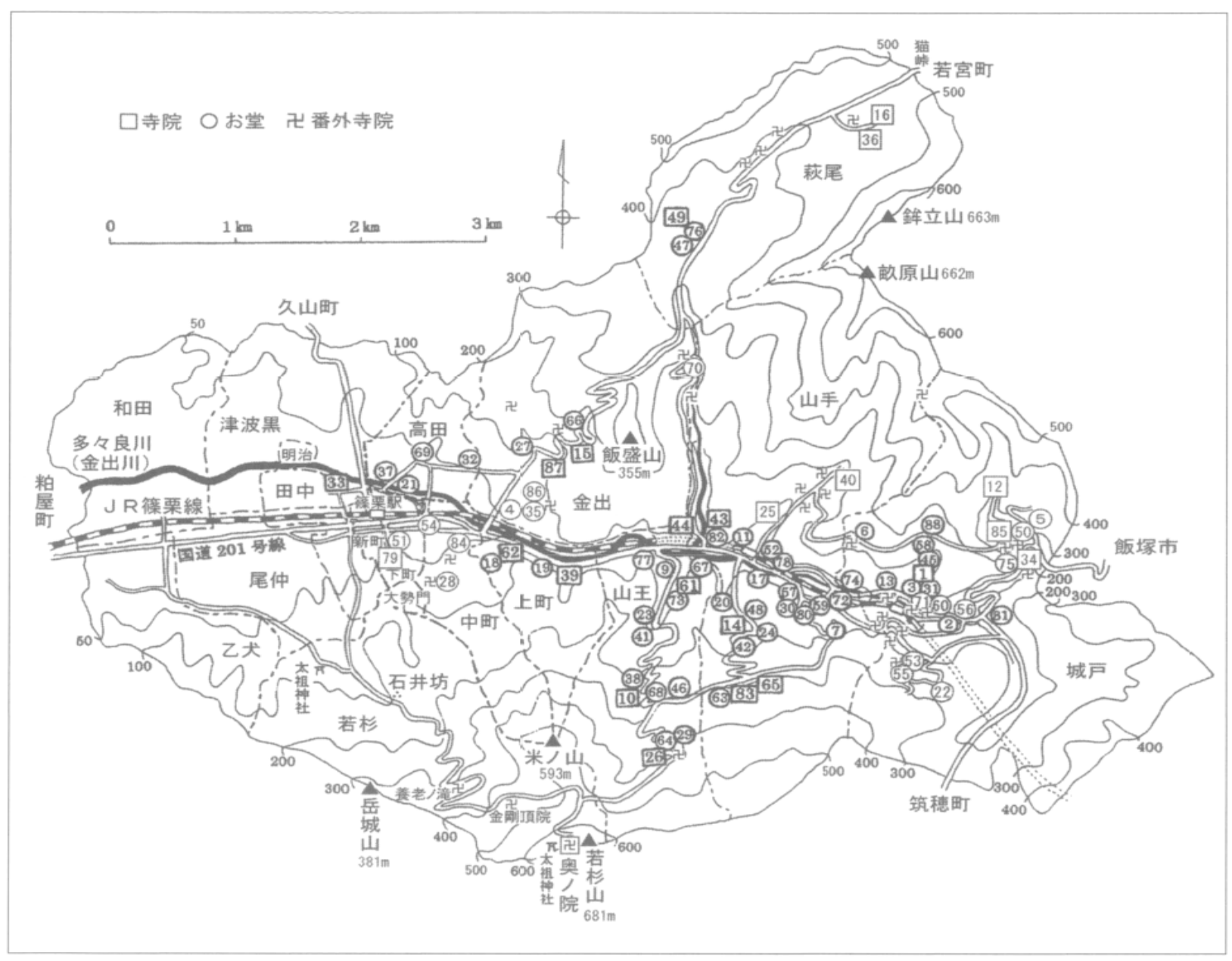

Fig. I : Répartition des différents types de fudasho sur le circuit de pèlerinage des Quatre-vingt-huit lieux saints de Shikoku à Sasaguri.

ou encore «Quatre-vingt-huit lieux saints de Sasaguri » (Sasaguri hachijū hakka-sho reijō 篠栗八十八ヶ所霊場). Parmi les innombrables « nouveaux Shikoku » de tout le pays, ceux de Sasaguri, de l'île Shōdo (département de Kagawa 香川県) et de Chita 知多 (département d'Aichi 愛知県) ont reçu le nom de «trois grands du Japon » (Nihon sandai 日本三大), car avec plusieurs centaines de milliers de visiteurs chaque année, ils sont les plus fréquentés.

Le pèlerinage de Shikoku à Sasaguri est situé dans la commune de Sasaguri (canton de Kasuya 糟屋郡, département de Fukuoka 福岡県), qui se trouve seulement à vingt minutes en train de Hakata 博多, gare centrale de la ville de Fukuoka 福岡市. 《Ville-dortoir » de ce centre économique de Kyūshū qu'est Fukuoka, la commune de Sasaguri compte un nombre impressionnant de temples et d'oratoires dispersés sur tout son territoire (fig. I). Cette commune est aussi un site paysager remarquable, marqué par ses vallées encaissées, par le vert abondant de ses forêts qui recouvrent soixante-dix pour cent de sa superficie, et d'où jaillissent sources et cascades à profusion. Au printemps, mille cerisiers déploient les blancheurs de leur pleine floraison sur le site dit «nouveau Yoshino » (Shin Yoshino 新吉野). C'est ainsi un endroit où l'on peut goûter pleinement les joies des quatre saisons. 
Long de quarante-six kilomètres, le circuit de pèlerinage traverse la totalité de la commune. Il est possible de le parcourir dans son entier en deux jours en voiture, ou en trois ou quatre jours à pied.

On dit que le "vrai Shikoku » est composé des quatre-vingt-huit lieux saints où Kūkai, le Grand Maître Kōbō, originaire de cette région, se serait rendu durant son périple de pratiques d'ascèse au tout début de sa vie de moine. Aussi, dans tous les «nouveaux Shikoku », une grande importance est-elle accordée au fait de venir s'incliner devant chacune des quatre-vingt-huit statues bouddhiques : centres de vénération des quatre-vingt-huit temples et oratoires qui jalonnent le parcours, ces statues sont des reproductions de celles qui se trouvent dans les quatre-vingt-huit temples du Shikoku originel. Généralement, ce ne sont pas les spécificités ou les grâces particulières de tel ou tel de ces quatre-vingt-huit lieux qui retiennent l'attention du pèlerin, mais bien plutôt le fait de parcourir le circuit dans son ensemble. Ces quatre-vingt-huit sites du pèlerinage sont en fait considérés comme formant un seul et même lieu saint. La coutume veut que l'on dépose dans chacun de ces lieux une petite vignette de papier ( $f u d a$ 札) sur laquelle on a inscrit ses demandes à l'adresse des bouddhas et autres entités bouddhiques qui y sont vénérés. Aussi le pèlerinage porte- $\mathrm{t}$-il également le nom de «lieu[x] (où l'on dépose les) vignettes » (fuda [wo osameru] tokoro 札[を納める]所), abrégé en «lieu[x] des vignettes 》(fudasho 札所). Sasaguri ne fait pas exception à cette règle.

Les pèlerins viennent de tout le pays, surtout du département de Fukuoka, et de ceux de Saga 佐賀県 et Kumamoto 熊本県 qui lui sont limitrophes. On avance le chiffre de plus d'un million de visiteurs annuels. Cela tient sans doute aussi à ce que les moyens de transport sont très commodes depuis Fukuoka et Kita-Kyūshū 北九州市, ces centres urbains particulièrement peuplés de l'archipel.

Selon la tradition locale, le pèlerinage de Sasaguri fut créé au milieu du XIX siècle, à la fin de la période d'Edo, par une nonne et quelques ardents fidèles. Au début du XIX ${ }^{e}$ siècle, grâce au climat de détente politique et à la richesse économique de la période dite « de la culture Kasei » $(K a-S e i \text { bunka 化政文化 })^{13}$, les gens des milieux populaires acquirent une assez grande liberté de déplacement en prétextant des pèlerinages aux sanctuaires d'Ise (département de Mie 三重県) ou de Konpira 金昆羅 (département de Kagawa). En outre, aux environs de 1835, année du millième anniversaire du décès de Kūkai, la vénération pour le Grand Maître Kōbō connut un grand essor, et l'on peut supposer qu'augmenta alors le nombre des pèlerins de Fukuoka qui se rendaient à Sasaguri pour faire le circuit de pèlerinage. C'est en tout cas après la création du Shikoku de Sasaguri que cette petite localité isolée devint, au début du $\mathrm{xx}^{\mathrm{e}}$ siècle, un lieu majeur de l'industrie touristico-religieuse, alors qu'elle n'avait été, jusqu'au XviII ${ }^{\complement}$ siècle, qu'une simple étape sur une voie de passage transversale.

13. Kasei est la forme abrégée du nom des deux ères Bunka 文化 (1804-1818) et Bunsei 文政 (1818-1830) qui composent cette période. (N.D.T.) 


\section{Éléments constitutifs du pèlerinage}

\section{L'objet du pèlerinage}

Ce qui motive le pèlerin differe selon le pèlerinage. Mais il existe des référentiels communs à l'ensemble des pèlerins qui font un même circuit. Le plan intitulé "Carte du circuit de pèlerinage des quatre-vingt-huit lieux saints de Shikoku à Sasaguri ${ }^{14} »$ (fig. 2) a été élaboré par la section des jeunes du syndicat des auberges de la commune de Sasaguri et publié en 2005 par l'office communal de tourisme. On en trouve des exemplaires simplifiés, distribués gratuitement au bureau d'information devant la gare. Sur cette carte sont indiqués en rouge les endroits où sont vénérées les reproductions des statues principales de chaque "lieu de vignettes » (fudasho) du pèlerinage originel. Le numéro de chacun de ces quatre-vingt-huit lieux est inscrit dans un cercle, en blanc sur fond rouge pour les vingt-quatre temples (jiin 寺院), en rouge sur fond blanc pour les petits oratoires (o-dō $j$ 堂). La réplique de l'Oku-no-in 奥の院 («temple du Fond », c'est-à-dire le lieu le plus saint et/ou prestigieux) du mont Kōya 高野山 ${ }^{15}$ est signalée par un cercle rouge portant seulement la mention "Oku », et sont indiqués par une simple svastika orangée $(\nexists)^{16}$ tous les temples et oratoires qui ont été progressivement ajoutés au circuit. Appelés communément «temples surnuméraires » ou simplement « hors numérotation》(bangai [jiin] 番外寺院), ces derniers sont des lieux qui ne portent aucun des quatre-vingt-huit numéros du pèlerinage originel de Shikoku, et qui ne se trouvent pas dans le modèle. À Sasaguri, ces temples « hors numérotation » sont des points-clés du circuit attirant beaucoup plus de visiteurs que bien des petits oratoires numérotés dépourvus de force d'attraction. Aussi est-ce sans doute pour cette raison qu'ils ont été inscrits sur cette carte officielle.

Sur le plan, la totalité des « temples» (jiin), " oratoires » (dō 堂) et «temples hors numérotation » (bangai jiin) ${ }^{17}$ s'élève à cent vingt lieux, lesquels forment l'objet du pèlerinage de Shikoku à Sasaguri ${ }^{18}$. Mais il faut noter que, pour des raisons de calendrier et d'itinéraire, de nombreux pèlerins retranchent de leur parcours un certain nombre d'oratoires, alors qu'à l'inverse, on les voit affluer vers les temples surnuméraires. Par ailleurs, il existe également dans la commune beaucoup d'autres temples ou oratoires « hors numérotation " qui ne sont pas signalés sur la carte, et où se rend un nombre non négligeable de pèlerins. Chaque pèlerin a sans doute des

14. Format A2, imprimé des deux côtés, plié en trois ; prix : cent yens. Cette carte est vendue à l'office du tourisme de la gare de Sasaguri, dans toutes les auberges, les magasins de souvenirs et les fudasho.

15. Monastère fondé par Kükai, l'un des principaux centres du bouddhisme Shingon. (N.D.T.)

16. La svastika est un symbole bouddhique qui est notamment utilisé dans la cartographie pour signaler les temples et les monastères bouddhiques. (N.D.T.)

17. Les temples, qu'ils soient ou non compris dans les quatre-vingt-huit stations, sont des structures importantes gérées par des moines qui y résident, alors que les oratoires, simples abris d'une statue en bord de route ou petits bâtiments ouverts, sont placés sous la responsabilité de gardiens, les dōmori 堂守, qui habitent plus ou moins près d'eux. (N.D.T.)

18. Voir la liste des temples et des oratoires à la fin de cette contribution, tableau I. 


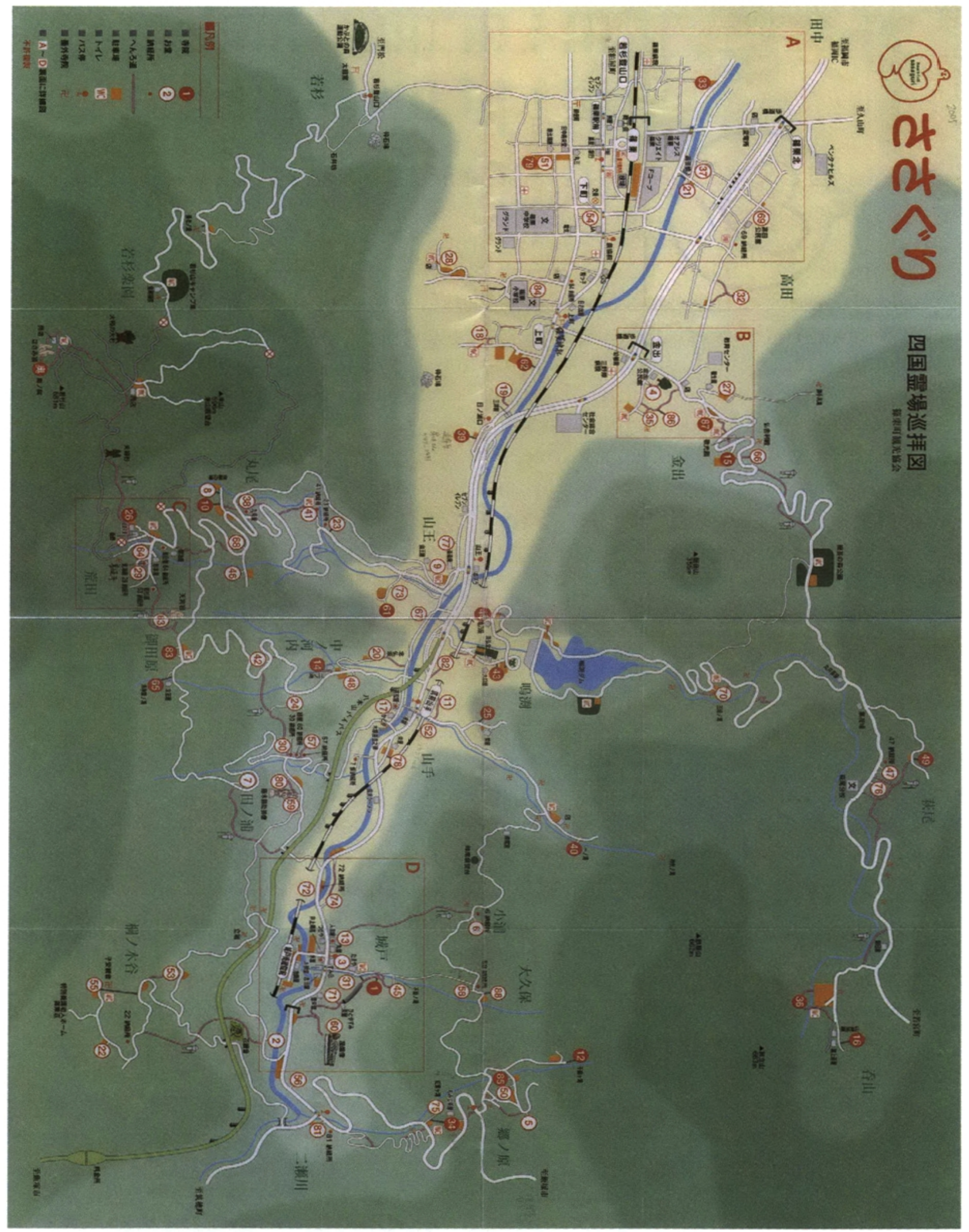

Fig. 2 : Carte du circuit de pèlerinage des quatre-vingt-huit lieux saints de Shikoku à Sasaguri (Sasaguri Sbikoku reijo junpai zu ささぐり 四国置场巡拝図).

(Office du tourisme de Sasaguri.) 
préférences parmi toutes les entités vénérées dans chacun de ces lieux ; néanmoins chaque fudasho ayant fondamentalement été constitué autour de la statue principale de chacun des quatre-vingt-huit temples originels, ce sont ces vénérés qui sont au centre du culte, et non les statues qui leur sont associées, comme celles du Grand Maître Kōbō ou de Fudō myōō 不動明王, situées à l'intérieur ou à l'extérieur du bâtiment.

On peut penser que c'est sous l'effet d'une reconnaissance positive de la force d'attraction des temples de Sasaguri qu'est née cette distinction entre « temples » et " oratoires ${ }^{19}$ ». Dans les temples, en effet, des moines ${ }^{20}$ reçoivent les demandes des pèlerins, accomplissent les rituels, et administrent des cimetières ou des columbariums où ils assurent des services post-funéraires, distribuent des amulettes de protection, vendent des articles destinés aux pèlerins. Aussi ces temples séduisent-ils beaucoup plus que les oratoires où rien de tout cela n'existe. En outre, comme le pèlerinage représente un axe majeur des activités touristiques de la commune, les moines et les employés des temples jouent un rôle non négligeable dans le cadre communal ${ }^{21}$. L'association Hōsei 法青会, qui réunit les jeunes générations des moines de Sasaguri, organise chaque année des présentations extérieures des statues principales de leurs temples (de-gaichō 出開帳), des séances de théâtre, des « écoles pour enfants 》 (terakoya 寺子屋), autant d'activités qui drainent les visiteurs vers la commune.

Bien que les uns et les autres soient également des fudasho, il existe des différences formelles assez marquées entre "temples » et " oratoires », et ce tant du point de vue de la superficie de l'enceinte (étendue pour les premiers, plus limitée pour les seconds), que du nombre des statues et des bâtiments que l'on y trouve. Le temple Kōshō-in 弘照院 $\left(\mathrm{n}^{\circ}{ }^{87}\right)$ et l'oratoire de Kokūzō 虚空藏堂 à Takata 高田 ( ${ }^{\circ}$ 2I) sont deux exemples très représentatifs de ces importantes disparités (fig. 3 et 4 ).

19. En règle générale, lorsqu'est mentionné $j i$ (ou tera) 寺 ou in 院, il s'agit d'un temple. Mais les fudasho suivants, bien que signalés ainsi, sont en réalité des oratoires $: n^{\circ} 18$, Sasaguri, Onzan-ji 篠栗恩山寺; $n^{\circ}$ 20, Kakurin-ji 鶴林寺; $n^{\circ} 27$, Kana.ide Kōnomine-ji 金出神峰寺; $n^{\circ}$ 28, Sasaguri kōen Dainichi-ji 策栗公園大日寺 ; $n^{\circ}$ 42, Naka-no-kōchi Bukkoku-ji 中/河内仏木寺; $n^{\circ} 54$, Nakamachi Enmei-ji 中町延命寺; $n^{\circ} 60$, Jinpen-ji 神変寺; $n^{\circ} 63$, Tengu-iwa-san Kisshō-ji 天狗岩山吉祥寺; $n^{\circ} 68$, Okabe Jinne-in 岡部神恵院; $n^{\circ} 84$, Nakamachi Yashima-ji 中町屋島寺. La raison en est que ces appellations renvoient aux noms de temples portant ces numéros dans le pèlerinage originel de Shikoku. En outre, le $n^{\circ} 70$ n'est pas identifiable par sa dénomination : Gotō no taki 五塔/滝 (cascade de la Pagode à cinq étages). C'est un oratoire, et il tire son nom de la cascade qui est à proximité. Il s'agit donc d'un nom de lieu.

20. Par convention, on parle de temple, monastère et moine dans le contexte bouddhique, et de sanctuaire et prêtre dans celui du culte des dieux (sbintō). (N.D.T.)

2I. Sur le site de l'office de tourisme de la commune de Sasaguri, dans la rubrique "Temples recommandés ", sont présentés les rites annuels et les particularités des temples suivants : les numéros I, 8, I0, I2, I4, 16, 34, 36, 40, 44, 49, 61, 62, 79, 83, 85, 87, l'Oku-no-in, le Kongōchō-in 金剛頂院 et le temple de la cascade Yōrō 養老/滝. 


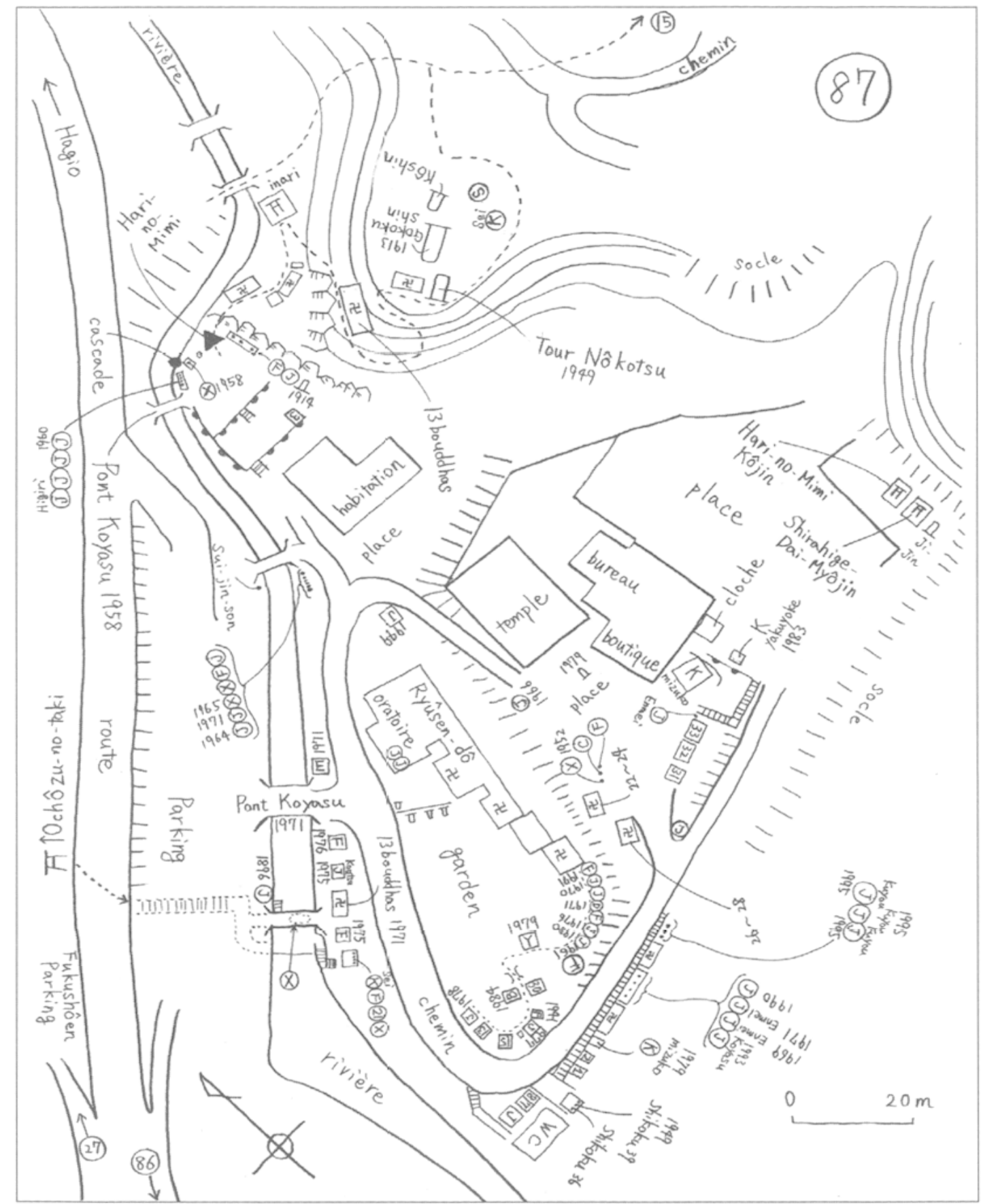

Fig. 3 : Plan du Kōshō-in et de son enceinte ( $\left.n^{\circ} 87\right)$. (Par l'auteur)

\section{Le circuit de pèlerinage}

Dans la mesure où il s'agit d'un pèlerinage à objets multiples, le chemin qui relie ces derniers est un élément structurel très important. À l'inverse, dans le cas de Sasaguri, où les nombreux fudasho sont répartis à l'intérieur de l'étroit territoire communal, on a plutôt l'impression, lorsqu'on fait le circuit, que ce sont ces derniers qui ont été posés le long de la route. Ici, sur le modèle de la dénomination «Shikoku benro » 四国遍路 donnée au 《vrai Shikoku », ce chemin de pèlerinage est appelé 


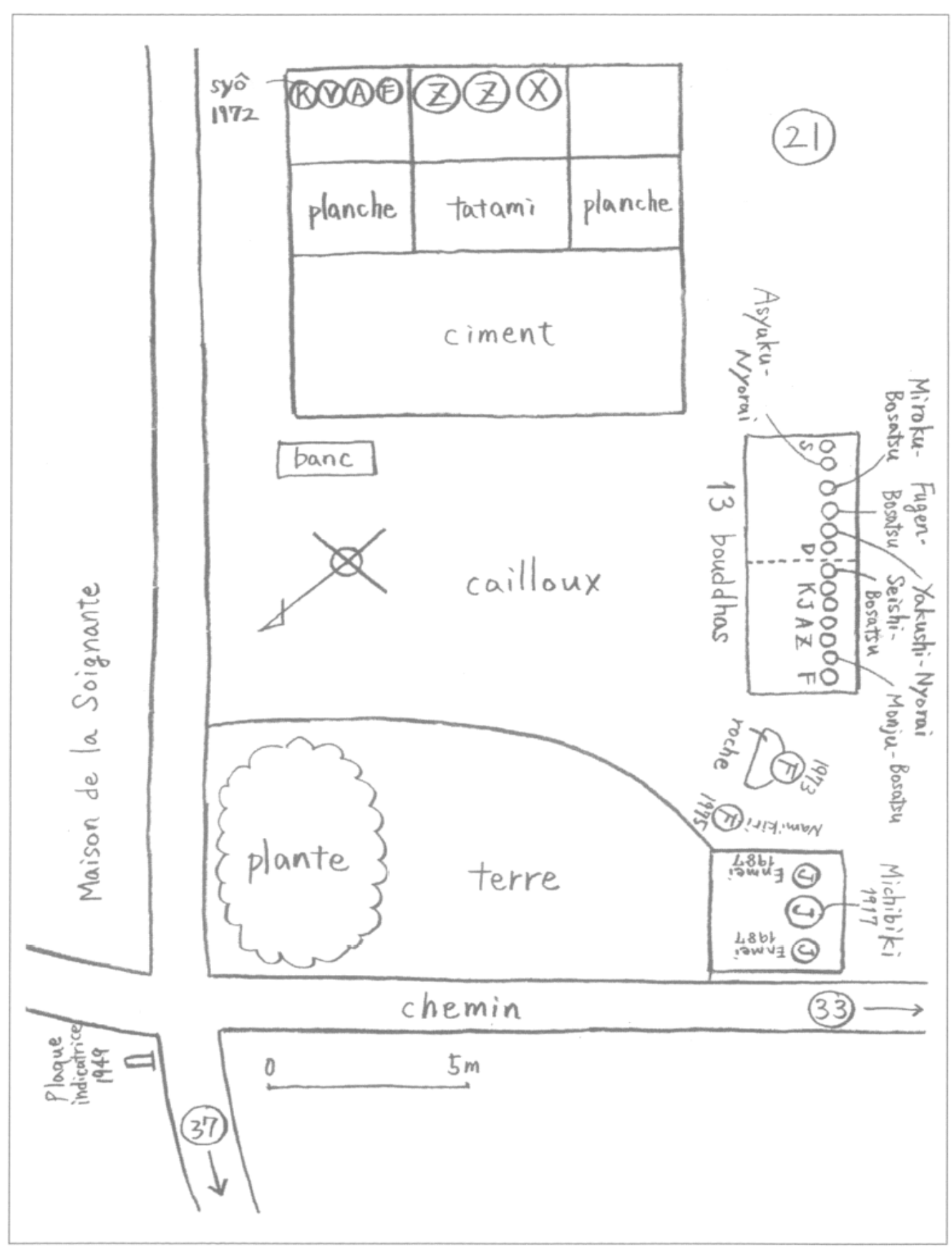

Fig. 4 : Plan du Kokūzō-dō et de son enceinte (n 21, Takata). (Par l'auteur)

"benro ». Cette notion est imbriquée de façon complexe avec celles de benrei 遍礼 ("vénérer/vénération partout»), de heji 辺路 (《route [qui va] partout, qui fait le tour ») ou beji 辺地 (《 terre des confins»). En saisir le contenu exact n'est donc pas chose facile. Mais elle renferme le sens de « trajet cultuel sur lequel on chemine en peinant ». Sur la carte citée précédemment, cette voie pédestre est signalée en rose comme benro michi へんろ道 ( " chemin du pèlerinage »). 
À la différence du parcours du « vrai Shikoku », à Sasaguri, si l'on veut rejoindre toutes les stations du circuit par le chemin le plus court, il est impossible de respecter l'ordre de leurs numéros. Aussi, comme dans la majorité des cas le pèlerinage de Shikoku se fait en suivant l'ordre des fudasho, certains pensent-ils que l'organisation dans le désordre du parcours de Sasaguri manque de sacralité22. L'ordre dans lequel circulent la plupart des pèlerins est en effet le suivant ; c'est aussi celui qui est indiqué sur la carte officielle :

Gare de Sasaguri $\rightarrow 33 \rightarrow 21 \rightarrow 37 \rightarrow 69 \rightarrow 32 \rightarrow 4 \rightarrow$ Shurin-ji 珠林寺 $\rightarrow 35 \rightarrow 86$ $\rightarrow 27 \rightarrow$ cascade Ochōzu 御手洗滝 $\rightarrow 87 \rightarrow$ I $5 \rightarrow$ Pavillon des reliques du Bouddha, Busshari-den 仏舎利殿 $\rightarrow 66 \rightarrow 49 \rightarrow$ Tōkō-in 東光院 $\rightarrow$ Jishō-in 慈照院 $\rightarrow$ Sanbō-in 三宝院 $\rightarrow$ Monju-in 文殊院 $\rightarrow 36 \rightarrow 16 \rightarrow 76 \rightarrow 47 \rightarrow$ dōjō de Kana.ide du Jimyōhō-in 慈妙法院金出道場 $\rightarrow 70 \rightarrow$ Saikoku-ji 西国寺 $\rightarrow 44 \rightarrow 43 \rightarrow 82 \rightarrow$ gare de Chikuzen Yamate 筑前山手駅 $\rightarrow$ II $\rightarrow 25 \rightarrow$ Henshō-ji 遍照寺 $\rightarrow$ Ichibata Yakushi nyorai 一畑薬 師如来 $\rightarrow$ Fudō-in de la cascade de Kamiyo 神代之滝不動院 $\rightarrow$ Tamamitsu Inari玉光 稻荷 $\rightarrow 40 \rightarrow$ cascade de Kamiyo 神代之滝 $\rightarrow 52 \rightarrow 78 \rightarrow \mathrm{I} 7 \rightarrow 20 \rightarrow 48 \rightarrow \mathrm{I} 4 \rightarrow 24$ $\rightarrow 42 \rightarrow 30 \rightarrow 57 \rightarrow 80 \rightarrow 59 \rightarrow$ Grand Maître (Kōbō) protecteur de la circulation, Kōtsū-anzen Daishi 交通安全大師 $\rightarrow$ Jizō-ji 地蔵寺 $\rightarrow$ la Pierre dressée, Tate.iwa 立岩 $\rightarrow$ Kannon qui accorde des enfants, Ko-sazuke Kannon 子授観音 $\rightarrow 53 \rightarrow$ Kannon de la progéniture facile, Koyasu Kannon 子安観音 $\rightarrow 55 \rightarrow 22 \rightarrow 2 \rightarrow 56 \rightarrow 81 \rightarrow$ Shōbō-in 聖法院 $\rightarrow 75 \rightarrow 34 \rightarrow$ Jūippō-ji 十一峰寺 $\rightarrow$ Shōtoku-ji 聖徳寺 $\rightarrow 5 \rightarrow 50 \rightarrow 85 \rightarrow$ I2 $\rightarrow 88 \rightarrow{ }^{2} \rightarrow 6 \rightarrow$ Fudō myōō 不動明王 $\rightarrow{ }_{13} \rightarrow$ gare du Nanzō-in de Kido, Kido Nanzō-in mae 城戸南蔵院前駅 $\rightarrow 3 \rightarrow 3 \mathrm{I} \rightarrow \mathrm{I} \rightarrow 45 \rightarrow 7 \mathrm{I} \rightarrow 60 \rightarrow$ Shōren-ji 正蓮院 $\rightarrow$ Jimyōhō-in 慈妙法院 $\rightarrow$ Yakuō-ji 薬王寺 $\rightarrow 74 \rightarrow 72 \rightarrow 7 \rightarrow 65 \rightarrow 83 \rightarrow 63 \rightarrow 29$ $\rightarrow$ Zentsū-ji 善通寺 $\rightarrow$ Oku-no-in 奥/院 $\rightarrow$ Kongōchō-in 金剛頂院 $\rightarrow$ cascade de Yōrō, Yōrō no taki 養老/滝 $\rightarrow 26 \rightarrow 64 \rightarrow 46 \rightarrow 68 \rightarrow$ Io $\rightarrow 8 \rightarrow 38 \rightarrow 41 \rightarrow 23$ $\rightarrow 73 \rightarrow 61 \rightarrow 9 \rightarrow 67 \rightarrow 77 \rightarrow 39 \rightarrow 19 \rightarrow 62 \rightarrow 18 \rightarrow 84 \rightarrow$ Myöfuku-ji 妙福寺 $\rightarrow 28$ $\rightarrow$ Tenjō Ichinen-ji 天浄一念寺 $\rightarrow 54 \rightarrow \varsigma 1 \rightarrow 79$.

Ce parcours débute dans le quartier de Tanaka H中, le plus proche de Fukuoka, et se poursuit à travers les quartiers de Takata, Kana.ide 金出, Hagio 萩尾, Yamate 山手, le quartier montagneux de Kido 城戸, pour ensuite faire demi-tour au pied du col qui mène à Yakiyama 八木山䟖, la commune limitrophe à l'est (Iizuka 飯塚市), et traverser les quartiers de Yamate, Sannō 山王, Kamimachi 上町 et Nakamachi 中町, avant de s'achever dans celui de Shimomachi 下町, lui aussi proche de Fukuoka. Il y a peu de différence avec celui qui était pratiqué à l'époque d'Edo. À Shikoku, la majorité des pèlerins commencent le circuit de pèlerinage au numéro un : le plus court chemin pour aller d'un fudasho à l'autre les conduit en fait à progresser jusqu'au numéro 88 en suivant les numéros dans l'ordre (2, 3, etc.). En revanche, à Sasaguri, si l'on vient de Fukuoka, le premier fudasho rencontré est le numéro 33 : c'est donc par là qu'on commence le circuit, et si l'on veut continuer en parcourant la distance la plus courte, on est obligé de faire le tour sans tenir compte de l'ordre des numéros portés par les lieux du pèlerinage. Il en est ainsi depuis la création du

22. C'est pourquoi certains pèlerins ont cherché à faire le circuit en suivant malgré tout l'ordre des numéros ; d'autres font apposer, dans l'ordre numérique, le tampon de chaque temple ou oratoire dans leur carnet de pèlerinage. 
parcours. Concernant les pèlerinages de l'île Shōdo et de Chita, deux autres parcours des « trois grands " nouveaux Shikoku, de même que dans la majorité des réplications du « vrai Shikoku », les lieux du pèlerinage sont alignés dans l'ordre normal de la numérotation. Quelques-uns néanmoins, tel celui du Grand Maître d'Inba (Inba daishi 印旛大師) à Tōkatsu 東葛 (département de Chiba), ont aussi cette particularité de former des circuits où les fudasbo sont dans le désordre. Cette différence, comme nous le verrons plus loin, reflète une volonté bien précise des fondateurs.

À Sasaguri, la route du pèlerinage traverse des sites naturels magnifiques offrant au regard une succession de vues splendides. La carte de 2005 en mentionne un certain nombre, ainsi que des éléments remarquables du paysage, dans l'ordre du cheminement : Grand camphrier (plus de mille ans d'âge), rivière « du Repos » (Ikoi no ogawa いこいの小川), cascade Ochōzu 御手洗 (du Lavement des mains, dite aussi Mitarai 御手洗), mont Iimori 飯盛山 (du Riz amoncelé), forêt de l'Arboriculture (Jugei no mori 樹芸の森), mont du Bouclier dressé (Hokotate san 鉾立山), cascade de la Pagode à cinq étages (Gotō no taki 五塔/滝), barrage de Narufuchi (du Gouffre d'eau qui gronde 鳴判ダム), Première cascade (Ichi no taki - 一滝), cascade de Kamiyo (du Monde des dieux 神代ノ滝), côte du Nenbutsu (Nenbutsu zaka 念仏坂), Deuxième cascade (Ni no taki二八滝), Pierre dressée (Tate.iwa 立岩), Kannon des fleurs (Hana Kannon 花観音), cascade des Feuilles rouges (Momiji ga taki 紅葉ヶ滝), cascade de Chizuru 千鶴ヶ滝 (Mille grues), belvédère de Mineo (des Crêtes 峰尾展望台), cryptomère du Dieu de l'orage (Raijin sugi 雷神杉), cascade de Fudō (Fudō no taki 不動/滝), cascade du Vou pur (Shōjō-gan no taki 清浄願 ノ滝), roche du Tengu (Tengu iwa 天狗岩), cryptomère des Époux (Me.oto sugi 夫婦杉), paroi-de-roc Qui enserre (Hasami iwa はさみ岩), mont Wakasugi (du Jeune cryptomère 若杉山), belvédère du mont du Riz (Kome no yama tenbō-dai 米山展 望台), Grand cryptomère du Yamato (Yamato no ō-sugi 大和の大杉), cascade du Vajra (Kongō no taki 金岡川の滝). Mais il existe aussi beaucoup d'autres cascades et de jardins situés dans les enceintes des temples, qui ne sont pas portés sur la carte. Ou encore, entre le Kōshō-in ( $n^{\circ} 87$ ) et l'oratoire de Kannon de la côte de Kannon (Kannon zaka Kannon-dō 観音坂観音堂, $\mathrm{n}^{\circ}$ 66), s'étend le parc de Kannon (Kannon kō.en 観音公園), où l'on peut voir au printemps, pendant la saison des pèlerinages, quelque cent cinquante prunus, deux cents cerisiers et deux cents azalées en fleurs. Les environs de la cascade de la Pagode à cinq étages (Gotō no taki) forment un site remarquable connu sous le nom de "vallée Yaba de Sasaguri » (Sasaguri Yaba-kei 篠栗耶馬溪) ${ }^{23}$ ou 《 val des Ermites »(Gotō senkyō 五塔仙峡). Enfin, sur la pente aux Sept virages de Gō-no-haru 郷/原, située entre l'oratoire de Kannon de la rivière Futase (des Deux gués) (Futase-gawa Kannon-dō二瀬川観音堂, $\mathrm{n}^{\circ} 8 \mathrm{I}$ ) et l'oratoire de Yakushi de la cascade des Feuilles rouges (Momiji-ga-taki Yakushi-dō 紅葉ヶ 滝薬師堂, $\mathrm{n}^{\circ} 75$ ), ont été plantés trois cent cinquante érables (rouges en automne) et mille cerisiers (en fleurs au printemps) qui évoquent Yoshino 吉野 et ses mille cerisiers (département de Nara 奈良県). Pour cette raison, cet endroit a reçu le nom de «nouveau Yoshino » (Shin-Yoshino).

23. Du nom du site de la vallée de Yaba (Yaba-kei 耶馬溪) du département d'Ōita 大分県 à l'est de Kyūshū, célèbre pour sa beauté. 
Soixante-dix pour cent de la superficie de Sasaguri sont occupés par des montagnes recouvertes de forêts essentiellement constituées de cryptomères, dont certains sont des arbres monumentaux de plus de cinq cents ans d'âge ; aussi est-ce cet arbre que la commune a choisi pour arbre emblématique. Une grande partie du chemin de pèlerinage passe au milieu de ces cryptomères, et ses dénivelés sont forts et nombreux sur ce territoire communal constitué en majorité de vallées et de montagnes. Le Honmyō-in 本明院 ( $\left.n^{\circ} 33\right)$ de Tanaka est situé à 50 mètres au-dessus du niveau de la mer, mais le Kannon-ji de Nomiyama 呑山観音寺 $\left(n^{\circ}\right.$ I6) est à 450 mètres. De là, le circuit s'abaisse jusqu'aux 70 mètres d'altitude de la rivière Tatara 多々良川, remonte à 350 mètres à la cascade de Kamiyo, redescend vers cette même rivière, remonte à 190 mètres au Bukkoku-ji ( $\left.\mathrm{n}^{\circ} 42\right)$ de Naka-no-kōchi ; puis, jusqu’à atteindre 300 mètres au Dainichi-dō ( $\left.n^{\circ} 55\right)$ de la vallée de Kiri-no-ki 桐の木谷大日堂, le parcours suit une série de montées et de descentes, redescend vers la rivière Tatara avant de remonter jusqu'à 300 mètres au Senkaku-ji 千鶴寺 $\left(n^{\circ}{ }_{12}\right)$, redescend à nouveau jusqu'à la rivière pour s'élever à 650 mètres à l'Oku-no-in, et s'achève en descendant progressivement jusqu’à 50 mètres au niveau du dernier fudasho, le Fudaraku-ji 補陀落寺 $\left(n^{\circ} 79\right)$. Ce parcours équivaut, en distance, à la montée du mont Fuji 富士山 (3776 m) à partir de Fuji-Yoshida 富士吉田, l'un des points de départ de l'ascension, dans le département de Yamanashi 山梨県 (soit à $40 \%$ du parcours total).

À l'époque où le pèlerinage se faisait à pied, monter jusqu'à Nomiyama et à l'Okuno-in représentait un effort important pour beaucoup de pèlerins ; aussi se reposaient-ils dans les buvettes au bord de la route (chaya 茶屋) avant d'attaquer la montée. Boissons chaudes sucrées, gâteaux fourrés aux haricots rouges, jus de fruits, biscuits craquants de mocbi (senbei 煎餅) ou encore gelée sucrée en vermicelle (tokoroten ところてん, Gelidiaceae) comptaient parmi les friandises qu'on pouvait y savourer. Il ne subsiste aujourd'hui que quelques-unes de ces buvettes autrefois nombreuses, comme celles de Marui 丸井茶屋 et de Chikamichi 近道茶屋 ( du Raccourci»). Autrefois, tout au long des chemins de pèlerinage, était aussi largement pratiqué le settai 接待, c'est-à-dire l'« accueil » des pèlerins à qui les habitants offraient gracieusement à manger et à boire. De nos jours, seuls quelques secteurs et quelques fudasho de-ci de-là perpétuent encore cette coutume.

\section{Les pèlerins}

Le chiffre d'un million de pèlerins est avancé lorsqu'on évoque la fréquentation annuelle du pèlerinage de Sasaguri. Mais c'est là le résultat d'une enquête faite à l'entrée du Nanzō-in 南蔵院 $\left(n^{\circ} I\right)$, au moyen d'un appareil de comptage automatique, qui a donc enregistré toutes les entrées, au nombre desquelles il faut compter non seulement celles des pèlerins, mais aussi celles des visiteurs se rendant uniquement à ce temple, ou encore les allées et venues de tous les employés et commerçants. Or le Nanzō-in est un temple qui se distingue parmi tous ceux de Sasaguri : il est renommé pour les prêches de son supérieur qui connaissent une grande célébrité ; dans son enceinte sont installées des boutiques très animées ; les rites annuels y sont nombreux ; on y trouve aussi une gigantesque statue du Bouddha couché (nebanzō 涅媻像) de quarante-et-un mètres, ainsi que des columbariums d'une capacité de treize mille niches pour urnes funéraires. Aussi est-ce un lieu très fréquenté par 
des visiteurs venant de tout le pays mais aussi de l'étranger ${ }^{24}$, et ce n'est pas à partir de ces chiffres que l'on peut évaluer le nombre réel des pèlerins circulant sur l'ensemble du circuit de Sasaguri. Si l'on en croit les gardiens des temples et des oratoires, il y aurait aujourd'hui à peine cent mille pèlerins ayant pour objectif de visiter les quatre-vingt-huit fudasho. Or parmi eux se trouvent aussi ceux qui ne se rendent qu'au Nanzō-in et sur les lieux de pèlerinage englobés dans l'enceinte de ce dernier : au Kannon-ji de Nomiyama ( $\left.n^{\circ} \mathrm{I} 6\right)$, au Tennō-in 天王院 $\left(\mathrm{n}^{\circ}{ }_{36}\right.$ ), au Zentsū-ji (hors numérotation) et aux fudasbo qui en sont proches, et enfin au Fudaraku-ji ( $\left.n^{\circ} 79\right)$, où s'achève le parcours. Aussi, dire que l’on fait « le pèlerinage de Sasaguri » peut-il en réalité représenter, selon les personnes, beaucoup de choses différentes.

Les pèlerins formant des groupes de plusieurs dizaines de personnes viennent principalement des départements de Kumamoto, Nagasaki 長䛴県, Saga, Yamaguchi 山口県, Aichi et de la ville de Kita-Kyūshū. Ceux qui viennent en famille ou avec des amis sont surtout des habitants de la ville de Fukuoka, du canton de Kasuya ou de la région de Chikuhō 筑豊, c'est-à-dire des environs relativement proches. Quant aux habitants de Sasaguri, ils ne pratiquent pas beaucoup ce pèlerinage. Les groupes importants ont commencé à diminuer à partir des années 1990, et en 2010 , il ne subsistait plus qu'un seul groupe de cent personnes guidé par Sugyō Nobuyuki 須堯宣行, le prêtre du sanctuaire Ishizuchi daigongen de Kyūshū 九州石鎚大権現社 (quartier Nord de Kita-Kyūshū Kokura 北九州市小倉北区).

Né en 1960, Sugyō a participé depuis l'âge du collège au pèlerinage de Sasaguri qu'organisait son père, dont il a pris la relève en 1992 , pour continuer à conduire ses fidèles. Son père, qui était né en 1929 à Iizuka 飯塚市 (département de Fukuoka), avait été un disciple de l'église Yoshimi 吉見教会, mais en 1964, il prit son indépendance et fonda le sanctuaire Ishizuchi daigongen de Kyūshū. Le mont Ishizuchi 石鎳山, au centre des pratiques et du culte de ce groupe, est une montagne de Shikoku qui entretient des liens forts avec le temple Maegami-ji 前神寺, numéro 64 du « vrai pèlerinage de Shikoku ». Ce groupe commença à faire le pèlerinage de Sasaguri en 196I et vient chaque année depuis cette date. En outre, il s'arrange aussi pour faire en deux ans le circuit complet du « vrai Shikoku » et des cent Kannon (Hyaku Kannon 百観音) ${ }^{25}$. Le groupe est guidé par plusieurs responsables portant des bâtons à anneaux (shakujō 錫杖) et à qui l'on donne le nom de sensei 先生 (《maître »). On dit que ceux qui n'ont pas fait le pèlerinage un assez grand nombre de fois « sont vaincus par le bâton à anneaux » (shakujō ni makeru 錫杖に負ける), c'est-à-dire qu'ils tombent malades, car leurs forces ne peuvent en supporter la puissance (celle des

24. Sur le Nanzō-in, voir dans ce même volume la contribution de Suzuki Masataka 鈴木正崇, "Modernisation des temples bouddhiques et société locale : le Nanzō-in de Sasaguri », p. 351-42I.

25. Depuis l'époque d'Edo, on appelle « pèlerinage des cent Kannon » le circuit qui englobe : le pèlerinage des Trente-trois Kannon de la région occidentale (Saigoku sanjū san Kannon reijō 西国 三十三観音霊場), lequel est à cheval sur les zones urbaines de Kyōto, Ōsaka et les départements de Shiga 滋賀県, Nara, Wakayama 和歌山県, Hyōgo 兵庫県, Gifu 岐皁県; celui du Kantō 関東 (Bandō sanjū san Kannon reijō 坂東三十三観音霊場) ; et celui de Chichibu 秩父 (Cbichibu sanjū san Kannon reijō 秩父三十四観音霊場) situé dans le département de Saitama 埼玉県. 
entités qui les habitent). La fille de Sugyō qui fait partie du groupe est considérée comme susceptible d'être très facilement possédée par les âmes. Lorsque j'ai moimême accompagné ce groupe à l'occasion d'un de ses pèlerinages à Sasaguri, elle se sentit mal en raison de l'emprise d'âmes dans un certain nombre de fudasho, et dut subir un rite d'exorcisme (tsukimono otoshi 憑き物落とし, « qui fait tomber l'agent de possession ") sous la forme de coups sur le dos donnés à l'aide d'un volume du Sūtra de la Grande Sapience (Dai-bannya-kyō 大般若経). Cette fois-là, l'épouse de Nashida 梨田, l'entraineur de base-ball professionnel, faisait partie du groupe. Celle-ci pratique ordinairement l'ascèse de la cascade et dit avoir été Hosokawa Gracia 細川 ガラシャ dans une vie antérieure ${ }^{26}$. Il y avait également un maitre de divination, un masseur, un malade du cancer en phase terminale. Tous étaient des fidèles réguliers du sanctuaire Ishizuchi daigongen de Kokura et les personnes âgées étaient assez nombreuses.

Autrefois, chaque année, au printemps, avait lieu l'ouverture du pèlerinage et les alentours de la gare de Sasaguri étaient envahis par les groupes de pèlerins en vêtements blancs qui sortaient des trains les uns après les autres. De nos jours, c'est encore au printemps, à la saison des fleurs, et à l'automne, lorsque les feuillages rougissent, que les pèlerins sont les plus nombreux. Les raisons de leur venue sont variées, et l'on remarque aujourd'hui que, tout en disant qu'ils éprouvent un certain attrait pour l'aspect religieux, ils reconnaissent que c'est le côté ludique, la randonnée ou l'intérêt pour l'histoire locale qui constitue leur motivation principale. Ceci est sans doute dû au fait que les pèlerins portant le vêtement blanc et dont la démarche est ancrée dans le culte du Grand Maître Kōbō de la période Shōwa 昭和 (1926-1989) ont pris de l'âge et sont de moins en moins nombreux. On raconte que durant les périodes de Taishō 大it (1912-1926) et Shōwa, chaque année, au printemps, on pouvait voir se suivre sans interruption, entre Tanaka et Nomiyama, des files entières de pèlerins qui avaient l'entrain des voyages de loisir en groupes, et que cela avait tout du rite saisonnier.

C'est ce type de pèlerinage festif au caractère ludique accentué qui s'est le plus modifié selon les époques, alors que n'ont cessé de venir plus discrètement ceux dont la démarche repose sur des motifs religieux comme les rites pour les morts, sur la pratique personnelle, sur des demandes particulières ou encore sur la reconnaissance pour des vœux exaucés. Aujourd'hui encore, on peut voir dans les divers lieux du pèlerinage de Sasaguri de jeunes couples adressant des prières. Ils ne portent plus le vêtement blanc du pèlerin, sont en tenue de les jours, mais serrent dans leurs mains des chapelets dont ils n'ont pas l'habitude; ils ont une expression empreinte de sérieux et certains ont les yeux gonflés. Les souffrances et la tristesse de la mort en couche, de la stérilité, des séparations ou de la maladie sont aussi de notre époque.

Sur la carte du pèlerinage sont signalés les chemins pédestres pour les pèlerins, ainsi que les stations de bus et les gares ferroviaires, mais rares sont ceux qui aujourd'hui font le parcours à pied. Même les personnes qui ont pour but de pratiquer l'ascèse

26. Hosokawa Gracia 絒川ガラシャ (1563-1600), de son nom de naissance Akechi Tama 明智珠, fut l'épouse du daimyō Hosokawa Tadaoki 細川忠與. Elle est connue pour s'être convertie au catholicisme sous l'influence des jésuites. 
de la période du froid au Nanzō-in, ou le groupe de Sugyō, utilisent des véhicules pour les passages difficiles ou les portions de route où les dénivelés sont importants. Beaucoup de pèlerins font le circuit soit avec des voitures où ils peuvent monter jusqu'à six ou dix, soit avec les minibus des auberges, soit avec les petits cars des offices de tourisme et, sur la carte, les parkings sont indiqués avec précision. Les pèlerinages faits dans la journée sont devenus la règle et l'utilisation des auberges de Sasaguri a diminué drastiquement. La carte mentionne vingt-cinq auberges et hôtels, c'est-à-dire près de deux fois moins que dans la première moitié du $\mathrm{xx}^{\mathbf{e}}$ siècle ${ }^{27}$.

Un des critères permettant de distinguer les pèlerins des visiteurs qui n'en sont pas est l'existence ou l'absence de la pratique rituelle. La plupart des pèlerins respectent les rituels bouddhiques, allumant une bougie à chaque lieu visité, offrant de l'encens, des pièces de monnaie, des récitations de sütra (nōkyō 納経) ou déposant des vignettes. Les offrandes en espèces s'élèvent aujourd'hui à plusieurs pièces de cent, cinquante, dix ou cinq yens, et à Sasaguri, la coutume veut qu'en plus de l'offrande à la statue principale, on laisse une pièce d'un yen devant chaque statue en pierre de l'enceinte. Généralement, un pèlerin qui fait le nōkyō, c'est-à-dire une offrande de récitation ou de transcription de sütra devant l'autel du temple, peut demander aux desservants de service, comme preuve de cette offrande, l'apposition du nom, du numéro et du tampon à l'encre rouge (shuin 朱印) du temple sur son carnet de pèlerinage ${ }^{28}$ (nōkyōchō 納経帳), moyennant trois cents ou cinq cents yens. À Sasaguri, si l'on appose soi-même le tampon sur son carnet, on verse cent yens, et deux cents si l'on demande la calligraphie du nom du temple. Dans le cas où cette calligraphie doit être demandée dans un endroit distinct du fudasho, ce lieu est signalé sur la carte du pèlerinage à l'aide d'un point rouge. Mais sur ce circuit de Sasaguri, presque personne ne fait cette demande, mis à part les pèlerins venant du Kantō, où cette pratique est répandue.

\section{Les temples «bors numérotation》(bangai jiin 番外寺院)}

Objets du pèlerinage, circuit et pèlerins sont des composantes qui ici ne diffèrent pas beaucoup de ce que l'on peut constater sur les autres pèlerinages du pays. Toutefois, la particularité de Sasaguri est la présence de nombreux temples non inclus dans le comput des quatre-vingt-huit temples du parcours, appelés bangai 番外,

27. On ignore le nombre exact des auberges et hôtels de Sasaguri à l'époque où ces structures d'accueil étaient les plus nombreuses. Mais lorsqu'il fit le pèlerinage de Sasaguri en 1934 (Shōwa 9), Nakano Shiyō 中野柴葉 nota qu'il y avait soixante-quinze établissements pouvant accueillir entre soixante-dix et cent trente personnes (Nakano Shiyō, Sbin-Sbikoku bachijü bakka-sho junpai 新四 国八十八ケ所巡拜, p. 59, p. 83). Et sur sa carte du pèlerinage (Sasaguri Shikoku bachijü bakka-sho reijo fudasho annai 筆栗四国八捨八ヶ所需場札所案内) publiée en 1927 (Shōwa 2), Ino.ue Isojirō 井上硪次郎 mentionne soixante-huit auberges. Il est donc fort probable que leur nombre ait aussi continué à augmenter après 1935 .

28. Quoiqu'un peu différent, ce carnet peut sans doute être rapproché du crédential (sp. credencial) du pèlerinage de Saint-Jacques-de-Compostelle. (N.D.T.) 
qui attirent l'attention ${ }^{29}$. Ailleurs aussi, on peut trouver des arrêts sur le circuit appelés 《fudasho hors numérotation 》(bangai fudasho 番外札所) ou simplement 《 hors numérotation " (bangai-san 番外さん) qui, bien que dépourvus de numéro officiel, sont considérés comme faisant partie intégrante du parcours, au même titre que tous les temples numérotés. Néanmoins, il s'agit là d'une présence en sus, et il est extrêmement rare que ces lieux deviennent plus importants que les fudasho du circuit officiel. Ils ont plutôt tendance à être nettement moins visités que ces derniers $^{30}$. À l'inverse, à Sasaguri, les temples surnuméraires sont parfois beaucoup plus fréquentés que certains des quatre-vingt-huit stations et peuvent même posséder une force d'attraction qui séduit un nombre considérable de pèlerins venus de l'extérieur de la commune. C'est notamment le cas de ceux qui sont placés sous la responsabilité d'un gardien d'oratoire ou de temple de type charismatique (reinō shükyōsha 霊能宗教者, “ religieux ayant des pouvoirs »), appelé couramment ici “ intercesseur " (ogamiya san 拝み屋さん, 《 invocateur ») ou 《 pratiquant de l'ascèse » (gyōja sama 行者様), et vers qui ne cessent de se presser une foule de fidèles venant demander du secours pour leurs maux et souffrances.

Ceci est sans doute aussi valable pour les régions d'Okinawa, de l'ouest du pays et de Shikoku, mais à Sasaguri, ces spécialistes religieux sont visités par le flot incessant de ceux qui cherchent à connaître les moyens de remédier aux soucis, angoisses, souffrances et malheurs auxquels ils sont confrontés : problèmes de famille, dettes, fugues, mauvaise santé, cancer, dépression, attaques, maladies, accidents, troubles du développement, absentéisme scolaire, retrait social (bikikomori 引き籠り), faillite, célibat, stérilité. Beaucoup d'entrepreneurs ou d'élèves en période de préparation aux examens viennent aussi pour demander (otazune お尋ね) comment saisir chance et succès. Pour eux, causes et nature du bonheur ou du malheur ne peuvent être connues que par la voyance (reishi 霊視, 《vision subtile ») ou la divination (uranai 占い); aussi viennent-ils chercher auprès de ces spécialistes religieux charismatiques une « réponse » ou une « divination» (banji 判じ), c'est-à-dire un oracle ${ }^{31}$.

29. Alors qu'ils entrent dans la catégorie des oratoires, sur la carte sont signalés comme «temples hors numérotation " les lieux suivants : le Pavillon des reliques du Bouddha (Busshariden 仏舎利殿), Yakushi d'Ichibata (Ichibata Yakushi nyorai 一畑薬師如来), Tamamitsu Inari 玉光 稲荷, le Grand Maître protecteur de la circulation routière (Kōtsū anzen daishi), la Pierre dressée (Tate.iwa), Fudō myōō 不動明王.

30. Sur la carte, le Kongōchō-in et la cascade de Yōrō sont classés parmi les temples hors numérotation. Mais comme ils sont très éloignés du circuit de pèlerinage de Sasaguri, et qu'ils sont tous deux situés dans le quartier de Wakasugi qui, historiquement et culturellement, est distinct du village de Sasaguri, on peut penser qu'avant l'introduction de la voiture, ils furent peu fréquentés par les pèlerins de ce pèlerinage.

31. À Sasaguri, le terme banji désigne tout particulièrement les explications ou les interprétations des choses de ce monde venant des bouddhas, des dieux ou des âmes et transmises par les spécialistes religieux considérés comme ayant des pouvoirs. Il s'agit d'une forme d'oracle. On dit également, lorsque des paroles sont dispensées par ces intercesseurs, que l'« omikuji (la "divination") sort 》(omikuji ga deru 御御筆 [おみくじ] が出る). Sont aussi utilisées des expressions comme

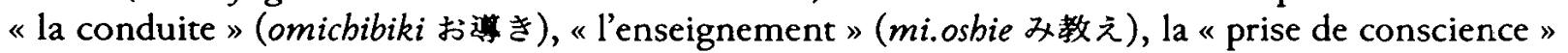
(« révélation») (osatoshi お諭し), «l'indication divine 》 (goshinji ご神示). 


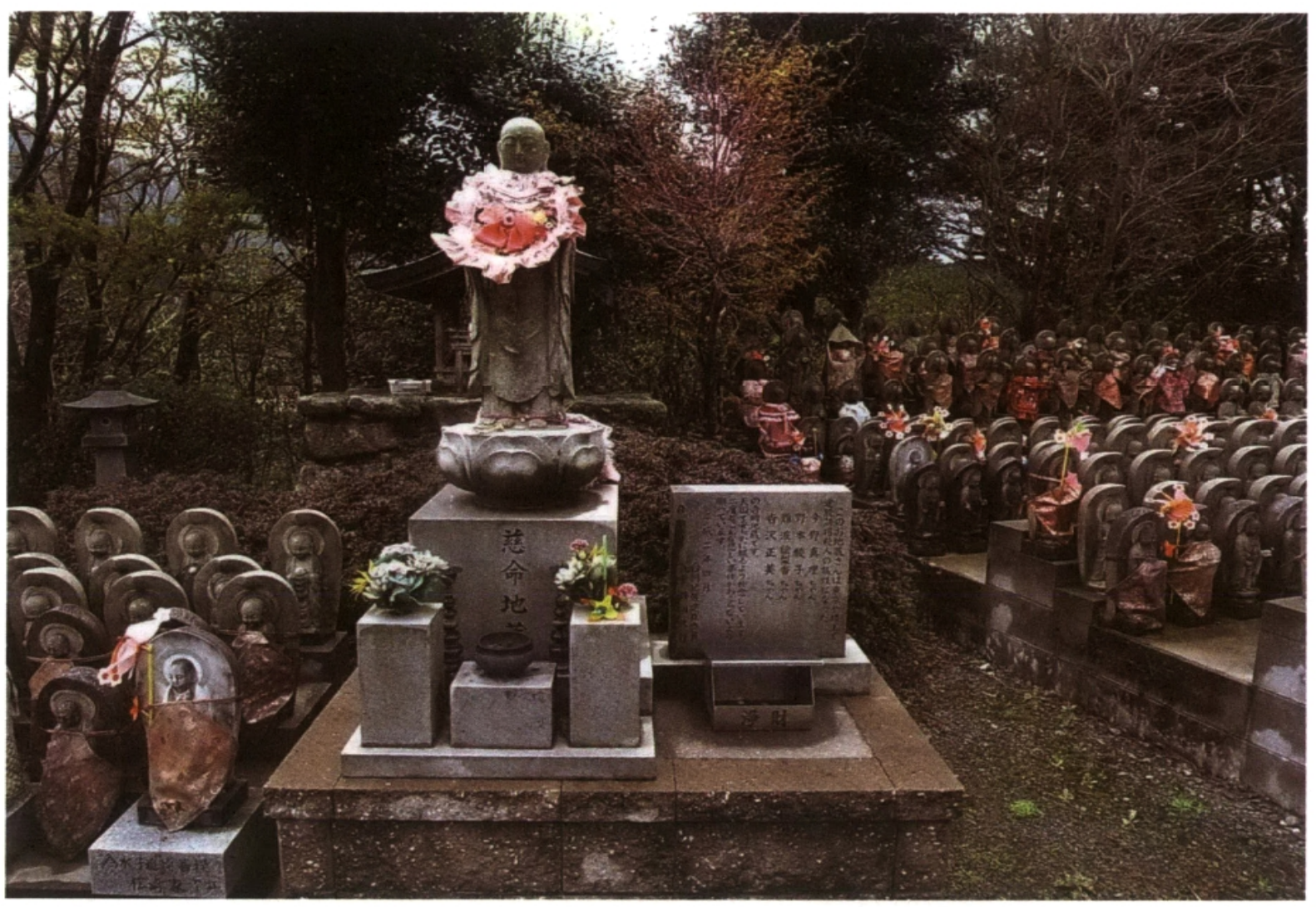

Fig. 5 : Monju-in, temple surnuméraire (Nomiyama) et les Jizō pour les enfants morts à la naissance et les foetus avortés (toutes les photos sont de l'auteur).

Tout au long du circuit de pèlerinage de Sasaguri, de même que sur ceux de la région nord de Kyūshū, on peut voir une multitude de statues, de reproductions en bois du corps humain et des pieds ou des bras, de plaquettes funéraires (ibai 位牌) ${ }^{32}$, dont beaucoup ont été apportées là en offrandes sur les directives de ces religieux charismatiques. Parfois, on a même l'impression que le pèlerinage de Sasaguri est enfoui sous la masse des statues qui y ont été déposées, et les principaux artisans de la création de cette atmosphère particulière sont ces religieux à qui l'on reconnaît des pouvoirs.

32. Ihai 位牌 : la plaquette funéraire porte le nom posthume attribué au défunt par le moine du temple bouddhique qui l'y inscrit au moment de sa mort, ainsi que le nom qu'il portait de son vivant, son âge et la date de son décès. Il en est fait plusieurs (en bois, en papier), dont une est déposée sur sa tombe lors des funérailles; une autre est disposée au temple où sont assurés les services post-funéraires ; une autre, sur l'autel bouddhique familial ; beaucoup d'autres peuvent aussi être ensuite placées sur des lieux de culte, de pèlerinage, etc. (N.D.T.) 
Le temple hors numérotation Monju-in Jizō-ji 文殊院地藏寺 (fig. §) est aujourd'hui situé à Nomiyama, mais il a été fondé originellement dans le département de Saga où il recrutait ses fidèles. C'est pour des raisons immobilières qu'il a été transféré à Nomiyama en 1978. Ce temple est dédié au bodhisattva Monju, dont la statue est vénérée sur l'autel principal. Mais dans l'enceinte, on trouve de nombreuses statues du bodhisattva Jizō : «Jizō de la mort soudaine »(Pokkuri Jizō ぽつくり地蔵), « Jizō de la progéniture facile » (Koyasu Jizō 子安地蔵), «Jizō sans tête »(Kubi-nashi Jizō 首なし 地藏), « Jizō des rites pour les morts» (Kuyō Jizō 供養地蔵), « Jizō qui appelle » (Maneki Jizō 招き地蔵), 《Jizō qui attire la bonne fortune » (Fukuyose Jizō 福よせ地蔵), etc. Une autre statue monumentale de Jizō, cntic̀rement peinte en rouge, est réputée pour être particulièrement efficace dans la lutte contre le cancer. À ses côtés, deux autres Jizō, dont l'un peint en jaune et l'autre en vert, ont respectivement des vertus pour guérir de la paralysie et des maladies de cœur. (On peut se demander si ces couleurs sont ou non associées à celles des feux tricolores de la signalisation routière !). Sur le panneau disposé à l'entrée de ce temple est peinte la formule : «temple des foetus/enfants morts (par avortement) » (mizuko no tera 水子の寺), et un grand nombre de photos d'enfants sont alignées devant l'autel principal. Les fidèles sont surtout des gens qui viennent demander des rites pour les enfants morts, et notamment morts avant la naissance par avortement. Une peinture de trois mètres sur trois dressée dans l'enceinte représente les berges du fleuve des Enfers (Sai no kawara 賽の河原), ainsi que les anecdotes chantées dans les hymnes bouddhiques de Jizō, psychopompe et protecteur des enfants morts dans l'au-delà. Selon le supérieur de ce temple, l'avortement est la cause d'horribles maladies inguérissables par la seule médecine, qui provoquent troubles et malheurs à l'intérieur des familles. Aussi est-il nécessaire, selon lui, que les femmes ayant fait l'expérience de l'avortement fassent accomplir des rites pour les âmes de ces enfants morts, par affection pour eux.

Les transferts de fudasho sont beaucoup plus fréquents sur le circuit de Sasaguri que sur ceux de tous les autres, et cela tient pour une part à l'activité des temples hors numérotation, à l'instar de ce temple de Nomiyama. Lorsque, pour une raison quelconque, un gardien d'oratoire ou de temple numéroté ne peut plus en assurer la charge, il arrive souvent que l'un de ces temples hors numérotation prenne la relève, gère l'oratoire, et par là acquière la possibilité d'être intégré au nombre des quatre-vingt-huit. À l'inverse, si un temple qui était anciennement numéroté perd son statut, il conserve parfois une affluence de pèlerins égale à celle dont il bénéficiait avant sa dégradation en «surnuméraire». 


\section{Historique de l'élaboration du pèlerinage de Shikoku à Sasaguri}

\section{Les origines}

Selon la tradition locale, c'est une nonne nommée Jinin 慈忍 qui serait à l'origine de ce pèlerinage de Shikoku à Sasaguri. Le document le plus ancien relatant cette création est une inscription gravée sur une stèle de pierre, située près de l'oratoire de Fudō à la cascade de Kido 城户/滝不動堂 $\left(n^{\circ} 45\right)$, sur une roche dite « roche Heike 》 (Heike iwa 平家岩). Il y est inscrit que la nonne Jinin, originaire du village de Mei-no-hama 姪浜, canton de Sawara 早良郡 (actuel Mei-no-hama, arrondissement de l'ouest de Fukuoka 福岡市西区), fonda cet oratoire en I835 (Tenpō 天保 6) ${ }^{33}$. 1835 est l'année du millième anniversaire de la mort du Grand Maitre Kōbō dite «entrée en concentration » (nyūjō 入定), qui fut célébrée solennellement dans tout le pays ; il est probable que le culte du Grand Maître connut également un essor important à Kyūshū à ce moment-là. Dans le nord de cette région, au cours de la première moitié du XIX ${ }^{e}$ siècle, le développement du commerce fut la source de richesses qui permirent à beaucoup de gens de se rendre jusqu'au « vrai Shikoku », ce qui engendra des échanges d'informations par-delà les frontières régionales. Ceci a pris appui sur l'arrière-plan global de détente politique, de développement économique et de maturité culturelle qui a caractérisé la période Bunka 文化 et Bunsei 文政 (1804-1829). Il faut ajouter à cela que Sasaguri est situé sur la grande voie de circulation reliant Fukuoka-Hakata et Shikoku. Aussi est-ce dans ce contexte qu'a dû s'imposer l'idée de créer, à cette époque et à cet endroit, une réplique du pèlerinage de Shikoku ${ }^{34}$.

La tradition locale veut que le temple numéro 45 où se trouve cette stèle soit le lieu où, au Moyen Âge, se cachèrent et s'implantèrent les Heike 平家 vaincus par les Genji 源氏 (fin du XII' siècle). Et c'est le nom d'un de ceux qui s'en disent les descendants, un membre de la famille Kiryū 桐生, qui est gravé au premier rang des gestionnaires de cet oratoire. Comme les Heike ont été exterminés dans la bataille de Dan-no-ura 壇/浦 au nord de Kyūshū (II85), il existe dans toute cette région un grand nombre de légendes relatives aux rescapés Heike qui se seraient enfuis et cachés. Cela concorde sans doute avec cette tradition voulant que Jinin ait également fondé à cet endroit le

33. Voir le document I placé à la fin de cette contribution ainsi que tous les autres documents et tableaux. Résumé de l'inscription : le commencement du Shikoku de Sasaguri date de 1835 (Tenpō 6) et il fut rétabli durant le $7^{\mathrm{c}}$ mois intercalaire de 1854 (Kaei 范永 7). La fondatrice en fut Jinin, et les responsables (sewanin 世話人) de cette époque étaient au nombre de sept, dont Kiryū Rihei 桐生利平. Pour la restauration, ils étaient huit, parmi lesquels Kiryū Rihei. Des débuts jusqu'à ce jour, cinquante ans ont passé. En ce mois de mars de 1885 (Meiji I8), trente-six responsables, dont Kiryū Genshirō 桐生源四郎, dressent cette stèle.

34. Ce phénomène n'est pas limité à Sasaguri. Durant la première moitié du XIX ${ }^{\complement}$ siècle, tout le pays connut une sorte de vogue de création de nouveaux pèlerinages de Shikoku. Mes seules investigations m'ont permis d'en dénombrer trente-sept. L'ère Tenpō 天保 débuta en 1832 et elle est célèbre pour la longue famine qui dura jusqu'en 1839. Mais celle-ci sévit principalement dans les régions du Kantō et du nord-est, alors qu'à cette même époque, la disette pour cause de mauvaises récoltes n'a pas été constatée dans l'actuel département de Fukuoka. Or, même dans les régions sinistrées de l'est et du nord-est, furent créés plusieurs nouveaux circuits de Shikoku. 


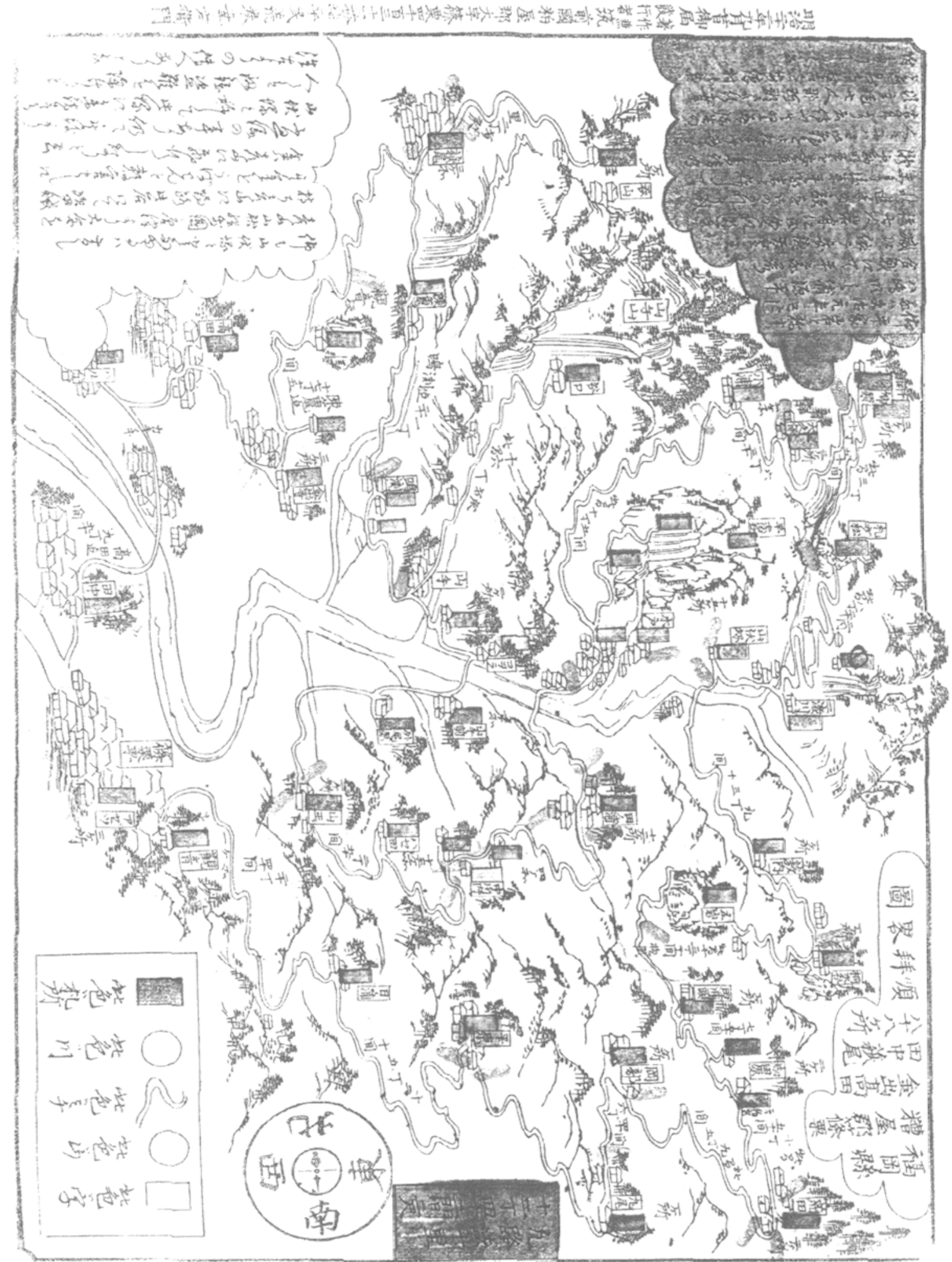

Fig. 6 : Le circuit simplifié du pèlerinage de Sasaguri en 1889 (carte imprimée, Meiji 22, par Aramaki Kō.uemon) (Fukuoka-ken Kasuya-gun Sasaguri Kana.ide

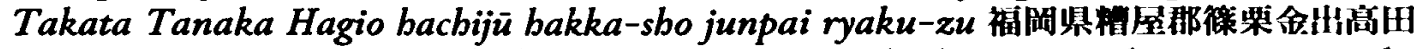

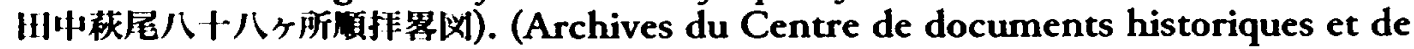
matériaux ethnographiques de Sasaguri) 
temple Antoku-ji 安徳寺, pour qu'y soient accomplis des rites à la mémoire d'Antoku 安徳天皇 (II78-I185), l'enfant empereur qui disparut en mer avec les guerriers vaincus. Sur la carte du pèlerinage de Sasaguri imprimée en 1889 (Meiji 22) (fig. 6, Hachijü bakka-sho junpai ryaku-zu 八十八ヶ所順拝略図) par le gardien de l'oratoire numéro SI, Aramaki Kō.uemon 荒巻幸右衛門, il est mentionné que, d'après l'histoire locale de ce tertre appelé « roche Heike », les Heike disparurent à Yashima 八嶋 et Dan-no-ura, mais que l'empereur Antoku et sept de ses suivants se cachèrent à cet endroit et purent ainsi échapper à leurs poursuivants ; aussi le tertre fut-il dénommé « roche Heike »; une statue de Fudō myōō fut installée à la cascade et le village prit alors le nom de village Antoku 安徳村 ${ }^{35}$. Le lieu de naissance de ce pèlerinage de Shikoku à Sasaguri est ainsi riche en éléments propres à générer des narratifs, qui sont encore renforcés par le fait que l'initiatrice en fut une femme et que l'époque était celle de la grande famine de Tenpō (1833-1839). Tout ceci explique que, de l'époque Meiji jusqu'à nos jours, de nouvelles interprétations et recompositions ont sans cesse été apportées à cette histoire de fondation.

Il est en outre important de préciser que la nonne Jinin n'eut peut-être pas l'intention de créer un pèlerinage. La réplication du « vrai Shikoku » peut en effet se faire en réunissant quatre-vingt-huit statues faites à l'image de celles du modèle et en les déposant toutes à l'intérieur d'un même oratoire ou d'un même secteur géographique. C'est ainsi qu'opéra Mokujiki Gyōdō 木喰行道, pratiquant de la pérégrination à l'échelle du pays, qui ouvrit un oratoire de Shikoku en I80I dans son hameau natal de Mukawa 向川 à Maruhata 丸畑 du village de Furuseki 古関村, en province de Kai 甲斐国 (actuellement Marubatake 丸畑, Shimobe 下部町, département de Yamanashi) ${ }^{36}$. Une telle réplication en un seul lieu peut être rapprochée du culte des mandala, et repose sur la croyance selon laquelle, si l'on regroupe de nombreuses statues en les organisant selon un certain ordre, comme pour former un cercle magique, et qu'on y associe certains rituels, il en émane un pouvoir mystérieux. On a relevé dans tout le pays des exemples d'assemblage en un même endroit (ou encore sur une même feuille de papier) des trente-trois Kannon ou des statues des quatre-vingt-huit fudasho destinés à être l'objet de vénération principal lors de rituels pour les morts. Aussi est-il tout à fait possible de penser que Jinin a réuni et vénéré les quatre-vingt-huit bouddhas des fudasbo en un centre cultuel à l'Antoku-ji

35. Somosomo Heike iwa to shō su tsuka wa, Bunji gannen, midoshi, Yashima, Dan-no-ura, Genpei gassen nite, Heike raku metsu ni yorite, Antoku tennō, shujūshichi nin, iwa tsuka ni, okakure asobasare, otte no teki wo, onogareshi nari. Sore yori kōrai, Heike iwa to shō shite, taki Fudō myōō wo anchi sbi, sonmei wo, Antoku mura to nazuketarishi to iu.

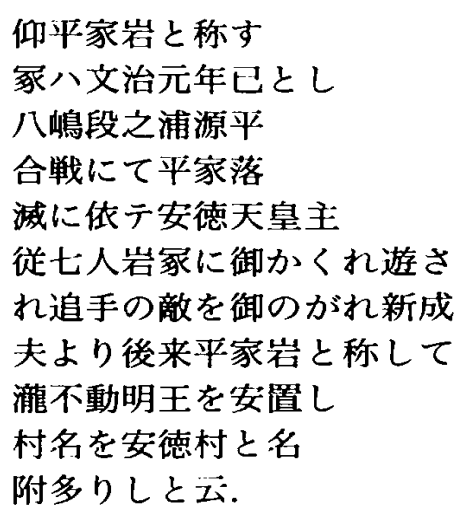

36. Voir Anne Bouchy, "Une voie de l'“art premier" dans le Japon du XviI 'siècle. La statuaire d'Enkū, pérégrin de l'Essentiel », L'Homme 165 (2003), p. 143-172. (N.D.T.) 
qu'elle fonda à la roche Heike, pour en faire un temple dédié au service des âmes des Heike, ancêtres de la famille Kiryū. Le troisième mois de 1835 (Tenpō 6) est à la fois le millième anniversaire de la mort du Grand Maître Kōbō disparu au $3^{\mathrm{c}}$ mois de 835 (Jōwa 承和 2) et le $750^{\circ}$ anniversaire de la fin dramatique de l'empereur Antoku et des Heike en II85 (Genryaku 元暦 2). Si l'hypothèse concernant la fondation de l'Antoku-ji comme temple dédié aux services de ces morts est recevable, on peut penser que les Kiryū, lointains descendants des Heike, ont apporté leur soutien à Jinin. Dans ce cas, la fabrication des quatre-vingt-huit statues n'aurait pas eu pour objectif la création d'un circuit de pèlerinage.

Or, cette stèle de la roche Heike a été dressée pour le cinquantième anniversaire de la création du pèlerinage de Shikoku à Sasaguri. L'historique détaillé de cette édification fut consigné par l'un des responsables, Kiryū Genshirō 桐生源四郎, mentionné précédemment, et probablement descendant de Kiryū Rihei 桐生利平, qui fut l'un des initiateurs de ce même pèlerinage (voir le document 2$)^{37}$. Selon ce texte, Hirai Shōkō 平井勝幸 édifia une stèle en 1719 (Kyōhō 享保 4$)^{38}$ et, de là, se répandit largement la renommée du village de Sasaguri comme lieu de la venue de Zenmui Sanzō 善無畏三蔵 (cinquième patriarche de la branche Shingon du bouddhisme ésotérique) et du Grand Maître Kōbō Kūkai (huitième patriarche du Shingon). Et c'est dans le but de suivre les traces de ces maîtres que Jinin arriva à Sasaguri en I835 (Tenpō 天保 6), s'installa à Kido où elle pensa faire la réplication du « vrai Shikoku » afin de diffuser le culte du Grand Maître Kōbō et de demander le salut des âmes des défunts. Mais Jinin ne parvint pas à réaliser complètement cette intention, car certains de ses fidèles auraient eu des problèmes, dont la cause aurait alors été attribuée au fait qu'elle n'avait pas encore atteint un stade de purification

37. Archives de la famille Kiryū $n^{\circ}{ }_{4}$ (Centre de documents historiques ct de matćriaux ethnographiques de la commune de Sasaguri, Sasaguri rekishi minzoku shiryō-shitsu 筗栗歴史 民俗資料穻). Ce document, composé de huit pages seulement, comporte en plusieurs endroits des phrases inachevées. Et comme son contenu est à peu près identique à celui du texte de la stèle commémorative dressée dans l'enceinte de l'oratoire de Yakushi à Ta-no-ura 出/浦楽師堂 ( ${ }^{\circ}$ 59) en 1895 (Meiji 28), on peut penser qu'il s'agit du brouillon de ce dernier. La mention « composé par Uchikawa Aidō » 内川䗖道撰 signifie que le texte écrit par Kiryū Genshirō a servi de base à Uchikawa pour rédiger un texte en langue savante. Uchikawa Aidō était un homme venu de l'extérieur, mais en tant que prêtre du sanctuaire tutélaire du village de Sasaguri, Suwa jinja 諏訲神社, il représentait l'autorité du gouvernement de Meiji qui cherchait à faire du culte des dieux une religion d'État, et c'est lui qui fut l'instigateur de l'édification de cette stèle. Tō Ichirō 藤喜一郎, l'un de ceux qui soutenaient Uchikawa Aidō, était le premier maire du village de Sasaguri après Meiji et, à ce titre, celui qui détenait l'autorité du gouvernement central de Meiji. Tō Kihachirō 藤喜八郎, qui est nommé en tête des responsables, fut le second maire. Outre ces trois noms, on trouve également en première ligne celui de Kiryū Genshirō. Voir le document 3 : Inscription de la stèle commémorant l'œuvre de Fujiki Tōsuke.

38. La tradition locale veut que cette stèle soit l'actuel socle des statues de l'oratoire appelé 《Kannon au Trou » (Ana Kannon-dō 穴観音掌) de l'oratoire de Kannon de Ta-no-ura 田ノ浦観 ir (Kyōhō 7) et y aurait déposé le Sūtra du Cour de la Sapience (Hannya shin-gyō 般茯心経), celui de Kannon (Kannon-gyō 観音経), du Lotus (Hokke-kyō 法曅経), des Rois Bienveillants (Ninnō-kyō 仁玵経), de Fudō (Fudō-kyō 不動経) et du Baton à anneaux (Shakujō-kyōo 錫杖経). 
suffisant, et donc de détachement par rapport à ce monde : « elle n'avait pas épuisé son karma » (jigō imada tsukizu 自業未だ尽きず). Aussi Jinin aurait-elle diparu après avoir mis en place seulement vingt statues.

Cette histoire condense ce qui se transmettait dans la famille Kiryū ainsi que les informations réunies par Kiryū Genshirō. Ce dernier était une importante personnalité locale. En 1884 (Meiji 17 ), il fut très actif dans le cadre d'une action judiciaire. Il avait en outre la capacité de composer toutes sortes de documents. C'est lui qui écrivit la plus grande partie de la volumineuse "Demande pour l'inscription dans le Registre des temples et sanctuaires de Sasagur ${ }^{39}$ ", afin de faire reconnaitre officiellement par l'administration nationale l'existence du pèlerinage de Sasaguri. Dans l'en-tête de ce document, où Kiryū Genshirō retrace l'historique du circuit, il est mentionné que le pèlerinage de Shikoku à Sasaguri a commencé dans les années $180 \mathrm{O}-1804$ (Kyōwa 享和), avec l'installation par des fidèles de statues à des endroits purs des montagnes et des vallées du village de Sasaguri. Puis durant le $3^{\mathrm{e}}$ mois de 1835 (Tenpō 6), la nonne Jinin du temple Antoku-ji du village de Meino-hama, canton de Sawara, ayant fait connaître son vou de créer sur place un nouveau pèlerinage des quatre-vingt-huit lieux de Shikoku, Kiryū Rihei et d'autres se concertèrent avec les habitants du quartier de Kido du village de Sasaguri : vingt statues furent ainsi sculptées puis installées. Mais divers « problèmes 》 (shöge 障礙, " obstacles") se produisirent et il ne fut pas possible d'achever la sculpture des quatre-vingt-huit statues ${ }^{40}$.

Chaque année, le $2 \mathrm{I}$ du $3^{\mathrm{e}}$ mois ont lieu dans tout le pays des rites célébrant l'anniversaire de la mort du Grand Maître Kōbō, et c'est le moment où culminent les manifestations du culte envers ce dernier. Jinin fit dresser la stèle de la roche Heike au $7^{\mathrm{C}}$ mois de 1835 : elle aurait donc renoncé à son entreprise au bout de seulement quatre mois. Il semble que Kiryū Genshirō poursuivit son enquête, et dans le texte qu'il écrivit en 1895 pour le monument commémoratif de Ta-no-ura (sis à côté de l'oratoire de Yakushi, $n^{\circ}$ 59) en s'appuyant sur la « Demande pour l'inscription dans

39. Meisaichō hennyū negai 明細帳編人願, daté de juin 1894 (Meiji 27) : archives de la famille Kiryū $n^{\circ} 5$ (Centre de documents historiques et de matériaux ethnographiques de la commune de Sasaguri).

40. Hitotsu. Yuisho. Kyōwa nenchī, Sasaguri mura, san.ya shōjō no chi, tokorodokoro ni, shinkō no mono,

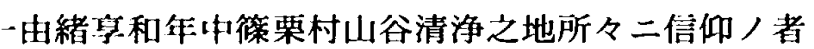

butsuzō wo anchi shitaru yori okori, Tenpō roku nen san gatsu, Sawara-gun Mei-no仏像习安置シタル依リ起リ天保六年三月早良郡姪

bama mura, Antoku-ji Jinin zenni to mōsu mono, shingan no tame, Shin Sbi濱村安徳寺愁忍禅尼卜申者心願/為入新四

koku bachijū-bakka-sho wo sōsetsu seshi koto wo, honson Kido buraku yūshisha, 国八拾八ヶ所 $习$ 㓣設セシ事 $习$ 本村城戸部落有志者

Kiryū Ribei, Inoue Ibachi, sono ta, dōburaku jinmin ichidō ni hakari, nijut-

桐生利平井上伊八其他同部落人民一同二汹少式拾

tai no butsuzō wo chōshi, dōji ni anchi seri. Shikaredomo, chüto, shō-

体ノ仏像 啀シ同時二安置セリ然レトモ中途障

ge arite, tsuini sono nozomi wo batasu atawazu shite, yamu.

链アリテ遂二其望ミア果ス能ハスシテ忖ム 
le Registre des temples et sanctuaires de Sasaguri » citée précédemment, il rectifia le nombre des statues réellement faites en le réduisant à dix-huit (document 3). Selon ses investigations, il s'agissait des statues principales des dix-huit fudasho suivants : $1,4,5,6,10,12,13,22,28$, $31,35,37,53,58,71,74,79,88$. Celles-ci sont appelées «bouddhas de Tenpō » (tenpō butsu 天保仏) (fig. 7), et l'on estime qu'elles datent du $8^{\mathrm{e}}$ mois de 1835 . C'est sur ce chiffre que se fonde l'inscription du monument commémoratif.

Mais selon cette même enquête de Kiryū Genshirō, ces dix-huit statues ne seraient pas les plus anciennes. Celles des fudasbo 2, 3, 34, 45, $56,60,66$ et 83 dateraient de 1802 (Kyōwa 2) ${ }^{\mathbf{4 1}}$. Il est donc fort possible qu'avant même la venue de Jinin, l'idée du nouveau Shikoku ait déjà vu le jour et qu'en 1802 , un certain nombre de statues aient déjà été installées. Toutefois Genshirō ne précise rien à ce sujet. Quoi qu'il en soit, il est clair que ces statues n'ont pas été sculptées dans l'ordre numérique. Ceci tient sans doute à la volonté du donateur. La tradition veut par exemple que le fudasho numéro 88 d'Ōkubo 大久保 ait été créé parce que la famille Kiryū, habitant cet endroit, se sentait liée au temple Ōkubo 大察寺 du « vrai Shikoku ». Sur les circuits de nouveaux Shikoku de tout le pays, on relève aussi des créations de fudasho dont le

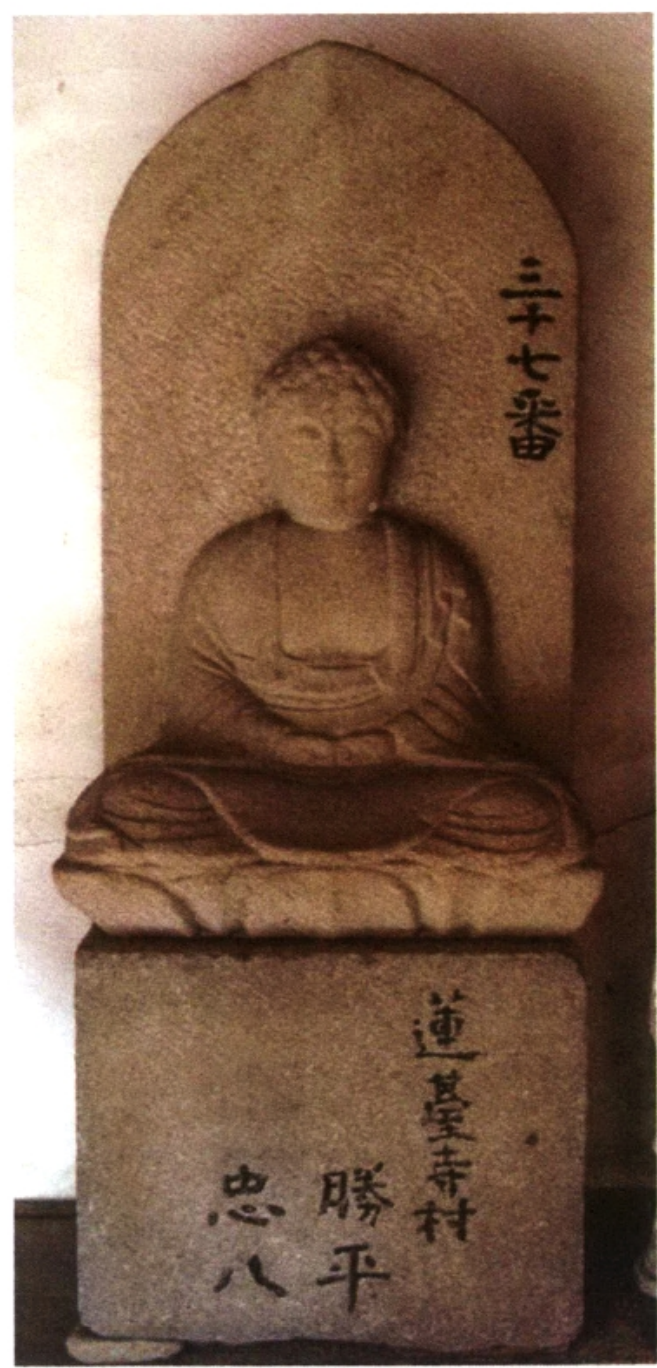

Fig. 7 : Bouddha de Tenpō (oratoire d'Amida, $\mathbf{n}^{\circ}$ 37, Takata). numéro correspond à l'âge qu'avait le donateurfondateur ; ou encore, dont le numéro résulte du fait que les tisserands manifestent une préférence pour le numéro Io, Kirihata-ji 切幡寺 (car bata 幡, “ la bannière ", c'est aussi bata 機, "le métier à tisser »). De même, ceux qui sont nés une année placée sous le signe du lièvre souhaitent une statue du bodhisattva Monju qui en est le protecteur. Or seul le numéro 31 du vrai Shikoku, Chikurin-ji 竹林寺, a pour centre de vénération ce bodhisattva : ainsi ils installent le 3I. Ce sont donc les souhaits des donateurs-fondateurs qui occasionnèrent le « désordre » dans lequel les statues du pèlerinage furent sculptées à l'origine. C'est là une des raisons pour lesquelles, à Sasaguri, le pèlerinage s'effectue également sans suivre l'ordre numérique ordinaire.

41. Mais aucune de ces statues, y compris celles que l'on appelle les «bouddhas de Tenpō », ne porte de mention de date. On ignore ce sur quoi s'est appuyé Kiryū Genshirō pour en évaluer la date de création. Or par la suite, il fit une rectification pour les quatre statues des fudasho $\mathrm{n}^{\mathrm{os}} 45$, $56,60,83$, qu'il donna comme étant de l'époque Kyōwa (180I-1804): on peut donc penser qu'il s'est basé sur des traditions orales. 


\section{La mise en place du "Shikoku de Sasaguri »}

Selon la tradition locale, c'est Fujiki Tōsuke 藤木藤助 qui aurait fait sculpter les quelques dizaines d'autres statues pour compléter les quatre-vingt-huit fudasho et en faire le circuit de pèlerinage de Shikoku à Sasaguri. Une stèle de l'enceinte de l'oratoire de Kannon de Naka-no-kōchi 中/河内観音堂 $\left(n^{\circ} 48\right)$ porte une inscription dont le sens est le suivant ${ }^{42}$ : “L'instigateur (gansbu 願主, le " maître du vœu ») qui mit en place les quatre-vingt-huit fudasho du nouveau Shikoku est Fujiki Tōsuke du quartier de Ta-no-ura ; ses assistants sont Kiryū Rihei de Kido, Hirai Seishichi 平井 清七 de Ta-no-ura, Murase Shinpei 村瀨新平 de Naka-no-kōchi, Arisumi Zenjirō 有隅善次郎 de Sannō, Arisumi Bunsuke 有隅文助 de Maruo 丸尾. Inscription faite par Mino Shichi 三野七 le $7^{\mathrm{e}}$ mois intercalaire de 1854 (Kaei 嘉永 7, uruu 7 gatsu閏七月). 》

On peut comprendre par là que cette stèle fut édifiée à la suite de la construction de la stèle de la roche Heike. Pour confirmer cette hypothèse, Genshirō écrit que la « reconstruction » du pèlerinage de Sasaguri Shin-Shikoku date du $7^{\mathrm{e}}$ mois intercalaire de 1854 (Kaei 7 ).

Selon le document 2, Fujiki Tōsuke était un habitant de Ta-no-ura qui, ardent fidèle du Grand Maître Kōbō, accomplit une dizaine de fois le vrai pèlerinage de Shikoku ${ }^{43}$. Le 21 du $8^{\text {e }}$ mois de 1850 (Kaei 3), ayant pris la décision d'achever le dessein initial de Jinin, il abandonna son travail pour se consacrer à la collecte de fonds. Un an et demi plus tard, au cours du $3^{\mathrm{C}}$ mois, commencèrent les travaux, et trois ans plus tard, les soixante-deux statues restantes étaient achevées. Il les installa alors dans des lieux choisis pour leur quiétude et la beauté de leur paysage, et malgré son grand âge - il avait plus de soixante ans -, il partit à Shikoku chercher de la terre sainte. Ainsi, après un pèlerinage de quelque deux mille kilomètres, Tōsuke rapporta de la terre de chacun des quatre-vingt-huit fudasbo de Shikoku qu'il dćposa à l'intérieur de chacune des statues correspondant au numéro de l'endroit d'où venait cette terre. Le $18 \mathrm{du} 7^{\mathrm{c}}$ mois de 1855 (Ansei 2 ), le circuit du nouveau pèlerinage de Shikoku à Sasaguri était achevé. L'hypothèse d'une « reconstruction » en 1854 (Kaei 7 ) est donc une erreur. Après sa mort, pour célébrer l'œuvre de Fujiki Tōsuke,

42. Ta-no-ura

ganshu Fujiki Tōsuke

Kido

Kiryū Ribei

Shin Shikoku bachijü bakka-sho [se] Ta-no-ura

Hirai Seishichi

konryù shitatematsuri [wa] Naka-no-kōchi

Murase Shinpei

Kaei shichi nen [nin] Sannō

Arisumi Zenjirōo

Köin uruu sbicbi gatsu nicbi Maruo

Mino Sbichi ga sbosu Arisumi Bunsuke
田之浦

願主藤木藤助

城户

桐生利平

新四国八拾八ヶ所世田之浦

平井清七

奉建立話中河内

村瀨新平

嘉永七年人山王

有隅善次郎

甲寅閏七月日丸尾

三野七書有隅文助

43. Il aurait été le second fils de Kanazawa Tasuke 金澤太助 habitant à Naka-no-kōchi, et aurait ensuite été adopté par la famille Fujiki de Ta-no-ura (Nanseki Takeshi 南石武, éd., Kasuya Yöroku 粕屋要録, 1973 [ $\mathrm{r}^{\mathrm{re}}$ éd. 1968], p. 127). 
le maire et les habitants du village de Sasaguri édifièrent en I895 (Meiji 28) une statue de bronze de trois mètres de haut à son effigie, dans l'enceinte de l'oratoire de Yakushi de Ta-no-ura ( $\mathrm{n}^{\circ}$ 59) où il avait installé son ermitage $\mathrm{e}^{44}$.

Dans la « Demande pour l'inscription dans le Registre des temples et sanctuaires de Sasaguri ", Kiryū Genshirō résume comme suit les activités de Fujiki Tōsuke : le $3^{\mathrm{e}}$ mois de 1852 , Fujiki Tōsuke reprit la suite du projet lancé par Jinin. Le $2^{\mathrm{e}}$ mois de 1855, les quatre-vingt-huit statues étant toutes achevées, il partit faire le vrai pèlerinage de Shikoku. Le $3^{\mathrm{c}}$ mois de I86I (Bunkyū I), Kiryū Rihei et plusieurs autres obtinrent l'autorisation du fief de Fukuoka, et le $8^{\mathrm{c}}$ mois de cette même année, ils déposèrent auprès du fief l'argent nécessaire à la réfection du chemin de pèlcrinage. C'est ainsi que s'acheva cette entreprise de plusieurs années ${ }^{45}$.

En effet, après la mort de Tōsuke en 1859 (Ansei 6) mentionnée dans le document 2, dix hommes dont Kiryū Rihei et Ino.ue Ihachi 井上伊八 poursuivirent son travail. En 186I (Bunkyū x), ils obtinrent de l'administration du fief de Fukuoka l'autorisation de créer ce pèlerinage, et le $8^{\mathrm{e}}$ mois de cette même année, ils déposèrent auprès de cette administration l'argent collecté pour réaliser les travaux de réparation de la route du circuit. Aussi l'année i86I est-elle la date de la création officielle de ce pèlerinage de Sasaguri. Le fait qu'il y ait eu besoin d'aménager les routes et les chemins pourrait indiquer que la pratique du pèlerinage commença dès que Fujiki Tōsuke installa les statues. Il n'est en tout cas pas douteux que Tōsuke et les cinq compagnons qui l'avaient suivi dans son pèlerinage à Shikoku firent en grande pompe le circuit durant trois jours pour déposer la terre dans tous les fudasho. Ce dut être un moment de joie pour tous les villageois qui l'avaient aidé dans son entreprise, comme pour les gardiens d'oratoires. Aujourd'hui encore, il n'est pas rare de rencontrer des files de pèlerins au

44. Cette slatue fut perdue lors des réquisitions de métaux d'avant guerre. Selon l'inscription, elle aurait été faite pour commémorer le $2555^{\mathrm{C}}$ anniversaire de la fondation du Japon (I895), mais si l'on en croit le document 2, il est possible que cette stèle ait été dressée en I893 (Meiji 26). En I89 I fut célébré le trente-troisième anniversaire de la mort de Fujiki Tōsuke, et l'on peut penser que c'est à partir de cette époque que le pèlerinage de Sasaguri commença à être très fréquenté.

45. Kaei go nen san gatsu, dōson, Ta-no-ura, Fujiki Tösuke naru mono,

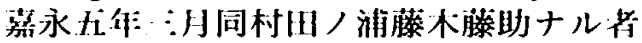
buppō ni kieshi, dai gan jōjū no i wo okoshi, migi yūshisha to 仏法二州依シ大䝠成就，意习興シ们份志者卜

tomoni, Jinin ni no soshi wo keizoku shi, Ansei ni nen ni gatsu ni itari, bacbi-

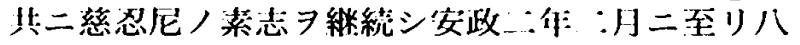
jū hakka-sho no butsuzō wo chōshi, Tōsuke uji (saisan hon Shikoku wo junpai shi owaru). Shikōshite

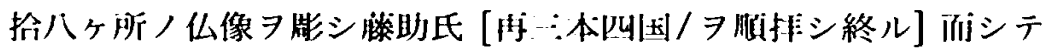
Bunkyü gannen san gatsu, kyū Fukuoka banchö no kyoka wo ete,

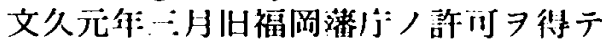

dōnen bacbi gatsu ni itari, Kiryü Ribei hoka, sümei no yüshisha yori,

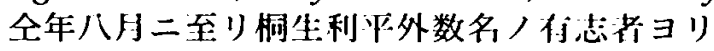

dōro shüzenhi toshite, ikubaku kano kin.in wo jōnō sbi,

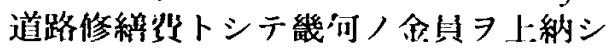

sünen no kokku, anchishi owaru to iu.

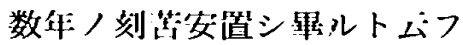




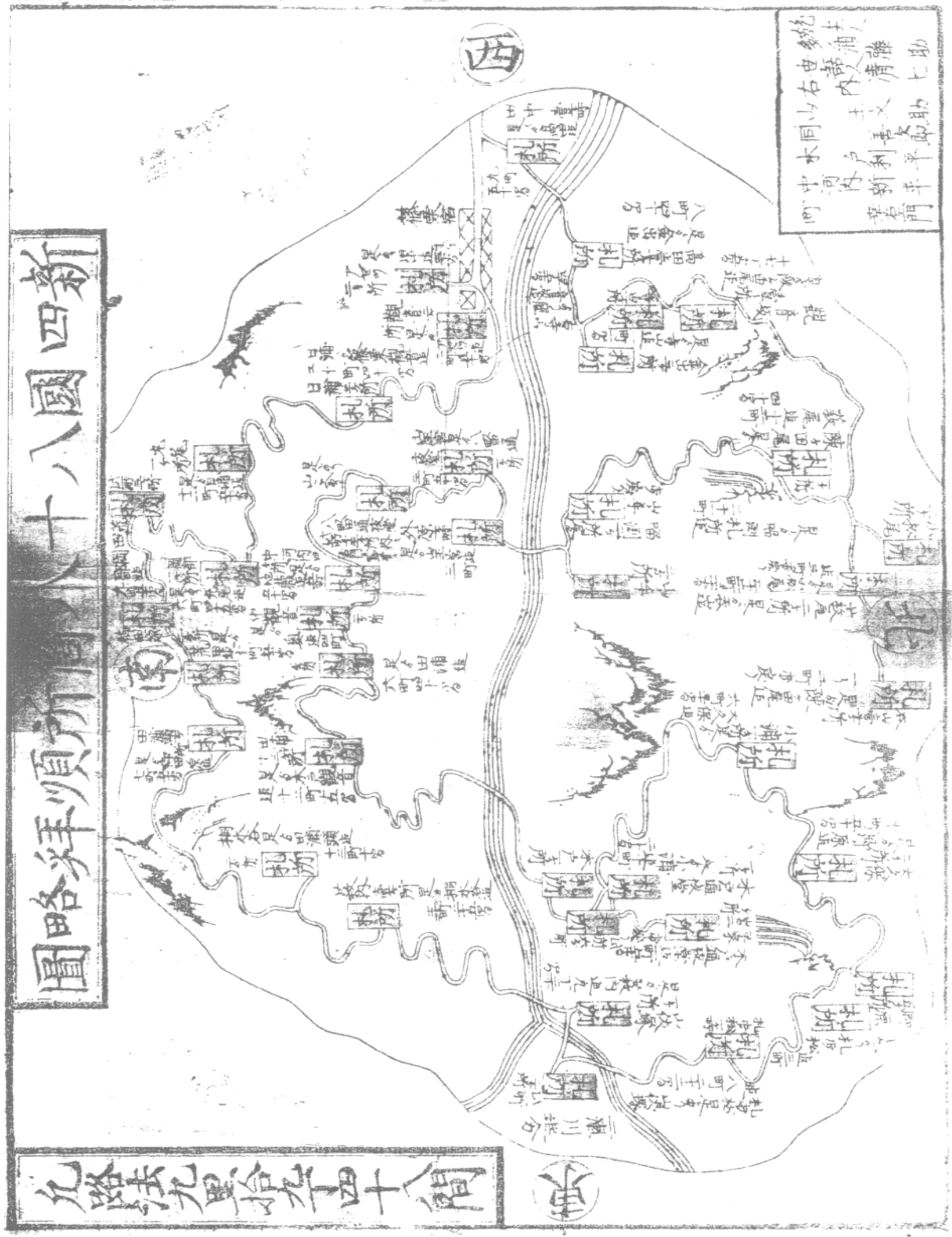

Fig. 8 : Carte simplifiée des quatre-vingt-huit lieux saints du circuit du nouveau Shikoku

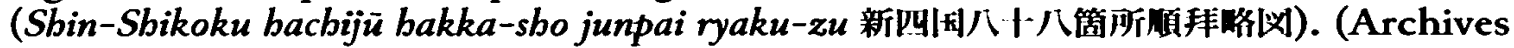
du Centre de documents historiques et de matériaux ethnographiques de Sasaguri) 
printemps, au moment de l'ouverture du pèlerinage, mais à l'époque, aucun de ceux qui avaient partagé joies et peines de l'entreprise avec Tōsuke ne pouvaient manquer cette première et unique célébration de l'ouverture du pèlerinage.

La "Carte simplifiée des quatre-vingt-huit lieux saints du circuit du nouveau Shikoku » (Shin-Shikoku bacbijü hakka-sho junpai ryaku-zu 新四国八十八箇所順拜略図, fig. 8) rend compte de ce qu'était le pèlerinage au moment de sa création. Il s'agit d'un feuillet imprimé, conservé actuellement à la bibliothèque départementale de Fukuoka et dans l'ancien ermitage Ishii-bō de Wakasugi à Sasaguri. L'auteur en est inconnu, mais une note figurant au dos du second exemplaire fournit quelques pistes $^{46}$. Il y est précisé que le $3^{\mathrm{e}}$ mois de 1852 (Kaei 5 ), Kentei 賢貞, neuvième génération des supérieurs de l'Ishii-bō 石井坊, fait cette inscription ; qu'il s'agit d'une xylographie de l'époque de la création du pèlerinage des quatre-vingt-huit lieux saints de Sasaguri par Fujiki Tōsuke de Ta-no-ura et ses six compagnons; et que Kentei y appose son sceau par précaution.

Affilié au shugen de la branche Honzan 本山派 à l'époque d'Edo, l'ermitage Ishii-bō est situé dans la vallée de Droite (Utani 右谷) du mont Wakasugi, où la tradition locale veut que Zenmui Sanzō et le Grand Maître Kōbō aient pratiqué l'ascèse ${ }^{47}$. Il semble que Fujiki Tōsuke ait suivi un enseignement du bouddhisme ésotérique sous la direction du supérieur Kentei ${ }^{48}$. Comme le sceau apposé sur ce document est celui de Kentei, on peut supposer que c'est lui qui a écrit cette note. Mais si l'on en croit l'enquête de Kiryū Genshirō, en 1852 , les quatre-vingt-huit statues n'étaient pas encore toutes sculptées. Aussi est-il difficile de penser que la note date de cette année-là, qui est celle où Fujiki Tōsuke lança le travail de sculpture. Pour célébrer cette entreprise, Kentei n'aurait-il donc pas, plus tard, mentionné cette date comme celle de sa "création" ? En tout cas, Kentei étant mort en 1876 (Meiji 9), cette carte est nécessairement antérieure à cette date.

46. Kaei gonen baru san gatsu, 嘉永五年春三月

Ishii-bō chūkōso yori kyū dai, Kentei shirusu. 石井坊中興祖ヨリ九代賢昼識（印）

Ta-no-ura Tösuke uji, boka roku mei, kyōryoku shite, Sasaguri

田ノ浦滕助氏外六名協力シテ篠栗

bachijū bakka-sho reijō wo sōritsu seshi tōji no mokuban

八十八ヶ所霊場 7 創立七シ垱時ノ木版

nari. Nen no tame, insu.

ナリ為念盯ス

47. Sur l'Ishii-bō et le shugen de Wakasugi, voir dans ce même volume Mori Hiroko 森弘子, “Le mont Wakasugi, son sanctuaire et le shugen dans l'histoire de Kyūshū et de l'Asie de l'Est ", p. 203-267.

48. Nakano Shiyō (Shin-Shikoku bachijū bakka-sho junpai, p. 9-II) écrit qu'il s'agissait du sbingon mikkyō 真言密教; ce terme semble désigner ici l'ésotérisme bouddhique en général. En réalité, la branche Honzan du shugen était affiliée au Shōgo-in 聖護院 (Tendai), mais du point de vue doctrinal, son enseignement pouvait être interprété soit dans le sens du Tendai, soit dans le sens du Shingon. Puisque dans les légendes relatives à Utani du mont Wakasugi, le Grand Maitre Kōbō et le moine indien Zenmui, tous deux patriarches du Shingon, jouent un rôle important, on peut penser que l'Ishii-bō penchait plutôt vers le Shingon. 
En bas à droite de la carte, sont seulement mentionnés les prénoms et le lieu d'habitation de (Fujiki) Tōsuke l'instigateur, vivant à Ta-no-ura, ainsi que ceux de ses assistants : (Hirai) Seishichi de Ta-no-ura, (Arisumi) Bunsuke et Zenjirō de Sannō, (Kiryū) Rihei de Kido, (Murase) Shinpei de Naka-no-kōchi, (Aramaki) Kō.uemon du quartier urbain. L'absence des patronymes laisse supposer que cette carte fut dessinée dans les années 1860 , peu de temps après que l'autorisation eut été accordée par le fief de Fukuoka ${ }^{49}$.

Cette carte montre qu'à l'époque d'Edo, les fudasbo étaient répartis entre cinq villages : Sasaguri, Hagio, Kana.ide, Takata et Tanaka. Dans chacun d'eux était déposé un certain nombre de statues, entre une et treize. À l'oratoire des veillées de Haseda (Haseda Tsuya-dō 八畧田通夜堂, près de l'actuel Sannō-ji 山王寺, le numéro 6r) était installée une statue d'Emon Saburō 右門三郎, de type « surnuméraire ${ }^{50}$ ». Comme la route du circuit et l'ordre des fudasbo y sont indiqués, on peut penser que le pèlerinage était réellement pratiqué. Il est pour le moins certain que cette carte a été composée en vue du pèlerinage de Shikoku à Sasaguri. Le sud se trouve représenté en haut de la carte, ce qui correspond à l'orientation qui était donnée à l'époque aux cartes du pèlerinage du «vrai Shikoku ». Au XIX siècle, des cartes du vrai pèlerinage de Shikoku apparurent en nombre considérable dans toutes les régions, et tout fidèle du Grand Maître dut en voir à un moment ou à un autre. Sur celle de Sasaguri, on peut voir que le dessinateur s'est donné du mal pour réduire au maximum les détours inutiles, et a tracé d'un seul trait un circuit tournant sur la droite, dans le sens des aiguilles d'une montre. Le titre précise clairement qu'il s'agit d'un " nouveau pèlerinage de Shikoku ", réplique du "vrai », ce qui a dû inciter à se rendre à Sasaguri, " en remplacement ", tous ceux qui souhaitaient ardemment faire le pèlerinage originel, mais ne pouvaient aller jusqu'à Shikoku pour des raisons de travail ou de santé.

\section{Développement du pèlerinage de Shikoku à Sasaguri}

La séparation autoritaire du bouddhisme et du culte des dieux imposée par le gouvernement de Meiji en 1868 a eu un impact majeur sur les pèlerinages de toutes les régions. Il y eut notamment des suppressions de lieux de pèlerinage, dans le cas où un sanctuaire était un fudasbo ou lorsque celui-ci était géré par un temple qui administrait un sanctuaire. Mais à Sasaguri, aucune de ces deux situations n'existait : aussi les effets de cette législation ne furent-ils quasiment pas ressentis au niveau du pèlerinage. En 1872 (Meiji 5), les habitants du village de Shimobaru 下原村 (canton de Kasuya) firent l'offrande d'une superbe sculpture rupestre de Fudō myōō à la roche Heike. Dans la monographie géographique du département

49. Les gens du peuple ne furent autorisés à porter des noms de famille qu'à partir de 1875 (le i3 février de Meiji 8).

50. La tradition veut qu'Emon Saburō 右門三郎 ou 右衛門三郎, dit aussi Yomon Saburō 衛門三郎), ait été le premier pèlerin à parcourir le circuit du pèlerinage originel de Shikoku qui aurait été fondé par le Grand Maître Kōbō. Cette légende est antérieure au panneau de bois du temple Ishite-ji 石乎寺 ( ${ }^{\circ}{ }^{\circ}$ I de Shikoku) daté de 1567 (Eiroku 永禄 10), sur lequel elle est gravée. 
de Fukuoka (Fukuoka-ken cbiri zensbi 福岡紫地理全誌, Nishi Nihon bunka Kyōkai 西日本文化協会, éd.) de 1876 , dix-sept oratoires, que ce soit de Kannon, du Grand Maître Kōbō et d'autres, furent répertoriés dans le chapitre consacré à Sasaguri. Et le 21 mars 1878 fut célébrée dans tous les fudasho le $25^{\circ}$ anniversaire de la création du pèlerinage ( Demande d'inscription dans le Registre des temples et sanctuaires de Sasaguri "). En I884, d'innombrables cérémonies célébrèrent dans tout le pays le I $050^{\circ}$ anniversaire de la mort du Grand Maître Kōbō : il est fort probable que des fidèles vinrent alors en grand nombre de l'extérieur, sur le circuit de Sasaguri ${ }^{51}$.

La carte imprimée en 1889 est un élément qui vient appuyer cette hypothèse (fig. 6). Ce qui la différencie principalement de l'autre carte (fig. 8) qui lui est antérieure, c'est son orientation : elle est en effet orientée comme pour des pèlerins qui viendraient de Fukuoka (l'ouest en bas, l'est en haut de l'image). En outre, partout sont représentés cascades, rivière, arbres, montagnes, qui plantent le décor d'un espace naturel remarquable.

Avec le fort développement industriel sous l'effet de la politique de renforcement économique et militaire engagée par le gouvernement de Meiji, la demande en charbon pour la sidérurgie et les chemins de fer connut une hausse exponentielle, et dans le nord de Kyūshū, notamment à Sasaguri, les années i88o furent une période de grande prospérité des mines de charbon. Aussi peut-on supposer que les exploitants et les ingénieurs des mines recherchant des lieux de loisirs dans des sites naturels réputés, ainsi que les mineurs abusivement exploités et leurs familles trouvant un secours dans le culte du Grand Maître Kōbō, pratiquaient les uns et les autres le pèlerinage de Sasaguri. On sait en tout cas que, parmi les pèlerins, se trouvaient beaucoup de geishas et de danseuses souffrant de maladies et des suites d'avortements. La carte faite par Aramaki Kō.uemon (fig. 6) a été imprimée en plusieurs versions différentes, ce qui témoigne de l'importance de sa diffusion.

S'ajoutent à cela des facteurs anecdotiques comme, par exemple, le fait que Nishi Gikan 西義観, que l'on donne pour le fondateur du Henshö-in 遍照院 ( $n^{\circ}$ 62) de Sasaguri en 1889 , était devenu célèbre pour ses images-devinettes. Celui-ci organisait dans tout le pays des séances de lanterne magique, alors à la mode, qui mettaient en scène la vie du Grand Maître Kōbō, et à cette occasion, il faisait la promotion du pèlerinage de Sasaguri. L'accueil des pèlerins qui offraient piécettes et riz dans

51. À cette époque, dans tout le pays, des fidèles imprimèrent en masse de petits livrets présentant les origines du pèlerinage originel de Shikoku et portant des titres tels que «Le Grand Maître Kōbō, fondateur des quatre-vingt-huit lieux de Shikoku » (Kōbō daisbi Sbikoku bachijū

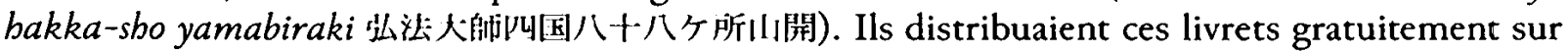
le circuit de Shikoku et sur les nouveaux Shikoku, ainsi que dans les temples shingon. Partout les nouveaux circuits de Shikoku semblent avoir été stimulés : ainsi, dans le Kantō, Nishi Arai 西新井 organisa une nouvelle pratique de pèlerinage des quatre-vingt-huit lieux appelée «le Grand Maître que l'on accompagne » (okuri daishi 䢠大師), consistant à faire circuler en grande pompe la statue du Grand Maître de village en village. Profitant de cet élan, le Shingon créa l'organisation appelée Mitsugon kyōkai 密㛜教会. Et apparurent successivement, en I889, les

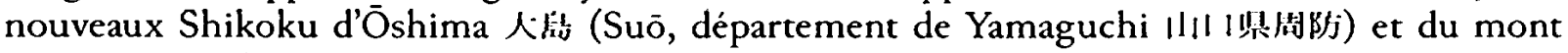
Hōrai 蓬篓山 (Nobeoka, département de Miayazaki 们㥓県延洞), puis en I89I, celui de l'île d'Iki 壱岐島 (département de Nagasaki). 
chaque fudasho dut également être organisé par les gardiens des lieux, qui prévoyaient boissons et friandises à cet effet.

On peut penser que c'est la conjonction de tous ces facteurs - les cartes d'Aramaki Kō.uemon, l'activité de promotion menée par Nishi Gikan, la prospérité de l'ensemble de cette région et la contribution des gardiens de fudasbo - qui entraîna l'afflux des pèlerins vers Sasaguri.

Les liens directs avec le pèlerinage de Sasaguri ne sont pas clairs ; toutefois le trafic routier entre Fukuoka et le bassin houiller du nord-est du département s'intensifia nettement à cette époque, et en 1887 furent entrepris de grands travaux pour transformer en départementale la route qui reliait ces lieux. Lorsqu'en I89I, l'ouverture de la nouvelle route fut achevée, le chef du village de Sasaguri, Tō Kinsaku 藤金作 (1844-1932), notable qui par la suite fut longtemps membre du conseil départemental de Fukuoka, fit planter à ses frais mille cerisiers et trois cent cinquante érables le long de l'ancienne voie, pour en faire un "nouveau Yoshino ${ }^{52}$ ». Ce lieu, qui est renommé pour « rappeler les mille cerisiers de Yoshino », devint un endroit où affluèrent les citadins de Fukuoka et du nord-est du département pour y admirer les fleurs au printemps.

Les années 1892-1896 (Meiji 25-29) furent celles de la restructuration des fudasho de Sasaguri. Ceci fit suite à l'Avertissement 44I par lequel le gouvernement de Meiji autorisait, pour cette seule fois, tous les temples et oratoires qui n'avaient pas encore déposé leur demande d'inscription dans le Registre des temples et sanctuaires (Jiin meisaichō 寺院明細帳 et Jinja meisaichō 神社明細帳), à s'y faire inscrire ${ }^{53}$. Ceci provoqua dans tout le pays un mouvement généralisé d'enregistrement des temples et des sanctuaires. En toile de fond, était présent le sentiment du danger de destruction qui menaçait ces structures religieuses. Et c'est pour cette raison que dans les années 1902-1907, Kiryū Genshirō rédigea la plus grande partie des 250 pages de la «Demande pour l'inscription dans le registre des temples et sanctuaires ». Partout furent donc constituées et déposées des demandes d'enregistrement, mais avec l'éclatement de la guerre sino-japonaise en $\mathbf{1 8 9 4}$, le suivi des dossiers par l'administration fut lacunaire, et beaucoup se virent refuser l'autorisation, ce qui ne fit qu'accroître le sentiment de danger. Comme circulait alors la rumeur selon laquelle les petits oratoires risquaient d'être supprimés, dans tout le pays se multiplièrent les transactions de vente et d'achat de temples qui n'avaient d'autre existence que celle d'un nom sur un papier. À Sasaguri, il était hors de question d'acheter le titre de temples de haut renom pour chaque fudasho. Aussi tenta-t-on d'obtenir l'autorisation de confier le titre de «supérieur gardien » de tous les fudasho à Chikushi Kenshū 筑柴賢秀, supérieur de l'Ekō-in 恵光院 qui avait la garde des statues et bâtiments bouddhiques

52. Sasaguri-chō bunkazai senmon iin kai 篗栗町文化財専門委貝会, éd., Sasaguri chōshi. Minzoku ben 策栗町諸:民俗編, 1990, p. 179.

53. Selon certains, cette restructuration aurait eu pour cause l'« interdiction des lieux saints de Sasaguri émise en 1886 (Meiji 19) par une ordonnance préfectorale " (Sasaguri-chō bunkazai senmon iin kai, éd., Sasaguri chōshi. Rekishi ben 筿栗町誌·楚史編, 1982, p. 244). Mais il semble qu'il y ait ici confusion avec l'arrêté de 1886 (le 8 juin de Meiji 19) du ministère de l'Intérieur interdisant en principe la construction et la reconstruction des temples et oratoires. 
du sanctuaire Hakozaki 管崎宮 de l'arrondissement Est de Fukuoka. Une première demande fut déposée le 25 septembre 1894 au bureau du canton de Kasuya, mais comme elle fut refusée, une seconde fut à nouveau déposée le i8 juillet 1897 . Celle-ci s'étant soldée par un nouvel échec, cette première stratégie fut abandonnée au profit de l'achat, en mars 1899, du nom et du rang du temple Nanzō-in 南藏院 au mont Kōya (département de Wakayama) ${ }^{54}$ et de la transformation de chaque fudasho en enclave éloignée de l'enceinte de ce dernier. Cette fois, l'autorisation fut accordée. Telle est du moins la version officielle de l'histoire.

De fait, l'année précédente, en 1898 , pour pouvoir reconstruire un temple détruit, le proche village de Wakasugi avait acheté le nom et le titre de Nanzō-in 南藏院 ${ }^{55}$. Aussi n'est-il pas impossible que ce soit ce «Nanzō-in » qui soit passé au village de Sasaguri. Par la suite, ce Nanzō-in du village de Wakasugi s'auto-proclama «temple du fond de la montagne de l'ouest 》: 西野山 [lecture inconnue] Oku-no-in 奥院. Cette « montagne de l'ouest » signifie sans doute «mont Kōya de l'ouest » (nishi no Kōyasan 西の高野山), c'est-à-dire de Kyūshū, indiquant par là l'existence de liens forts avec le Grand Maître Kōbō et le Shingon.

Quoi qu'il en soit, cette décision de transfert du nom et du titre d'un temple fut prise au cours de la réunion des gardiens d'oratoires qui s'étaient organisés en une association appelée Association du Vajra (Kongō-kai 金剛会). Les deux responsables en étaient Kiryū Genshirō et Tō Kihachirō 藤喜八郎, et le rôle de conseillers était assuré par Tō Kiichirō 藤喜一郎 et Uchikawa Aidō 内川愛道. Tous étaient aussi les principaux acteurs de l'édification de la statue de bronze du fondateur du pèlerinage, Fujiki Tōsuke (document 3).

Kiryū Genshirō, avec l'aide de Gunjima Kitarō 郡嶋畿太郎, parvint à faire supprimer le statut fusionné de tous les fudasho et à réaliser, en mai i9oı, le plan d'occupation des sols pour la nouvelle installation de quatre-vingt-huit sites distincts du pèlerinage disposant, chacun, d'une statue principale ${ }^{56}$. Il constitua et déposa en octobre de la même année la demande d'inscription de tous les fudasho comme enclaves éloignées de l'enceinte du Nanzō-in, les intégrant ainsi à l'enceinte de ce temple, et faisait de celui-ci le propriétaire d'un peu plus de trois mètres carrés (I tsubo 坪) dans chaque fudasho ${ }^{57}$. C'est entre 1902 et 1907 que les quatre-vingt-huit fudasho furent autorisés à prendre le statut d'« enclaves éloignées de l'enceinte du Nanzō-in " (Nanzō-in tobichi keidai 南蔵院飛地境内). Les formalités de donation du terrain de chaque fudasho au Nanzō-in se firent ensuite progressivement et c'est ainsi qu'on en vint en 1915 à dénommer le Nanzō-in « temple principal du Shikoku de Sasaguri » (Sasaguri Shikoku honji 箫栗四国本寺). Le nom et le titre de Nanzō-in ayant été officiellement transférés depuis le mont Kōya (l'un des principaux monastères fondés par le Grand Maître Kōbō), en tête des « Hymnes-guides pour le Shikoku

54. Sur le Nanzō-in, voir la contribution de Suzuki Masataka dans ce même volume, "Modernisation des temples bouddhiques et société locale : le Nanzō-in de Sasaguri ", p. 354-356.

55. Gōya Takeshiro 合屋武城, Chikuzen Wakasugi kyödoshi 筑前若杉郷士誌, 1957, p. I31.

56. Shin-Shikoku bacbiju bakka-sho shinsetsu cbi no tori 新四国八拾八ヶ 所新設地埜取, document conservé au Ni-no-taki ji 二) 滝寺 (fudasho $\mathrm{n}^{\circ}$ 14).

57. Nanzō-in tobichi keidai bennyū negai 南蔵院飛地境内編入願. 
de Sasaguri 》(Sasaguri Shikoku michibiki wasan 筆栗四国導和讃) composés en 1904 par Kusaba Chiyokichi 草場千代吉, ce pèlerinage fut appelé «Kōya de l'ouest ${ }^{58}$ ».

En 190I, les usines sidérurgiques nationales Yahata 八幡製鉄所 de Kita-Kyūshū commencèrent à fonctionner et les pèlerins venant de cette direction par Iizuka se firent plus nombreux. En juin 1904, grâce à l'entremise de Tō Kinsaku, notable local et membre de la Chambre des représentants, fut ouverte la gare de Sasaguri : ceci provoqua un afflux de pèlerins dont le nombre annuel était alors évalué à une centaine de milliers de personnes ${ }^{59}$. Une enquête gouvernementale de 1907 dénombre en effet 67500 clients par an pour les quarante auberges de Sasaguri ${ }^{60}$. Étant donné qu'à cette époque, beaucoup de pèlerins passaient la nuit dans les oratoires, temples et lieux de culte, ou bien étaient hébergés par les paysans, ce chiffre semble tout à fait correct.

On ne sait pas exactement comment s'organisait le circuit des pèlerins, mais si l'on se réfère aux «Hymnes-guides » cités précédemment, on constate qu'ils commençaient par le quartier de Tanaka et suivaient la même route que celle de la carte de 1889 (fig. 6). Ceci semble indiquer que ceux qui venaient de Fukuoka étaient les plus nombreux. Leurs pratiques rituelles étaient les suivantes. Ayant à la main le “ chapelet protecteur » (gonen no juzu 護念の数珠) et le bâton du vajra (kongō zue 金剛杖), ils faisaient, à chaque fudasbo, l'offrande d'encens et de fleurs et, tout en frappant le gong, récitaient les formules de repentance, les shingon (mantra) des Treize Bouddhas, le nom saint du Grand Maître, la prière pour le salut de tous les êtres, ainsi que des paroles de l'hymne au Grand Maître : "Merveille ! à l'ombre du mont Kōya de l'ouest, le Grand Maître est là ${ }^{61}$ ». Ils se purifiaient également dans les cascades en divers endroits. Ces hymnes sont centrés sur le culte du Grand Maître Kōbō ; avec « larmes de bonheur » ou « repentance », ce parcours de « pratique sincère » consistait à " marcher en prière » pour demander les «bienfaits en ce monde et dans l'autre » ainsi que l'« élimination des fautes et des malheurs », en gardant à l'esprit l'hommage au Grand Maître ; aussi les bouddhas et bodhisattvas

58. Nanseki Takeshi 南石武, Sasaguri sbōshi benran 篠栗小史便覧, 1966, p. I19-I2I.

59. Kasuyagun yakusho 糟屋郡役所, éd., Kasuyagun shi 糟屋郡志, 1924, p. 6.

6o. Sasaguri-chō bunkazai senmon iin kai, éd., Sasaguri chōshi. Rekishi hen, p. 247-248; Sasaguri chōshi. Minzoku ben, p. 30.

61. Les formules de repentance sont les quatre vers suivants : «Tous les actes mauvais que j'ai commis, qui ont pour cause l'avidité, l'irascibilité et la bêtise sans bornes, et sont tous produits par mon corps, ma parole et mon esprit, j'en fais ici acte de repentance totale » (Gashaku shozó shoakugō, kaiyu mushi ton jin chi, jüshin go.i shi shoshō, issai ga kon kai sange 我昔所造諸惡業、皆由無始領䀧痴、 從身語意之所生、一切我今皆惟侮). Les shingon des Treize Bouddhas sont des mantra évoquant chacun des Treize Bouddhas et Bodhisattvas vénérés lors des rites qui célèbrent chaque anniversaire du décès d'un défunt (sur les Treize Bouddhas, voir aussi la contribution de Suzuki Masataka dans le présent volume, «Modernisation des temples bouddhiques et société locale : le Nanzō-in de Sasaguri », p. 376, n. 53). Le nom saint du Grand Maître est la formule "Hommage au Grand Maître, diamant qui illumine l'univers " (Namu daishi benjō kongō 南無大師遍照金剛), répétée trois fois. La prière pour le salut de tous les êtres sont les quatre vers exprimant la volonté « d'étendre à tous les êtres les mérites personnels résultant de l'acte présent de dévotion, afin que nous puissions tous ensemble accéder à la voie de l'Éveil »(Gan ni shi kudoku, fukyū o issai, gatō yo sbujō, kaigu jōbutsudō 願以此功徳、普及 於一切、我等与采生、皆共成仏道). Les paroles de l'hymne au Grand Maître sont celles du premier verset des hymnes de Köbō daishi Goeika 弘法大師御詠歌, les « Hymnes au Grand Maître Kōbō ». 
tendaient-ils une main secourable au pèlerin. Mais pour attirer les gens vers le Shikoku de Sasaguri, plutôt que de présenter les éléments relatifs au Grand Maître Kōbō, ce texte regorge d'expressions mentionnant les beautés naturelles des lieux à venir contempler ; ainsi : «terre d'une pureté sans égale », " eau du vajra », " lumière de la montagne », « courant pur », « pagode à cinq étages », « eau pure de roche », " cinq cascades », " le paysage, c'est celui de la première cascade », "brume d'eau de la cascade de Fudō ", " les mille cerisiers à fleurs octuples ou simples au fond de la brume », « eau pure de la cascade de Yakushi ", " vert profond », « nuages lumineux qui brillent dans le lointain », etc., et il est dit que ces splendeurs naturelles « éliminent la crasse (c'est-à-dire la souillure) du cœur».

\section{Apparition des temples “ bors numérotation 》 (bangai jiin 番外寺院 ou bangai 番外)}

Comme l'indique la carte de la figure 8 , qui mentionne l'existence d'une statue d'Emon Saburō, il semble que, dès l'origine, aient été pris en compte comme faisant partie du circuit des fudasho non inclus dans comput des quatre-vingt-huit. Le premier texte où le terme "bangai " se trouve explicitement noté est le "Registre des quatre-vingt-huit lieux du nouveau Shikoku ${ }^{62}$ " compilé par Genshirō en 1897, dont la sixième page contient cette inscription :

«Au n 3255 de Kana.ide, village de Sasaguri ; "hors numérotation" [bangai]; statue principale : bodhisattva Jizō ; construit le $2^{\mathrm{e}}$ mois de 1855 (Ansei 2 ) ; donateur : Uchikawa Aidō ; distance du bureau de l'administration du fief : 3 ri 里 25 chō 町; propriété communautaire de Kana.ide (représentants : Furuya Kanjirō 古屋勘次郎 et deux autres personnes) ; représentants des vingt fidèles : Furuya Kanjirō, Matsuo Tōzō 松尾藤三, Kiryū Genshirō ; oratoire de 2 mètres de côté (environ); terrain de $20 \mathrm{~m}^{2}$ (environ) ${ }^{63}$. »

62. Shin-Shikoku hachijū hakka-sho daichō 新四国八拾八ヶ所台帳.

63. Sasaguri mura öaza Kana.ide sanzen nihyaku gojūgo banchi 篠栗村大字金仙三千武百五拾五番地

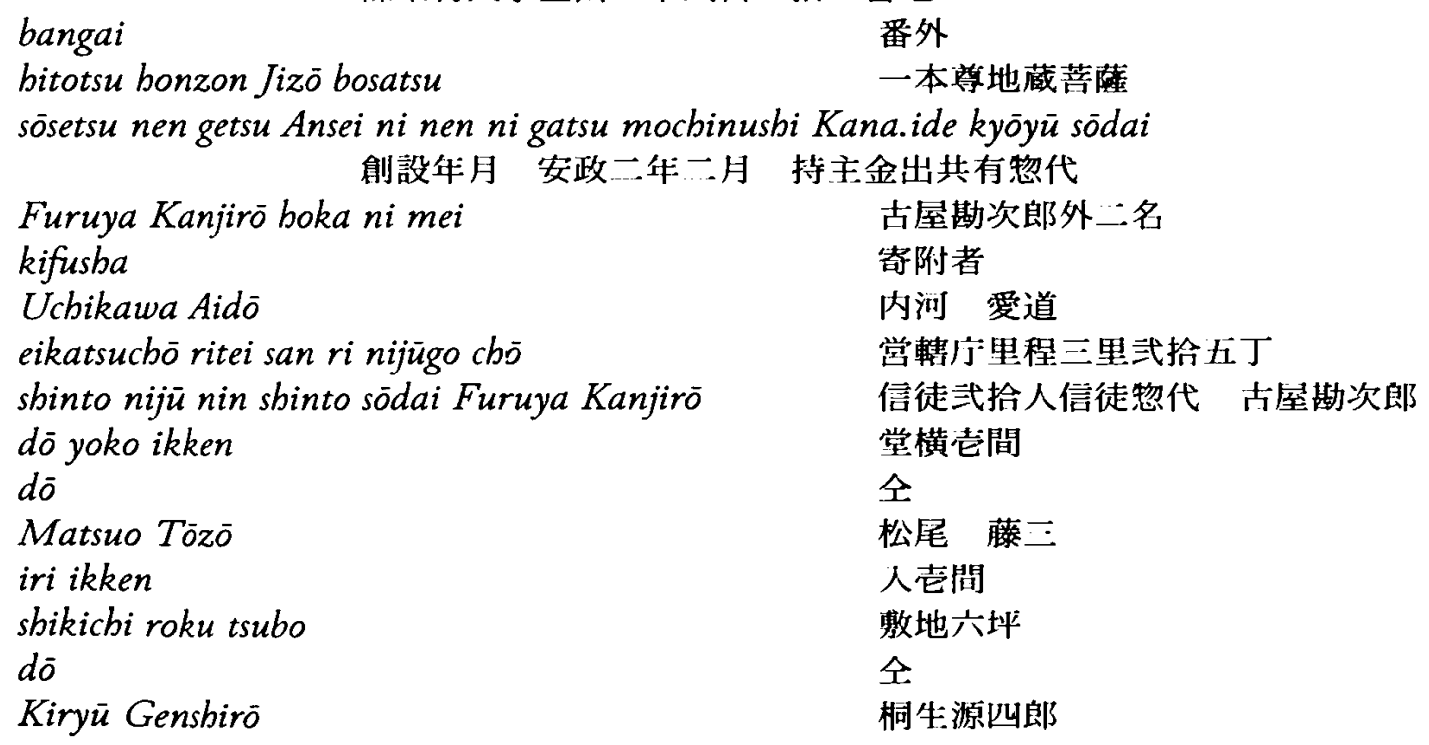


Le donateur, Uchikawa Aidō, fut aussi à l'origine du mouvement pour édifier la statue en l'honneur de Fujiki Tōsuke (document 3). Kiryū Genshirō tenait le rôle de représentant des fidèles, de même que Matsuo Tōzō, qui fut probablement l'un des compagnons de Fujiki Tōsuke lors de son pèlerinage du vrai Shikoku pour rapporter de la terre sainte, et qui portait alors le nom de Furuya Tōzō 古屋藤三 (document 2). Étant le seul fudasho « hors numérotation » mentionné dans ce registre, il est donc le premier du circuit à avoir une existence officielle.

L'endroit où il se trouvait ( $\mathrm{n}^{\circ} 3255$ de Kana.ide sur le cadastre) était sans doute situé côté nord, dans le lieu-dit "Chas de l'aiguille 》(Hari no mimi 針の耳) du Kōshō-in 弘照院 $\left(\mathrm{n}^{\circ}{ }^{87}\right)$, près du bord de la rivière. Le fudasho 87 fut installé au Chas de l'aiguille avant I894. Mais comme il fut par la suite transféré à l'actuel bangai de la cascade du Lavement de mains (Chōzu no taki), le Chas de l'aiguille devint un bangai. Dans le « Guide du circuit des quatre-vingt-huit lieux saints du Shikoku de Sasaguri ${ }^{64}$ » paru avant 1927 (Shōwa 2), ce fudasho, qui était alors hors numérotation, est signalé par une svastika entourée d'un rond et il est placé sur le chemin du pèlerinage qui passe devant les lieux-dits cascade de Jin-ga-tao (陣田尾滝), Pierre dressée (Tate.iwa 建岩), cascade du Vajra (Kongō taki 金剛滝) ; aussi devait-il être visité en cours de route. Sur cette même carte est également indiquée la route vers le mont Wakasugi, l'Oku-no-in et la cascade Yōrō, que l'on peut supposer avoir été eux aussi considérés dès cette époque comme des lieux " hors numérotation » par lesquels passait le circuit.

Mais ce qui fut appelé plus tard l'Oku-no-in («temple du Fond») était à l'époque d'Edo le sanctuaire Haut du Taiso gongen 太祖権現社, l'un des pôles religieux majeurs de la région. Dans le volume annexe de la «Suite des chroniques du pays de Chikuzen ${ }^{65}$ » datant de 1793 (Kansei 寛政 5), au chapitre concernant le sanctuaire Haut (Taiso gongen Jōgū 大祖権現上宮), un paragraphe particulier est consacré au Chas de l'aiguille et à l'eau du Vajra à une pointe (Tokko-sui 独鈷水). Le premier est aujourd'hui appelé « Roche qui enserre » (Hasami iwa 挟み岩) et le second porte toujours le même nom. Dans cette "Suite des chroniques du pays de Chikuzen ", Kaibara Ekiken écrit ainsi, en 1703 (Genroku I6), au chapitre sur le mont Wakasugi où est vénérée la divinité Taiso gongen (volume 18 , canton de Kasuya Omote, vallée de Gauche, vallée de Droite) ${ }^{66}$ :

Lorsque Kōbō rentra de Chine, il gravit cette montagne, et c'est à cet endroit qu'il accomplit un rituel secret. Aujourd'hui encore cet endroit existe sous le nom d'eau du Vajra à une pointe.

On parlait donc de ce lien avec le Grand Maître Kōbō depuis les temps anciens. Mais à l'époque d'Edo, le sanctuaire était appelé sanctuaire Haut (Jōgū 上宮) et non pas Oku-no-in. On peut penser que l'apparition d'un lieu portant ce nom sur

64. Sasaguri Shin Shikoku hachijū bakka-sho reijō fudasho annai 篠栗四国八拾八ヶ所霊場札所案内.

65. Cbikuzen no kuni zoku fudoki furoku 筑前国続風上記附録, Kawazoe Shōji 川添昭二, éd., vol. 2, 1977-1978, p. 353-355.

66. Kaibara Ekiken 具原益軒, Cbikuzen no kuni zoku fudoki 筑前国続風上記, 1988 (compilé 1688-1710), p. 404. 
le mont Wakasugi remonte à Meiji. Dans la section du département de Fukuoka du « Livre illustré des sites célèbres du Japon ${ }^{67}$ » (datant de I898, Meiji 3I), l'image du sanctuaire Taiso porte la mention « Oku-no-in » et dans les explications correspondantes, il est précisé que c'est le nom que lui donnent les gens du lieu.

Ce type de cartes destinées à guider les pèlerins sur le circuit de Sasaguri furent éditées en grand nombre, mais elles étaient pratiquement identiques, mis à part le fait que certains noms de lieux étaient indiqués sur les unes et non sur les autres, comme par exemple l'«abbaye d'Arata 》 (Arata no sbū dō-in 荒田の修道院) ou l'《 ermitage de la vallée du Catalpa 》 (Kiri-no-ki tani no Koyasu-an 桐の木谷の子安庵), etc. Mais le fait qu'un certain nombre de temples et lieux de pèlerinage " hors numérotation 》 s'y trouvent également mentionnés semble montrer qu'ils étaient bien visités par les pèlerins. Avec la multiplication de ces bangai, les recettes des fudasho augmentèrent elles aussi, et l'on sait que dans les années 1930, les transactions sur les droits des fudasho se faisaient à des prix très élevés ${ }^{68}$. On peut d'ailleurs lire dans le règlement de 1898 de l'Association du Vajra mentionnée précédemment, au huitième article : «Ceux qui résident dans les lieux saints doivent avoir pour but la dévotion et en aucun cas la cupidité ». Ceci semble prouver que les fudasho et les abords du circuit étaient envahis par des gens qui cherchaient à attirer les pèlerins au moyen d'un battage tapageur, leur faisant miroiter des faits merveilleux ou des bienfaits afin de leur soutirer de grosses sommes d'argent, et leur imposant plus ou moins des rites de voyance ou de demande de protection. De fait, la prolifération des histoires d'âmes de morts a constamment entretenu une atmosphère très particulière au Shikoku de Sasaguri.

L'activité de ces fudasho hors numérotation s'est ainsi développée avec l'augmentation du nombre des pèlerins, ce qui provoqua toutes sortes de changements dans les liens de ce pèlerinage avec l'extérieur. On peut classer dans l'ordre chronologique les principaux événements connus qui ont jalonné ces transformations (tableau 2 ) $^{69}$. En ce qui concerne les tendances repérées chez les pèlerins, après deux grands pics d'affluence lors des deux célébrations du I $100^{e}$ puis du I $150^{\circ}$ anniversaire de la mort du Grand Maître Kōbo en 1934 (Shōwa 9) et en 1984 (Shōwa 59), à partir de l'ère Heisei (depuis 1989), leur nombre diminue et l'on constate une régression de la pratique du pèlerinage.

67. Shimizu Yoshiyasu 清水吉康, Dai Nippon meisho zuroku. Fukuoka-ken no bu 大日本名所 図録・福岡県之部, 1898, p. 42 et p. 72-73.

68. Kanao Sōhei 合尾宗平, Kaitei zōbo. Fūdo to seikatsu. Fukuoka-ken chishi 改訂增補: 風土 と生活・福岡縣地誌, 1935, p. 302-303.

69. Voir en fin d'article. 


\section{La dynamique du pèlerinage}

\section{Dynamique de création de l'objet de pèlerinage}

Dans la mesure où le pèlerinage est un acte de dévotion envers un objet éloigné, il est clair que la construction de ce dernier se trouve au centre de la dynamique qui entraîne la démarche pérégrine. C'est cet objet qui fait d'un individu un pèlerin.

Selon les objets de pèlerinage et les lieux saints, il existe quantité de types de forces d'attraction qui font prendre la route au pèlerin. Le plus souvent, l'attraction a pour origine la propagation d'histoires miraculeuses racontant l'apparition d'un bouddha vivant, la pluie de vignettes divines ou l'obtention de grâces immédiates. Dans le cas du « vrai Shikoku » et de ses réplications, les principales forces d'attraction sont l'implantation de statues miraculeuses, et la dévotion au Grand Maître Kōbō et à certaines entités (le bodhisattva Kannon et autres entités bouddhiques). Même s'il s'agit de "répliques ", la croyance veut que les miracles soient autant susceptibles de s'y produire que sur les lieux du vrai Shikoku.

À Sasaguri, ce qui fut principalement valorisé lors de la mise en place du pèlerinage, c'est le fait que des statues reproduisant celles du vrai Shikoku furent installées dans chaque fudasho. En effet, celles-ci ne sont pas seulement les objets vers lesquels se dirige le pèlerin, mais elles constituent aussi une présence qui garantit la paix et la sécurité pour les familles et la communauté locale. La fabrication de statues en pierre fut ainsi exécutée avec une attention toute particulière. Si la date de 1802 (Kyōwa 2) est bien celle de la fondation de ce pèlerinage, cela signifie qu'il a fallu plus de cinquante ans pour que les quatre-vingt-huit statues soient achevées, et cet objectif est resté constant alors même que les organisateurs ont changé. À voir leur force de continuité peu commune, on peut dire que le pèlerinage de Sasaguri a pour noyau central la volonté initiale d'affirmer que celui-ci est un «nouveau Shikoku » reproduisant le « vrai » à l'identique.

Si l'on considère la dynamique de création des statues de pierre de chaque fudasho, il est certain que les facteurs déclencheurs majeurs en ont été l'essor, à l'échelle nationale, du culte du Grand Maître Kōbō lors des célébrations de l'anniversaire de sa disparition et, dans cette mouvance, le vou de Jinin de créer un nouveau Shikoku. Mais il ne faut pas perdre de vue l'importance du facteur d'attraction que fut l'accueil, par les gens au centre du quartier de Kido, de l'élan qu'insuffla par la nonne venue de l'extérieur. Kiryū Rihei et les autres responsables eurent un rôle moteur, et c'est grâce à l'effet que leur action du dedans eut sur le dehors, que purent être obtenues ces aides et soutiens de l'extérieur, à l'instar des capitaux extérieurs versés au $n^{\circ} 35$ depuis Hoshimaru à Asakura (朝倉市星丸), de ceux que le temple Rendai-ji d'Iizuka (魬塚市蓮寖寺) apporta au no 37 , de l'aide extérieure reçue pour l'achèvement du pèlerinage par Fujiki Tōsuke et ses compagnons de Ta-no-ura, ou encore des connaissances apportées de l'extérieur par le supérieur de l'Ishii-bō de Wakasugi. Aussi l'essor du culte du Grand Maître Kōbō, et l'impulsion donnée par Jinin, cette femme du dehors qui en propagea l'effet sur place, furent-ils loin d'être les seuls facteurs déterminants de cette création.

Les circonstances particulières attachées au quartier de Kido à cette époque ne sont pas connues ; mais n'est-ce pas parce que s'y manifesta alors la volonté de 
surmonter des difficultés internes ou de provoquer une profonde transformation locale qu'on eut recours à des dynamismes externes, notamment aux puissantes forces du dehors qu'étaient celles du pèlerinage de Shikoku, du Grand Maître Kōbō ou encore de riches fidèles ? La société japonaise est dite fermée sur elle-même, mais lorsque surviennent des problèmes internes, les pressions extérieures y sont instrumentalisées pour accomplir des révolutions. C'est sans doute pour des raisons de cet ordre que les Kiryū et leurs compagnons apportèrent à Jinin, cette femme venant d'ailleurs, leur soutien politique et économique, en lui facilitant la tâche, et en mettant à sa disposition lieux et moyens financiers.

Pour acquérir les capitaux nécessaires à l'accomplissement de son entreprise, Fujiki Tōsuke, et avec lui les jeunes gens qui transportèrent la terre depuis Shikoku, n'ont pas ménagé leurs efforts pour surmonter leurs difficultés. Et il est vraisemblable que lorsque les gardiens d'oratoires habitant dans un autre quartier que celui de Kido acceptaient la garde de statues venant elles-mêmes du dehors, ils le faisaient aussi pour résoudre des problèmes internes, personnels ou familiaux.

Si l'on considère les actes de Jinin, des Kiryū, de Fujiki Tōsuke, des jeunes gens ou des gardiens d'oratoire, la dynamique de création de l'objet du pèlerinage apparaît non pas comme le résultat d'un effet périphérique, mais comme ayant pour force motrice majeure l'acte de réception d'éléments du dehors par un noyau du dedans. Ce qui a été décisif, c'est l'élan impulsé par des gens d'action comme Fujiki Tōsuke et ses jeunes compagnons qui, tout en étant des gens du dedans, purent servir d'intermédiaires entre intérieur et extérieur. Autrement dit, l'important était, non pas que la position sociale de ces acteurs soit, intérieurement ou extérieurement parlant, marginale ou non, mais bien que leur action sociale soit ou non médiatrice.

Il est clair, comme le montre l'élaboration du circuit (fig. 6), que l'idée d'un " nouveau Shikoku » est le noyau sur lequel repose la création de ce pèlerinage. Beaucoup d'habitants de Sasaguri pensent même que c'est par référence au fait que les fudasho du pèlerinage original sont répartis entre quatre provinces (aujourd'hui départements) - Awa 阿波国 (Tokushima 徳島県), Sanuki 讃岐国 (Kagawa 香川県), Iyo 伊予国 (Ehime 愛媛県) et Tosa 土佐国 (Kōchi 高知県) - de Shikoku, que leurs répliques ont été installées dans les quatre villages de Takata, Kana.ide, Hagio et Sasaguri (devenus de nos jours des quartiers de cette commune). En réalité, dès l'origine le village de Tanaka était aussi compris dans le circuit et l'on n'a pas trace de cette idée de la réplique des quatre provinces avant l'époque Meiji. Mais si Fujiki Tōsuke, malgré son grand âge, a voulu à tout prix rapporter de la terre de Shikoku, et si Kiryū Genshirō a réussi à achever l'installation d'une statue par fudasbo, c'est bien parce qu'ils avaient tous deux la volonté de créer un nouveau Shikoku.

En outre, aujourd'hui encore, seul l'Oku-no-in conserve une place prééminente parmi tous les temples surnuméraires qui ont proliféré le long du circuit : c'est là le reflet de la coutume voulant que, lorsqu'on a terminé le pèlerinage de Shikoku, on se rende toujours à l'Oku-no-in du mont Kōya. Il suffit de voir comment les temples hors numérotation cherchent à acquérir à n'importe quel prix (fort) le titre et le numćro d'un fudasho du circuit, ou encore comment les choses peuvent s'envenimer jusqu'au procès autour de la question de la propriété d'un numéro de lieu saint, pour comprendre combien la conception de la réplique du Shikoku original est 
ancrée à la fois dans l'esprit des gardiens des fudasho et dans celui des pèlerins. Les temples hors numérotation se développent parce qu'ils se trouvent sur le chemin des pèlerins, et il suffit qu'en raison du changement d'implantation d'un fudasho numéroté, la route du pèlerinage soit modifiée pour que ces lieux sans numéros dépérissent en se trouvant mis « hors circuit ». Il est rare que la force d'attraction d'un temple hors numérotation dépasse celle des fudasho numérotés.

Pour toutes ces raisons, on peut dire que la dynamique principale dans la construction du pèlerinage de Shikoku à Sasaguri est celle de la réplication qui transplante en dedans une force du dehors ${ }^{70}$.

\section{Dynamique de réplication}

Lorsque les ressources de puissance subtile ou de pouvoir se trouvent à l'extérieur, il est possible de fabriquer efficacement du matériau culturel en imitant ou en détournant celles-ci avec un minimum d'efforts matériels et intellectuels. Les Japonais ont souvent été critiqués pour leur habileté à pratiquer l'imitation; néanmoins la technique voulant que la production de nouveautés s'appuie sur la maîtrise préalable de modèles, de façons de faire (kata カ夕), fait partie de la créativité et a toujours été la force motrice engendrant le renouvellement social et culturel (la révolution, au sens propre).

Autour de la création d'objet de pèlerinage, on constate souvent qu'il y a eu le projet d'une forme d'économie d'énergie en transposant à l'intérieur d'un groupe, d'un espace, des ressources qui leur sont extérieures. Et c'est notamment le cas des créations de pèlerinages de petite envergure, où la dynamique de réplication joue un rôle central. Dans la langue japonaise, utsushi ウツシ, le terme qui désigne cet acte de réplication, recouvre les quatrc registres linguistiques principaux de la « copie »

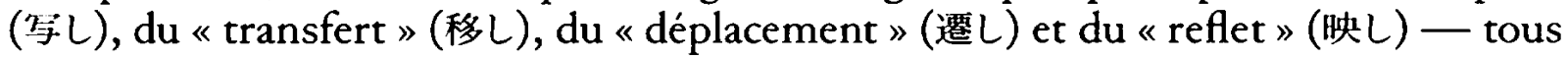
se prononçant pareillement utsushi.

Comme on le voit dans les mots «photographie » (sbashin 写真), «transcription 》 (tensha 転写) ou 《description» (byösha 描写), qui comprennent tous le caractère sha 写, la copie (utsushi 写L) est l'acte par lequel on crée quelque chose de nouveau qui ressemble à un modèle, une forme (kata カ夕/形/型) originaux. Cette notion comprend les nuances de reproduction directe et mécanique. Lors de la reproduction ou de l'imitation d'un modèle sont utilisés des symboles ou des rituels qui figurent celui-ci. Dans le cas des réplications de pèlerinages, cela se manifeste par l'importance accordée aux pratiques symboliques et au caractère de mise en scène. Dans les arts martiaux et les diverses techniques artistiques, il est principalement exigé de reproduire les modèles en vigueur dans chacune de ces « voies » (dō 道), et dans le shugendō, le rituel essentiel qu'est l'entrée dans la montagne (nyūbu 入峰), dont le modèle, qui se déroule dans les monts Ōmine, a été reproduit à l'identique dans toutes les montagnes du pays où était implantée une organisation sbugen. Dans les copies de pèlerinages de Shikoku, sont reproduits non seulement la forme

70. Le parc du nouveau Yoshino et la vallée Yaba de Sasaguri, ces «substituts (mitate 見立て), sont sans doute eux aussi construits sur ce principe de la réplication. 
des statues de chaque fudasho du Shikoku d'origine, suivant le nombre sacralisé de quatre-vingt-huit, mais aussi l'utilisation des termes «Shikoku » et « quatrevingt-huit », les lieux hors numérotation, la combinaison par paire des noms et des numéros des fudasho, ou encore les objets rituels (vêtement blanc, gilet estampé, bâton du vajra), les hymnes des quatre-vingt-huit temples, les pratiques rituelles comme le tour par la droite, les récitations de sūtra (nōkyó 納経), l'obtention des sceaux de chaque temple, l'accueil des pèlerins par la population locale sous forme de dons de nourriture, de boissons et d'hébergement gratuit.

En second lieu, le «transfert 》 (utsushi 移 $L$ ) est le fait de porter un objet en totalité ou en partie d'un endroit à un autre, de déplacer quelque chose (mono $€ /)$, une existence (sonzai 存在) constituant un original. C'est le corps matériel réellement transplanté qui est le point d'ancrage où se fixe la sacralité, et qui permet le transfert de cette qualité sacrée. Lorsqu'on édifia à l'époque d'Edo les réplications du mont Fuji que sont les « tertres du Fuji » (Fuji zuka 富士塚), il était essentiel que soit transportée de la lave noire venant des flancs du Fuji. On peut également citer les réplications de Lourdes, faites à partir de l'eau puisée à la source sainte ${ }^{71}$. L'acte majeur dans le processus de création du pèlerinage de Sasaguri par Fujiki Tōsuke et ses jeunes compagnons fut avant tout le transfert de la terre sainte rapportée du Shikoku originel. Dans toutes les innombrables réplications locales du pèlerinage de Shikoku, cette "Terre » est un élément fondateur indispensable. De même que dans tous ces nouveaux Shikoku ont été transplantées les « images 》 (miei 御影, osugata 御姿) de la statue principale que l'on reçoit dans chaque fudasho.

Le sens de " déplacement 》 (utsushi 遷し) est compris dans le précédent. Mais ce caractère est plus spécifiquement employé pour désigner l'acte consistant à changer de lieu le siège d'une divinité (senza 遷座), un sanctuaire (sengü 遷宮), ou encore le fait de mourir (senka, senge 遷化, le « départ de l'âme »), c'est-à-dire qu'il est utilisé dans le cas d'entités (non visibles) (mono $₹ /)$, particulièrement vénérables comme les dieux, les bouddhas ou les âmes de personnes remarquables. Ce terme s'applique parfaitement au cas du sanctuaire Ima-Kumano 今熊野 (nouveau Kumano) installé à Kyōto par l'empereur retiré Go-Shirakawa 後白河院. L'intention initiale de Jinin, lorsqu'elle entreprit de fonder le pèlerinage, fut de reproduire les statues de chaque fudasho de l'original, et l'on peut penser que conjointement au dessein de faire cette « reproduction ", elle avait aussi celui d'y installer l'âme de ces entités (bunrei kanjō 分霊锥請, «invitation à venir d'une partie de l'âme »). À l'origine, les fudasho, comme tous les oratoires dédiés au Grand Maître Kōbō qu'on trouve partout sur le bord des routes et des chemins de montagne à Sasaguri, étaient sans doute regardés comme les lieux de résidence de l'âme du Grand Maître Kōbō, fondement même de la dévotion du pèlerinage de Shikoku. Ces âmes des divinités, des bouddhas ou des saints transférées sont aussi tranquilles que l'œil d'un typhon, mais elles constituent le noyau de la construction et de la gestion de l'espace pérégrin.

71. Lors d'un tel processus de transfert, se pratique également la transplantation de végétaux, comme par exemple l'arbre appelé nagi 梛 (Podocarpus Nagi) de Kumano, le cryptomère (Cryptomeria japonica) de Fushimi Inari 伏見稲荷 (à Kyōto) ou le maki 槙 (Sciadopitys verticalis) du mont Kōya. 
Enfin, le "reflet » (utsushi 映 $\iota$ ) désigne la forme que l'on peut voir par réflexion lorsqu'on éclaire un objet; c'est donc la projection d'un original dans un espace différent. Le fait de restituer l'univers créé par la lumière de la conscience est un acte humain fondamental. L'opérateur qui, par reproduction, éveille la pensée de l'original est appelé «substitut »(mitate 見立 $て$ ). Dans le cas de la construction d'un objet de pèlerinage, correspond au substitut tout ce qui reflète le nom des fudasbo du vrai Shikoku, ou encore l'esprit, l'âme du modèle. Ainsi, à Sasaguri, c'est un ensemble d'éléments identiques à ceux en usage à Shikoku qui reflète l'esprit du modèle original, à savoir : la dévotion pour le Grand Maître Kōbō ; l'emploi de l'expression « à deux/compagnons sur le chemin » (dögyō ninin 同行二人) ${ }^{72}$ et du mantra " Hommage au Grand Maître, diamant qui illumine l'univers » (namu daishi henjō kongō 南無大師遍照金剛) ; l'introduction du culte pour l'Oku-no-in du mont Kōya ; la conception du pèlerin comme un henro 遍路 (pratiquant du « chemin lointain ») et de sa pratique comme une ascèse ; le culte du "blâme » (otogame お㐴め) ${ }^{73}$, que l'on retrouve au Kannon-ji de Nomiyama ( $\left.n^{\circ} 16\right)$; ou encore cette appréhension particulière de la totalité du territoire de Sasaguri, espace de pèlerinage, comme étant une surface uniformément sainte, et non en ses seuls points que sont les fudasho. Autant de facteurs qui reflètent l'esprit manifeste du vrai Shikoku. Et c'est cet esprit qui, fondamentalement, sous-tend l'acte réel qu'accomplit le pèlerin cheminant sur le circuit.

Par la «copie» (写), le «transfert» (移) de la structure de l'ensemble de l'original de Shikoku et de chacun de ses lieux de vénération, le pèlerinage de Sasaguri est devenu cet espace saint du « nouveau Shikoku ». Ensuite, en « reproduisant » (" 5 ) dans cet espace les symboles et les ritualités du modèle, les pèlerins et les gardiens d'oratoires ont mis en place une cosmologie du nouveau Shikoku, dans laquelle sont plongés tous les actcurs du pćlerinage. Enfin, en "réfléchissant " (映) l'esprit même du vrai Shikoku, qui a pour arrière-plan cette cosmologie encore plus vaste du secours (kyūsai 救済) selon le bouddhisme, l'ensemble contribua à intensifier la "sacralité » de l'espace et de l'acte de pérégrination, constituant ainsi une forte stimulation pour que les gens se rendent en pèlerinage au "nouveau Shikoku ».

Ainsi, la réplication (utsushi), ressort de l'actualisation de la puissante sacralité propre au pèlerinage originel de Shikoku, permet de créer relativement facilement un espace de pèlerinage similaire à celui du modèle, dans des lieux qui n'ont initialement aucun caractère sacré, et d'inciter à la pratique de la pérégrination et de l'accueil bénévole des pèlerins. Autrement dit, la réplication, cette technique de construction et de gestion de l'espace, rend possible la mise en place de la sacralité d'un modèle dans des lieux sans aucune particularité, et d'en faire une terre sainte susceptible de devenir objet de pèlerinage. En outre, la réitération de cette technique permet de continuer à renforcer et intensifier cette sacralité.

72. Dōgyō futari exprime le fait que le pèlerin, même s'il est seul, pense qu'il est toujours accompagné par le Grand Maître Kōbō dans son pèlerinage.

73. Tout malheur qui arrive au pèlerin pendant le pèlerinage est regardé comme une punition de ses mauvais actes passés. 


\section{Dynamique de la genèse du pèlerin}

Les statues des répliques des fudasbo du vrai Shikoku ne sont pas forcément l'essentiel pour le pèlerin. Les motifs qui amènent à partir en pèlerinage dépendent largement de l'époque et de la situation géographique. Le pèlerinage de Sasaguri avait tout son sens, pour les habitants de la région nord de Kyūshū principalement, et notamment pour ceux de Fukuoka-Hakata. Et ce, essentiellement durant la période allant de I 880 à 1990 .

D’une façon générale, la raison avancée pour expliquer ce qui incite à faire un pèlerinage sur un circuit de "nouveau Shikoku » est la difficulté rencontrée pour se rendre jusqu'à celui du vrai Shikoku, c'est-à-dire une raison liée à l'époque. "On dit que le grabataire se lève sur ses jambes, que l'aveugle voit, que le sourd entend, voilà les nouvelles de Shikoku ": tels sont les miracles chantés sur le vrai Shikoku (d'après une stèle édifiée en 1845 dans l'enceinte de l'ermitage Shinnen 真念有, fudasho hors numérotation de Shikoku, à Tosa-Shimizu dans le département de Kōchi ìnjall 斨 1 : 任清水门j). Ceux qui souhaitaient obtenir des grâces de cet ordre partaient, par défaut, sur le circuit d'un nouveau Shikoku. De préférence, c'est bien sûr à Shikoku que l'on va, mais la dynamique de la réplication a fait des nouveaux Shikoku des substituts tout à fait acceptables pour la dévotion. Dans le fief de Fukuoka, entre la fin de la période d'Edo et le début de celle de Meiji, le pèlerinage de Sasaguri était le seul " nouveau Shikoku ", et comme il était proche de la ville sous le château, il s'avérait très commode comme substitut du modèle pour les gens de cette région. Sasaguri se trouve en effet sur la route qui mène à Shikoku, comme le montre la "Carte simplifiée des quatre-vingt-huit lieux saints du nouveau circuit de Shikoku » (fig. 8) ; la publication de cette carte eut certainement un rôle publicitaire essentiel. Aujourd'hui encore, la quasi totalité des pèlerins viennent de l'extérieur de Sasaguri, et il est très rare que les habitants de la commune fassent le circuit.

On ignore la date à laquelle les pèlerins commencèrent à se rendre à Sasaguri, mais on peut penser que, lorsque Fujiki Tōsuke en fit le tour pour déposer la terre de Shikoku dans chacun des fudasho, ceux qui avaient pris part à sa création et ceux qui avaient une dévotion particulière pour le Grand Maître Kōbō le suivirent tous en une sorte de rituel de fondation. Mais comme ceci ne reposait pas (encore) sur le culte d'un nouveau pèlerinage, sans doute cela s'apparentera davantage à un acte rituel unique.

La volonté de se rendre à tout prix à Shikoku est également liée aux fluctuations du culte du Grand Maître Kōbō. C'est ainsi que tous les cinquante ans, à l'occasion de l'anniversaire de la mort de celui-ci, le pèlerinage de Shikoku et toutes ses répliques locales connaissent un surcroît de fréquentation. La pratique dévotionnelle voulant que prier le Grand Maître et s'en remettre à lui permet d'en obtenir des " grâces » est l'une des incitations à se rendre au Shikoku de Sasaguri. Bien évidemment, celui qui considère qu'un tel culte relève de la superstition n'éprouve pas le désir de partir en pèlerinage. De nos jours également, les pèlerins sont très nombreux dans les jours qui précèdent ou suivent la date anniversaire de la mort du Grand Maître Kōbō, car celle-ci les encourage plus particulièrement à célébrer sa mémoire ou à honorcr ses vertus en faisant un circuit des quatre-vingt-huit fudasho. Et puisque faire le pèlerinage, que ce soit sur le circuit original ou sur ceux des nouveaux Shikoku, 
est considéré comme une imitation de l'ascèse accomplie par le Grand Maître, cette forme d'ascèse, bien que brève, a valeur de preuve et d'acte de dévotion envers lui.

La conception du pèlerinage comme une ascèse s'est largement répandue à partir de l'époque de Heian (794-1185). Se rendre auprès de nombreux bouddhas a été assimilé à la pratique de la voie bouddhique ainsi qu'à une façon d'accumuler des mérites et d'accomplir des services pour les morts; autant de motifs qui sont aussi ceux d'un bon nombre des pèlerins de Sasaguri. Dans cette commune appelée «village des bouddhas » (Hotoke no sato 仏の里), la règle veut que ce ne soit pas seulement devant les statues principales des temples et oratoires, mais aussi devant toutes celles de chaque enceinte, ainsi que devant les innombrables sculptures qui bordent routes et chemins - c'est-à-dire devant le plus grand nombre de statues possible - , que le pèlerin joigne les mains et dépose ses offrandes de fleurs, d'encens et de menue monnaie. C'est pourquoi tous se munissent de sacs entiers de pièces d'un yen. La conception du pèlerinage comme un service pour les morts est également confirmée par l'importance du nombre des lieux de Sasaguri où sont accomplis des rites pour les enfants et fotus morts. Elle l'est aussi par le fait que la grande majorité des statues installées dans l'enceinte des fudasbo ont été offertes par des pèlerins comme un rite à la mémoire des défunts de leurs familles. On peut lire dans leur démarche une volonté d'aller déposer au-debors, avec ces statues, la peine qui est pour eux une cause de blocage dans leur existence. C'est ce qu'on peut appeler la dynamique du « jeté/jetable après rite »(inori sute 枇り唅て).

Il est possible de faire un parallèle entre les pratiques coutumières très répandues de l'expulsion vers l'extérieur (c'est-à-dire, de l'endroit où l'on vit) des souillures, fautes ou forces néfastes, et le fait que le pèlerinage s'accomplit en partant ailleurs : ces deux types d'actes reposent en effet sur une même dynamique. Parmi les pèlerins de Sasaguri, les prêtres du culte des dieux, les devins, les spécialistes des rites thérapeutiques et autres religieux charismatiques attirent l'attention, et selon leurs dires, l'un des motifs de leur démarche pérégrine personnelle tient à leur activité professionnelle. De fait, comme leur travail les amène très souvent à lever les obstacles (sawari 障り, employé ici dans le sens de « forces néfastes ») qui sont causes de l'infortune d'autrui, ils prennent sur eux une part de ces influences négatives, ce qui finit par provoquer des effets nocifs sur leur état mental et physique. Aussi attendent-ils du pèlerinage qu'il les purifie de ce «passif » (uke 受け). C'est ainsi qu'en cours de route, ils accomplissent souvent les pratiques rituelles de purification que sont l'ascèse de la cascade ou la récitation du Sütra de la Grande Sapience (Dai-bannya kyō). On peut en dire autant des pèlerins qui gagnent leur vie en ôtant la vie animale, des pêcheurs, des employés des abattoirs ou des restaurateurs.

Néanmoins, l'attrait du pèlerinage de Sasaguri n'est pas uniquement lié au culte de Shikoku, du Grand Maître Kōbō ou à la vogue du pèlerinage lui-même. Favorisé par la qualité de son environnement naturel, Sasaguri est aussi un lieu où les citadins viennent se ressourcer, aujourd'hui comme autrefois. Le tourisme vert qui permet de parcourir vallées et montagnes, entrer dans les cascades, profiter des fleurs, des oiseaux et des paysages est l'une des forces attractives du circuit de Shikoku dans cette commune. Ce qui constitue la particularité de ce pèlerinage, c'est le cadre naturel très riche dont il bénéficie tout en étant extrêmement proche de Fukuoka 
et Kita-Kyūshū, les grands centres urbains de cette région nord de Kyūshū. C'est là sans doute ce que l'on pourrait appeler la dynamique du « revirement/retour vers la nature » (sbizen kaiki 然回㷌) pour le pèlerin. Est ancré dans cette dynamique tout un ensemble de démarches et de pratiques, comme le transfert vers les cascades et les vallées encaissées de fudasho numérotés, la construction de cascades artificielles dans l'enceinte de certains temples ou de jardins d'agrément et de parcs, le fait que les pèlerins cumulent pratiques rituelle et ludique en venant admirer les cerisiers en fleurs, les feuilles rouges à l'automne, les cascades et se baignent dans l'eau des rivières, ou encore qu'ils valorisent la marche à pied en cette époque de la voiture. C'est aussi ce qu'exprime la représentation du pèlerinage sur la carte de la figure 6 .

D'un côté, l'espoir d'être régénéré par le contact avec la nature et secouru par les bouddhas pendant le pèlerinage de Sasaguri, et de l'autre, la pensée de la totalité de Sasaguri comme un seul et même espace saint, sont les deux faces d'un même ensemble. Les dieux et les bouddhas sont décelés dans le milieu naturel et au sein des divinités et des bouddhas est découverte la nature. Et peut-être plus que le principe de réplication, est-ce la force d'attraction de cette réorientation vers la nature qui agit ici. Il y a une longue histoire de la vénération des symboles du monde naturel et du cosmos sous la forme d'entités cultuelles : le bodhisattva Jizō pour la terre, le bouddha Dainichi pour le soleil, Fudō myōō pour le feu ou le bodhisattva Kannon pour l'eau, par exemple ${ }^{74}$. Les grâces prodigieuses sont considérées comme la manifestation de la bienveillance du monde invisible. Si les pèlerins ne portent pas nécessairement grande attention aux fudasho en tant que lieux différenciés les uns des autres, c'est parce qu'ils n'ont pas manifesté d'intérêt pour cette terre sainte que Fujiki Tōsuke s'était donné le mal de rapporter de Shikoku comme une relique du Grand Maître Kōbō, et dont on ne sait quasiment plus aujourd'hui ce qu'il est advenu. De la même façon, la pratique rituelle du circuit par la droite a été oubliée de longue date. Tout ceci n'est-il pas ce à quoi a conduit le souhait de voir dans ces lieux de pèlerinage une possibilité de retour(nement) vers le monde naturel ?

Un autre facteur s'est ajouté aux effets de l'époque et à ceux des caractères du territoire pour produire des changements sur le pèlerinage de Sasaguri : c'est l'attente qui s'y est développée envers les spécialistes religieux ayant des "pouvoirs". Aujourd'hui encore, les pèlerins accordent une plus grande importance aux temples qu'aux oratoires, aux moines, aux maîtres des rituels (kitōshi 被裤仰i) ou aux devins qu'aux gardiens d'oratoires (dōmori 堂'守) ou au personnel des temples, et en cela, leur attitude reflète la grande attente que les gens de Kyūshū manifestent envers les personnes dotées de "pouvoirs ». Il existe à Sasaguri ce type de religieux dont on dit que leurs paroles (oraculaires) « touchent juste » (yoku ataruよく当たる), et auprès de qui se rendent en grand nombre les commerçants ou ceux qui ont des problèmes familiaux. En outre, les responsables des nombreux fudasho hors numérotation ont accueilli avec beaucoup de zèle les attentes des pèlerins. Un large éventail de bienfaits et de moyens correspondant à la variété des demandes est proposé : Hachiman «qui

74. Il y a là un jeu sur les graphies des noms de ces figures bouddhiques ou de leurs attributs et caractères. Ainsi « Jizō » s'écrit avec le caractère «terre » ji 地 (成) et l'iconographie représente Fudō myōō entouré de flammes. 
donne vie aux yeux 》 (Ikime Hachiman 牛目八幡) pour la guérison des maladies d'yeux, l'« eau de bonne vision » (seigan-sui 情眼水) prise dans la cascade, «Kannon qui accorde des enfants 》 (Ko-sazuke Kannon 子授忛観济) pour les femmes qui veulent enfanter, "Kannon de la progéniture facile 》 (Koyasu Kannon 子㚣観省) pour que les enfants ne meurent pas en bas âge, ou encore le Grand Maître " protecteur des transports" (Kōtsū anzen daishi 父通安全大師) pour éviter les accidents de la route. Mais la force d'attraction de ce type d'offres des charismatiques a brusquement disparu avec l'amélioration de l'efficacité thérapeutique due aux progrès de la médecine et la diminution de la pauvreté suscitée par l'essor économique. Â partir des années 1990, les demandes d'aide charismatique se sont déplacées des moines vers les « conseillers spirituels» (supirichuaru ka.unserā スピリチュアル・カウンセラー) citadins. Le pèlerinage de Sasaguri continue à avoir pour acteurs principaux les citadins des mégalopoles, mais l'attitude de ceux-ci est très différente de ce qu'elle était à l'époque des mines de charbon. Le principe de la quête de l'aide charismatique, en se déplaçant des temples et oratoires des montagnes vers les appartements des buildings urbains, est en train de construire une nouvelle manière d'accomplir les pèlerinages.

\section{Dynamique de transformation du pèlerin par les lieux de pèlerinage}

Le fait qu'aujourd'hui encore le pèlerinage de Sasaguri continue à rassembler des pèlerins en nombre non négligeable prouve néanmoins que ceux-ci y trouvent quelque chose qui leur est profitable. Si l'on conçoit généralement le quotidien comme l'espace-temps du dedans, le non-ordinaire correspond à l'espace-temps du debors. Il n'est pas rare que le simple fait de sortir de l'endroit de la vie quotidienne génère un état d'esprit joyeux, et il y a des pèlerins qui font le circuit de Sasaguri comme s'ils allaient pique-niquer, admircr les cerisiers en fleurs ou encore faire une randonnée. On peut évoquer les nombreux effets d'une démarche vers l'extérieur, mais, comme le dit le proverbe "Honte en voyage est balayée (n'en est pas une) » ( tabi no baji wa kaki-sute 旅の恥は掻き捨て) ; l'un des principaux résultats est certainement celui d'un allègement du corps et de l'esprit par rejet au-dehors de tout ce qu'on peut extérioriser, y compris déshonneur ou affliction. Si certains pèlerins s'y changent les idées en oubliant toute limitation ordinaire, d'autres, par un effet de «sympathie entre porteurs d'une même maladie ", obtiennent le réconfort en se libérant de ce qu'ils ont sur le cœur. Par ailleurs, le dehors, environnement auquel on n'est pas habitué, s'il provoque une fatigue psychosomatique due à la tension qu'il génère, est aussi un stimulant qui intensifie toutes les fonctions du corps et de l'esprit, et amplifie les forces de faible intensité. On y fait l'expérience d'une extension des limites de l'attention et celle de l'approfondissement de la perception. Et notamment dans un contexte comme celui du pèlerinage de Sasaguri, qui associe aspects religieux et mystérieux, on peut attendre un effet de transformation de l'attitude intérieure du pèlerin par le biais du pouvoir des dieux, bouddhas et âmes, ou encore par celui du monde naturel. Les événements les plus ordinaires peuvent y être interprétés comme des "grâces du Grand Maître ».

Mais le pèlerinage est aussi source d'effets beaucoup plus importants que celui procuré par le simple fait de se changer les idées. Rites au cours desquels sont utilisés 
clochettes, cloches, bâtons à anneaux émettant des ultrasons, usage d'instruments cultuels tels que l'encens et les bougies qui provoquent un flottement mental, récitations rituelles répétées avec ardeur, toutes ces pratiques cumulées durant le pèlerinage entraînent une concentration méditative. Certains pèlerins se livrent à l'ascèse de la cascade et à la purification, d'autres passent la nuit à réciter les sütra devant un autel. Se mouvoir dans un espace saturé de pouvoir subtil par la présence de nombreuses statues, tout en se focalisant sur la pensée des bouddhas, et ce sur une longue distance et pendant de longues heures, passer les journées à pratiquer des rites, tout ceci met fortement à l'épreuve le corps du pèlerin et impose une lourde contrainte à son esprit. Lorsqu'on fait cette répétition rituelle en parcourant un circuit de plus de cent stations, l'impression laissée par chacune des statues ou des bâtiments devient extrêmement brouillée, et le souvenir des diverses expériences se fait tout à fait confus. C'est là le propre des pèlerinages à lieux saints multiples et l'un des effets très particuliers opérant dans le cadre même de la dynamique du pèlerinage.

En outre, un circuit comme celui de Sasaguri, qui est situé dans un riche cadre naturel, permet à l'homme de profiter des bienfaits de l'environnement le plus ancien, sous forme des infrasons et des parfums émis par les forêts, des vibrations sonores produites par les eaux et les oiseaux, des ondes électromagnétiques diffusées naturellement, notamment par le soleil, régénérant par là esprits et corps mis à mal par l'environnement artificiel. Il faut ajouter à cela que la saison principale des pèlerinages se situe aux environs du 2i mars, jour anniversaire de la mort du Grand Maître Kōbō (dernière dizaine du $4^{c}$ mois selon l'ancien calendrier), c'està-dire au moment où l'archipel est entièrement recouvert par une haute pression, où la température s'élève, les jours s'allongent, la végétation est en bourgeons ou en pleine floraison ; aussi les pèlerins qui se meuvent dans cet environnement où tout le vivant s'active bénéficient-ils également d'une intensification de leur vitalité.

Il n'est pas rare que les changements physiques et mentaux ainsi suscités par le pèlerinage débouchent sur des expériences étranges. On peut évidemment penser que, si l'état de santé s'améliore parce que les petits problèmes physiques s'arrangent et que les douleurs disparaissent, ceci n'a pour autre cause que le renforcement des défenses naturelles et de la capacité d'auto-guérison généré par le mouvement. Mais comme, dans ce contexte, les plus petits événements fortuits sont interprétés comme étant des faits singuliers, manifestations des pouvoirs des dieux et des bouddhas, il n'est guère étonnant que les pèlerins les regardent comme des expériences qui dépassent le sens ordinaire des choses. Si des défunts ou des dieux ou bouddhas leur apparaissent en rêve, ils peuvent donc l'interpréter comme une expérience mystérieuse. Un insecte passant devant les yeux peut être vu comme une âme. Cette modification de la compréhension des choses, en produisant un effet psychosomatique, peut même provoquer des guérisons par effet placebo. S'ouvre ici, comme un possible, la réalisation de l'univers de "celui qui croit est sauvé ». Les innombrables ex-voto et offrandes déposés dans les fudasbo en remerciement de vœux exaucés sont là pour en témoigner. L'état d'esprit changeant, le sentiment d'avoir ćtć sccouru peut émerger, et si une guérison vient à se produire, celle-ci peut être conçue comme une "grâce " (goriyaku 御利集). À Sasaguri, de très nombreux spécialistes religieux sont là pour 
inciter le pèlerin à penser ainsi. Il est certain qu'une dynamique de transformation du pèlerin est à l'œuvre dans cette atmosphère générée par les rites, par les histoires qui sont transmises, par les lieux et les gardiens d'oratoires du pèlerinage.

Un bon exemple en est la statue du bodhisattva Kannon pour la progéniture facile, qui fut offerte en signe de reconnaissance au Kōshō-in (n $\left.n^{\circ} 87\right)$, en 1919 (Taishō 8), par Nakagawa Tōjirō 中川l藤次郎 de Hakata et son épouse, parce qu'ils avaient enfin obtenu un enfant grâce aux rites accomplis par le supérieur du temple de l'époque, Kido Chiryō 城智完, alors qu'ils n'avaient pu avoir de descendant jusqu'à cette date. Cette grande statue fut transportée à cet endroit par les gens de la confrérie des hymnes de Shikoku de Hakata qui la tirèrent jusque-là durant trois jours sur la route. Le supérieur Kido Chiryō était né en I882 (Meiji Is) à Tanaka ; et comme il était malvoyant de naissance, sa mère lui avait faire prendre le statut de moine bouddhique et il était devenu un maître de biwa (biwa hōshi 琵琶法们i) accomplissant les rites de purification des fourneaux. Il était entré dans cet ermitage en 1902 (Meiji 35) et pratiquait aussi la divination par les baguettes de bambou (zeicbiku 筮竹) et de bois (sangi 算木). Après l'installation de cette statue de Kannon, l'histoire des époux Nakagawa se répandit, et les pèlerins vinrent en foule à ce temple, qui devint célèbre comme fudasho où l'on obtenait des enfants ${ }^{75}$.

Bien souvent, lorsque quelqu'un pense avoir obtenu une grâce au cours d'un pèlerinage, il revient chaque année pour faire, en signe de reconnaissance, un pèlerinage de remerciement (orei mairi 御礼参り). Et l'on constate que s'il raconte son histoire autour de lui, cela peut décider ceux qui l'ont entendue à se rendre eux-mêmes sur le circuit. Tant que cette manifestation d'une efficace peut être expérimentée, le pèlerinage déclenche une réaction en chaîne, et peut aller jusqu'à provoquer des pèlerinages de groupe par des confréries de plus de cent personnes.

\section{Dynamique de transformation des lieux de pèlerinage par les pèlerins}

Les pèlerins venant de l'extérieur de Sasaguri étant de plus en plus nombreux à rentrer chez eux en ayant bénéficié de toutes sortes de transformations, la renommée du pèlerinage se répandit, ce qui fit s'élever progressivement le nombre des visiteurs. L'impact de ces pèlerins du dehors changea de façon notable ces lieux d'accueil.

Ainsi, en 1889 , on vit se succéder la nomination du gardien d'oratoire du Yakushi-dō

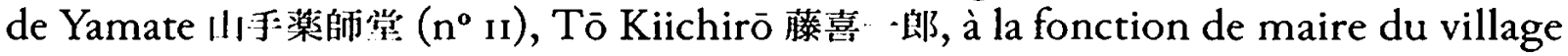
de Sasaguri, la publication de la carte d'orientation du circuit de Sasaguri établie par Aramaki Kō.uemon (fig. 6) et la fondation du Henshō-in ( $n^{\circ}$ 62) par Nishi Gikan. Or, à peu près au même moment, fut mis en place le trafic à double sens entre Fukuoka-Hakata, centre économique de Kyūshū, et le nord-est de cette région qui bouillonnait d'activité grâce aux mines de charbon. Cette année-là, fut aussi créé à Kido le "nouveau Yoshino " par le notable de Kana.ide qu'était le propriétaire du Kōnomine-ji 神峰寺 $\left(n^{\circ} 27\right)$, Tō Kinsaku. Aussitôt, on vit affluer chaque année les

75. Selon le supérieur du Kōshō-in, Kido Ryōshin 城/ ‘䆓件. 
pèlerins de Fukuoka-Hakata et du nord-est qui venaient également pour admirer les fleurs et faire du tourisme. Leur nombre augmentant, ces pèlerins-touristes de l'extérieur en vinrent à laisser à Sasaguri des sommes d'argent considérables qui provoquèrent de profonds changements dans le pèlerinage.

En effet, outre les offrandes en nature déposées dans chaque fudasbo, ils dépensaient beaucoup d'argent pour leur déplacement et leur séjour sur place, sous forme de frais annexes au pèlerinage liés aux transports, à l'alimentation et à l'hébergement. Les pèlerinages en groupe par train ou cars suscitèrent l'essor des compagnies de transport, ce qui fit venir encore davantage de monde. Beaucoup d'agriculteurs de la commune se convertirent en hôteliers ou en restaurateurs, et parmi eux s'installèrent également des gens venus de l'extérieur. On vit aussi s'accroître de façon spectaculaire les commerçants vendant aux pèlerins tout ce qu'ils désiraient acheter, souvenirs, plantes médicinales, instruments cultuels, friandises, boissons ou accessoires du pèlerin. Si l'on ajoute à cela ceux qui proposaient toutes les formes de services gravitant autour du pèlerinage, on comprend que le nombre des seuls gens de Sasaguri convertis en commerçants ou entrepreneurs n'a pu suffire pour répondre à la demande, et qu'il a fallu l'aide de gens de l'extérieur, ce qui fit ainsi augmenter la population locale. Mais plus encore que l'afflux des nouveaux implantés, c'est peut-être la dynamique voulant que l'on aille chercher au-dehors les techniques toujours plus avancées et efficaces des services, qui eut un impact profond dans la commune. Dès lors, Sasaguri ne cessa plus de s'imprégner des valeurs de l'extérieur.

Dans ce processus, vient aussi s'inscrire le fait que généralement, tous ceux qui ont obtenu des grâces font des dons en signe de reconnaissance, sous forme d'espèces ou d'objets. Aussi, les fudasho qui reçoivent notamment des fortunes ou des éléments de l'appareil cérémoniel, sont-ils entraînés dans une dynamique de renforcement du prestige et de l'autorité. Dans un premier temps est constitué l'ensemble des instruments cultuels bouddhiques courants, à commencer par les récipients où l'on brûle l'encens, les supports de bougies et les vases qui sont l'apparat de l'autel principal, les tablettes où l'on pose les sütra, les cloches, les instruments de percussion en bois et les lanternes. Puis, les unes après les autres, sont offertes les statues bouddhiques supplémentaires ainsi que celles du Grand Maître Kōbō, les tentures, etc. qui viennent compléter l'appareil rituel. Simples sculptures de pierre à l'origine, les quatre-vingt-huit statues originelles elles-mêmes finissent par être refaites sous forme de statues de bois somptueusement décorées d'or. Les pèlerins font ainsi don de statues, de cloches monumentales, de bâtiments pour l'habitation du religieux et de sa famille, de toilettes publiques. Dans ce processus, ils introduisirent également les objets en vogue sur le circuit du Shikoku originel, le bâton de pèlerin, le vêtement blanc et la façon de faire le service devant les autels. Certains,

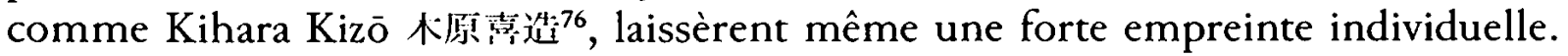
La volonté d'être légitimé aux yeux du monde étant identique chez les gardiens d'oratoires et de temples et chez les pèlerins, le pèlerinage de Sasaguri en vint à

76. Kihara Kizō 木㷧话 Sasaguri et un grand donateur à partir des années 1907 (aménagement des routes du pèlerinage, construction de bâtiments des temples et de leur enceinte, de plusieurs ponts de Sasaguri). 
acquérir une légitimité prestigieuse, qui, à partir du noyau des statues de pierre originelles, se construisit au moyen des dons venus de l'extérieur.

Les gardiens d'oratoires des fudasho firent accéder leurs enfants et disciples au statut de moines affiliés officiellement à la branche bouddhique légitime du Shingon fondée par le Grand Maître Kōbō. De leurs simples oratoires ou ermitages, ils firent de grands temples, dont ils aménagèrent l'enceinte en créant des lieux pour l'ascèse de la cascade, pour l'accueil des pèlerins, où ils plantèrent des arbres et firent des jardins ornementaux. Tout autour de ces lieux de pèlerinage, entrepreneurs, terrassiers, charpentiers et horticulteurs prospérèrent, de même que les tailleurs de pierre et les sculpteurs. Avec l'introduction des forces du debors, les fudasho de Sasaguri s'engagèrent sur la voie de la légitimité ou de l'autorité centrale.

Comme l'affluence des pèlerins de l'extérieur générait des profits énormes, le pèlerinage de Sasaguri devint un lieu favorable aux activités économico-religieuses. Étant devenus des commerces lucratifs, au rebours du discours bouddhique prônant la paix du cœur, les fudasho firent l'objet d'intenses transactions d'achat et de vente, tandis que surgissaient tout au long du circuit les temples hors numérotation, ouverts par des spécialistes religieux charismatiques venus du debors, et que s'accroissait la vente forcée des promesses d'efficace. Au nombre de ces gens de l'extérieur se trouvaient aussi des entrepreneurs malhonnêtes, des escrocs, de faux religieux charismatiques, des voleurs de troncs d'offrandes, des quémandeurs ou des incendiaires, toute une catégorie de porteurs de ce que l'on peut appeler les forces négatives.

Ainsi, que ce soit positivement ou négativement, tous ces gens venus d'ailleurs eurent un impact considérable sur Sasaguri. Il n'est en effet pas rare que les gens venant de l'extérieur renferment une force et une violence qui, les ayant conduits à rejeter ce qu'ils avaient acquis dans un autre dedans, les amènent à en partir et avancer coûte que coûte. Sous cet effet du dehors Sasaguri se transforma donc profondément.

En suivant les fluctuations qui marquèrent l'histoire du pèlerinage de Sasaguri, j'ai ici tenté de saisir la dynamique du pèlerinage. En s'appuyant sur cette analyse, il est possible de regrouper comme suit les quatre strates conceptuelles des dynamiques repérées. La première et la quatrième se rattachent à la problématique de la création d'un lieu de pèlerinage, tandis que la seconde et la troisième, à celle de son exploitation. On peut dire que les deux premières correspondent à la dynamique de la terre de pèlerinage et les deux secondes, à la dynamique du pèlerin.

$\left.\mathrm{I}^{\circ}\right)$ En ce qui concerne la dynamique de création d'un lieu de pèlerinage, nous avons certes pu mettre en évidence que les forces du debors contribuaient à transformer l'état du dedans, mais il est tout aussi clair que ce sont les actions issues du cœur même de l'intérieur qui en sont la force motrice. Ceux qui, tout en étant des gens du dedans, sont capables de jouer le rôle d'intermédiaires entre extérieur et intérieur, sont ceux qui sont en mesure d'être les chevilles ouvrières. Autrement dit, la création d'un lieu de pèlerinage a pour cause première une pression externe soutenue par une collaboration interne; puis l'entreprise de fondation à proprement 
parler est réalisée grâce à une impulsion donnée du dedans; enfin, c'est en s'appuyant sur toutes sortes d'éléments représentatifs de l'autorité, introduits successivement depuis l'extérieur, que ces lieux acquièrent une capacité d'attraction en tant que terre de pèlerinage.

$2^{\circ}$ ) Bien que les motivations qui conduisent les gens jusqu'à un lieu de pèlerinage soient multiples, on peut dire, pour simplifier beaucoup, que quelqu'un dont l'énergie se trouve dans un état négatif est attiré vers un univers (un espace-temps) où il espère que celle-ci deviendra positive. Cette dynamique évoque quelque peu la loi électrostatique de Coulomb. Si le système stimulateur se trouve là où l'on est, il n'est pas nécessaire de partir ailleurs ; aussi ne se fera-t-on pas pèlerin. La condition nécessaire à l'émergence du pèlerin est donc l'existence d'un système de stimulation au-dehors. Enfin, l'attraction exercée par un pèlerinage dépend fortement de contraintes temporelles et locales. On peut dire que c'est un phénomène qui naît au cœur d'accomodements entre le lieu de pèlerinage potentiel et celui qui examine la possibilité de partir en pèlerinage.

$3^{\circ}$ ) Quant à la dynamique de transformation du pèlerin par les lieux de pèlerinage, nous avons pu mettre en évidence l'importance accordée à l'effet dont le pèlerin est susceptible de bénéficier sur les lieux de pèlerinage qui se trouvent à l'extérieur. Ceci a permis de comprendre que c'est en introduisant en lui cette force extérieure qu'il active de lui-même son propre dedans, forces du corps et de l'esprit, énergie. Pour que cette transformation puisse avoir lieu, le pèlerin a besoin de sa puissance imaginative. Car elle est déterminante pour corroborer les effets rituels et les bienfaits de l'environnement naturel, ou encore ce qui apparaît au pèlerin comme les effets de "grâces". Tous ces effets peuvent se combiner de multiples manières et à d'innombrables degrés, faisant de l'expérience du pèlerin quelque chose qui est loin d'être simple. Mais l'on peut penser que ce qui contribue principalement à revigorer ses propres forces réside dans la puissance qu'il ressent au contact des symboles cultuels, dans les pouvoirs qu'il décèle au sein des rituels, dans l'entraide trouvée auprès de ses compagnons, et dans les effets sensibles provoqués sur son corps et son esprit par un environnement qui sort de l'ordinaire.

$4^{\circ}$ ) Enfin, concernant la dynamique de transformation des lieux de pèlerinage par les pèlerins, l'analyse montre que les énormes bénéfices générés par les masses de pèlerins venus du dehors provoquent un afflux de forces externes d'une grande violence, capable de bouleverser les structures économiques et la composition démographique internes de ces lieux. Selon la science économique, la terre, les capitaux et les forces de travail sont les trois fondamentaux de la productivité. À Sasaguri, c'est, de fait, l'introduction d'énormes moyens financiers et une puissance de travail considérable qui ont transformé la société locale. Et ce qui à première vue apparaît comme un enrichissement souhaitable des fudasho, se révèle être le résultat de l'intrusion d'objets et de valeurs de l'extérieur qui ont entraîné une servilité par rapport à l'autorité du dehors. Outre des aspects régis par la société, les pèlerinages en comportent aussi d'autres qui régissent la société, et nous avons pu vérifier ici que les recompositions des lieux de pèlerinage par une société que transforment les pratiques et les faits pérégrins sont une thématique de recherche importante. 
Pourquoi les gens vont-ils en pèlerinage ? Au fondement de leur démarche, il y a l'attente d'un effet de cette démarche. C'est de là que naissent l'attraction des lieux de pèlerinage et l'élan incitant à y aller. Et tandis qu'il induit des effets chez le pèlerin, l'acte de pèlerinage influence aussi les lieux qui en font l'objet, donnant ainsi naissance à une nouvelle puissance d'attraction et à de nouveaux élans. Ces quatre dynamiques constituent ensemble cette « dynamique du pèlerinage » que l'étude du Shikoku de Sasaguri a mis en lumière.

Adopter ici l'angle de la " dynamique » pour appréhender les transformations des pratiques coutumières a permis d'attirer le regard sur les questionnements concernant la nature et la puissance des forces mises en œuvre dans ces processus. Et c'est sans doute la première fois, dans le cadre des études japonaises sur le pèlerinage, qu'est abordée la question des forces générées par les pratiques coutumières que sont les pèlerinages.

Cette analyse montre que, sur le phénomène du pèlerinage, opère fortement l'effet de transformation du dedans par le détournement de modèles du debors, c'est-à-dire que la signification du dehors joue un rôle crucial et déterminant. Jusqu'à présent, les travaux et les enquêtes de terrain en ethnologie du Japon se sont principalement et avant tout intéressés à l'état des choses à l'intérieur des communautés locales ; aussi les pratiques coutumières qui s'exportaient vers l'extérieur ont-elles eu du mal à accéder au rang d'objets d'étude. Or, comme les pratiques coutumières de l'extérieur, où sont à l'œuvre des dynamiques différentes de celles qui existent dans les pratiques internes, possèdent elles aussi un sens majeur, il faudrait qu'à l'avenir, elles soient largement prises en compte par les recherches.

On peut résumer comme suit les effets intérieurs-extérieurs sur le pèlerinage de Shikoku à Sasaguri, à partir de la roche Heike que Jinin prit comme point d'ancrage et en tenant compte des distances et des voies de circulation : un vent soufflant de l'extérieur depuis le pèlerinage originel de Shikoku et depuis Mei-no-hama s'est engouffré du côté de la roche Heike, a déclenché un tourbillon à l'intérieur de Kido et, se propageant vers l'extérieur, a gagné l'ensemble de Sasaguri, a atteint Fukuoka, Hakata et le nord-est de la région, puis, grâce à l'extension du réseau ferroviaire des époques Meiji, Taishō et Shōwa (1868-1988), a rassemblé des pèlerins venant de régions situées au-delà des limites de Kyūshū, allant jusqu’à intégrer des forces éloignées comme celles du mont Kōya, de Tōkyō ou d'Ōsaka. Mais, depuis le début de l'époque Heisei (depuis 1989), avec le développement du train à grande vitesse et des avions permettant de se rendre directement sur le circuit originel de Shikoku, auquel vient s'ajouter le discrédit croissant du religieux amenant les gens à se tourner vers les structures médicales et les conseillers spirituels, le nouveau pèlerinage de Shikoku à Sasaguri, comme ceux de toutes les autres régions, a commencé à tomber dans l'oubli (document 4).

Néanmoins, même si la pratique du circuit de Sasaguri est en passe d'être oubliée, il ne faut pas perdre de vue l'ingéniosité et l'énergie déployées par les Kiryū et Fujiki Tōsuke. Ils ont eu à affronter une situation dans laquelle le recours aux forces du debors a été nécessaire pour venir à bout de problèmes du dedans. On peut penser que ces conditions ne vont sans doute guère changer à l'avenir. L'important, ce sont les moyens qui peuvent donner la possibilité de maîtriser et d'utiliser les puissantes 
forces extérieures de renouvellement que l'on introduit à l'intérieur. Pour cela, les capacités individuelles sont sans aucun doute insuffisantes, et même si l'on s'y emploie collectivement, il est certainement impossible de parvenir à les endiguer, à moins d'une grande abnégation. Si ceux qui se sont autrefois trouvés dans ce type de situation étaient non pas appelés « dirigeants " (sbibaisha 文配考), mais respectés sous le nom de sewanin 世話人, c'est-à-dire littéralement « ceux qui prennent soin, qui sont au service » (traduit ici par « responsables»), c'est parce qu'on voulait ainsi faire l'éloge de leur action qui, dans un esprit de dévouement visant d'abord à servir les autres, avait pour objectif la réalisation du bien-être collectif familial ou villageois. Et c'est vers ces actions des sewanin que notre attention doit se tourner.

Traduit du japonais par Anne Bouchy 


\section{Bibliographie}

AOKI Tamotsu 青木保

1985 Ontake junrei 御岳巡礼, Tōkyō, Chikuma shobō 筑摩莦原.

Bouchy, Anne

2003 "Une voie de l"art premier" dans le Japon du Xvir ${ }^{e}$ siècle. La statuaire d'Enkū, pérégrin de l'Essentiel », L'Homme 165, p. 143-172.

FujITA Akira 藤出明

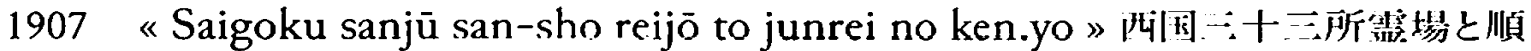
礼の権舆, Rekishichiri 箱史地理, vol. 10, n 1, p. 70-76; n², p. 47-54.

GoraI Shigeru 五. 来重

1959 Bukyō to minzoku 仏教と王俗, dans Shinkō to minzoku 信仰と民俗, Nibon minzokugaku taikei 日本民俗学大系, vol. 8, Tōkyō, Heibonsha ※风社, p. 323-34I.

1969 《Shinkō. Henro, junrei, yugyō hijiri » 信仰了——掘路·巡礼・遊行㧝, Dentō to gendai 伝統と現代, vol. 2, no 3 , Tōkyō, Gakutōsha 学燈社, p. 70-75.

HaRA Hideshirō 原秀四郎

1909 《Hachijū hakka-sho no kenkyū ni tsuite »八十八ヶ所の侀究について, Yūsei 住声, $\mathrm{n}^{\circ} 32$, Ōsaka, Shūyōdan 修盖网.

HosHINo Eiki 星野英糺

1977 《Hikaku junrei ron no kokoromi 》比較巡礼部の試み, dans Bukkyō minzoku gakkai 仏教民俗学会, éd., Bukkyō to girei 仏教と儀礼, Tōkyō, Kokusho kankōkai 国藏刊行会, p. 239-256.

KojIMa Hiromi 小嶋博已

1985 《 Tonegawa karyū.iki no shin Shikoku junrei» 利根川下流域の新四国巡礼, Seijō bungei 成城文芸, $113 / 114$, p. 128-164.

Kojima Hiromi 小㭡博七, éd.

1993 Saigoku junrei sanjū san-do gyōja no kenkyū 西国巡礼 -十:度行者の研究， Tōkyō, Iwata shoin 岩田传院.

MAEDA Takashi 前田卓

1971 Junrei no shakaigaku 巡礼の社会学, Kyōto, Mineruva shobōミネルヴア草房.

NAKaYAMA Kazuhisa 中山和久

1997 《Junrei to gendai » 巡礼と現代, Nibon minzokugaku 日本民俗学 2II, p. 32-65.

2000 《Junrei to gyōba no kankei 》 巡礼と行場の関係, Sangaku sbugen 山岳 修験 25, P. 58-71.

2005 《Junrei ni yoru idō no taiken »巡礼による移動の体験, Cbiiki kenkyū 地域 研究, $\mathrm{n}^{\circ} 4$, Yamanashi 山梨, Yamanashi kenritsu joshi tanki daigaku 山梨 罧立女子短期大学, p. 33-47.

2006 《Yusa no “omairi” bunka » 遊佐の『おまいり』文化, dans Kanda Yoriko 神田 より子, éd., Cbōkai sanroku Yusa no minzoku 烏海!做遊佐の民俗, vol. I, Yusa-chō 遊佐町 (Yamagata-ken い!形紧), Yusa-chō Kyōiku iinkai 遊份: 教育委異会, P. 374-50I. 
2008 «Mohō ni yoru junrei kūkan no sōzō. Sasaguri Shikoku reijō no hyōshō

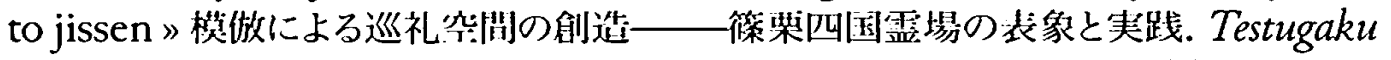
梊學 II9, p. 65-ı09, Tōkyō, Keiō gijuku daigaku Mita tesugakkai 僾應義 热大学二田折学会。

ODA Masayasu 小国莘保

1984 “Shōdo shima ni okeru utsushi reijō no seiritsu »小互島における”jし㙉 埸の成立, Jinbun chiri 人文地理, vol. $36, \mathrm{n}^{\circ} 4$, p. 347-36r.

SHINJō Tsunezō 新城常:

1982 Shinkō. Shaji sankei no shakai keizaishi teki kenkyū 新稿:社寺参非の社会経 済史的研究, Tōkyō, Hanawa shobō 塔萑分.

SHINNo Toshikazu 苫野俊和

1975 《Shikoku henro e no michi. Junrei no shisō》四国描路への道:巡礼の焽想, Kikan gendai shükyō 秀刊現代宗教, vol. $\mathrm{1}, \mathrm{n}^{\circ} 3$, p. 106-122.

SHINno Toshikazu It:野俊和, éd.

1996 Köza. Nibon no junrei 潇坐: 日本の巡礼, vol. I : Honzon junrei 本然巡礼, vol. 2 : Seiseki junrei 垃踖巡礼, vol. 3 : Junrei no kōzō to chibō junrei 巡礼 の構造と地方巡礼, Tōkyō, Yūzankaku shuppan 雄山得他版.

TAKEDA Akira 武H闭

1969 Junrei to minzoku 巡礼の民俗, Tōkyō, Iwasaki bijutsusha 若崎关術社.

TANAKa Hiroshi 田中博

1983 Junreichi no sekai 巡礼地の忙界, Tōkyō, Kokin shoin 古今書院.

TANAKA Tomohiko H小智彦

1986 《Kinki-chihō ni okeru chiikiteki junrei-chi 》近畿地方に拈ける地域的巡 礼地, Kōhe daigaku shigaku nenpō 袖广大学史学年報, $\mathrm{n}^{\circ} \mathrm{I}, \mathrm{p} .45-63$.

Monographies, bistoriographies locales et documents

ARAMAKI Kō.uemon 荒巻卖右街鬥

1889 Hacbijū bakka-sho junpai ryaku-zu 八ト八ヶ所順拈略快, Sasaguri.

Cbikuzen no kuni zoku fudoki furoku 筑们国続風卜言附録

1977-1978 Kawazoe Shōji 川添崛 :, éd., 3 vol., Tōkyō, Bunken shuppan 文献怆版 (compilé en 1793).

GōyA Takeshiro 命触武城

1957 Chikuzen Wakasugi kyōdoshi 筑㓩若杉制誌, Sasaguri, éd. privée.

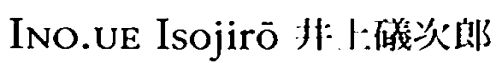

avant 1927 Sasaguri Sbikoku bacbijü bakka-sho reijō fudasho annai 策柴阳国八捨八ヶ所 留場札所案队, carte, s.l. n.d. (Sasaguri).

KaIBARA Ekiken 具原俭斬

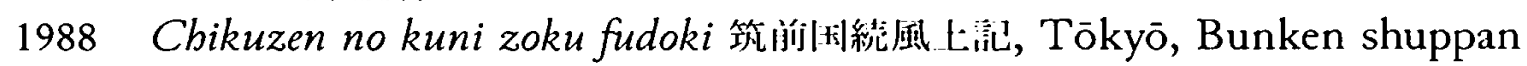
文献出版 (compilé en I688-1710). 


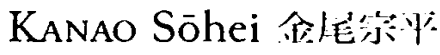

1935 Kaitei zōho. Füdo to seikatsu. Fukuoka-ken chishi 改訂增補:風土と生活・福 阔影地誌, Tōkyō, Tōkō shoin נ注.華院 ( $2^{\mathrm{e}}$ éd. augmentée).

Kasuya-gun yakusho 精屋都役所, éd.

1924 Kasuyagun shi 精琵俳志, Hakozaki-chō 箱崎町 (Fukuoka-ken), Kasuyagun yakusho.

KIRYŪ Genshirō 椅牛源阳郎

1894 Meisai-chō hennyū negai 明細帳編入願, s.l. (Sasaguri), archives de la famille Kiryū ${ }^{\circ} 5$, document conservé au Centre de documents historiques et de matériaux ethnographiques de la commune de Sasaguri, Sasaguri rekishi minzoku shiryō-shitsu 復栗歴史民俗資料茎.

1897 Shin-Shikoku hacbijuū hakka-sho daichō 新临尗八掵八ヶ所台帳, s.1. (Sasaguri).

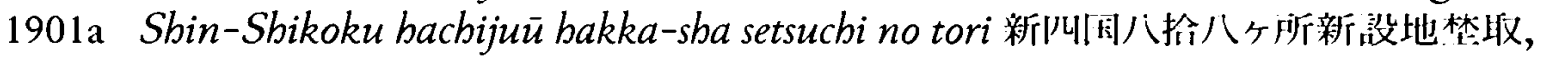
s.l. (Sasaguri), conservé au Ni-no-taki ji 二八流

1901b Nanzō-in tobishi keidai hennü negai 南藏院狮地境内編人願, s.l. (Sasaguri).

Kusaba Chiyokichi 荤場下代, ${ }^{\prime} i$

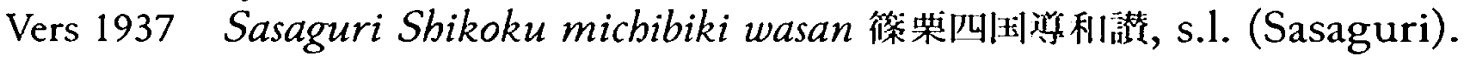

NAKANO Shiyō 中野紫藻

1935 Shin-Shikoku bachijū bakka-sho junpai 新忺目八十八ケ所巡拜, Fukuoka, Nakano Kageo 中野淙雄.

NANSEKI Takeshi 南们武

1966 Sasaguri shōshi benran 篠列小使便臨, Sasaguri, Shiseki hozon dōkōkai 尖跡 保们同好会.

NANSEKI Takeshi 南位武, éd.

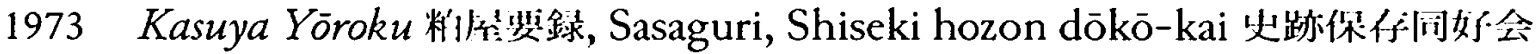
( $\mathrm{r}^{\mathrm{re}}$ éd. 1968).

Nishi Nihon bunka Kyōkai 临田本文化協会, éd.

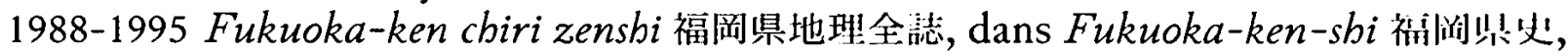
Kindai shiryōhen 近代史料編, 6 vol., Fukuoka.

Sasaguri-chō bunkazai senmon iin kai 篠栗町文化財曹鬥委其会, éd.

1982 Sasaguri chōshi. Rekishi hen 篠栗町誌・歷史編, Sasaguri, Sasaguri-chō.

1990 Sasaguri chōshi. Minzoku ben 篠栗町誌・民俗編, Sasaguri, Sasaguri-chō.

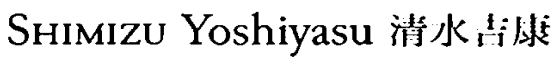

1898-1904 Dai Nippon meisho zuroku. Fukuoka-ken no bu 大ll本名所図録·福朔等之部, Ōsaka, Taisei-kan 人成館. 


\section{Annexes}

Tableau I : Liste des 88 lieux saints du pèlerinage de Shikoku à Sasaguri

\begin{tabular}{|c|c|c|c|c|}
\hline $\begin{array}{c}\mathrm{n}^{\circ} / \\
\text { bangai }\end{array}$ & $\begin{array}{l}\text { Nom du } \\
\text { fudasho }\end{array}$ & $\begin{array}{l}\text { Quartier, } \\
\text { lieu-dit }\end{array}$ & $\begin{array}{l}\text { Statue } \\
\text { principale }\end{array}$ & Remarques \\
\hline OI & $\begin{array}{l}\text { 南蔵院 } \\
\text { Nanzō-in }\end{array}$ & $\begin{array}{l}\text { 城戸 } \\
\text { Kido }\end{array}$ & $\begin{array}{l}\text { 釈迦如来 } \\
\text { Shaka }\end{array}$ & 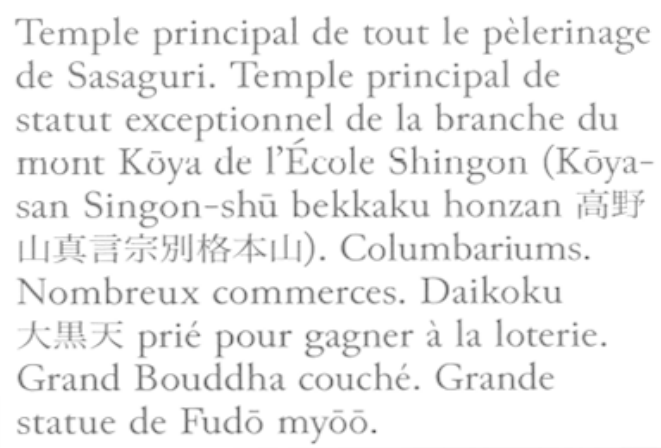 \\
\hline $\mathrm{O} 2$ & $\begin{array}{l}\text { 松ヶ瀬阿弥陀堂 } \\
\text { Matsu-ga-se } \\
\text { Amida-dō }\end{array}$ & $\begin{array}{l}\text { 松ヶ瀬 } \\
\text { Matsu- } \\
\text { ga-se }\end{array}$ & $\begin{array}{l}\text { 阿弥陀如来 } \\
\text { Amida }\end{array}$ & $\begin{array}{l}\text { Estampes des mains et des pieds } \\
\text { du Grand Maître Kōbō. Amulette } \\
\text { d'Awashima daimyōjin 淡島大明神. } \\
\text { Remise de ceintures de grossesse. }\end{array}$ \\
\hline 03 & $\begin{array}{l}\text { 城戸䣋迦堂 } \\
\text { Kido Shaka-dō }\end{array}$ & $\begin{array}{l}\text { 城戸 } \\
\text { Kido }\end{array}$ & $\begin{array}{l}\text { 釈迦如来 } \\
\text { Shaka }\end{array}$ & $\begin{array}{l}\text { Dans l'enceinte du nº } \text {. Gardien : } \\
\text { auberge. }\end{array}$ \\
\hline $\mathrm{O} 4$ & $\begin{array}{l}\text { 金出大日堂 } \\
\text { Kana.ide } \\
\text { Dainichi-dō }\end{array}$ & $\begin{array}{l}\text { 金出 } \\
\text { Kana.ide }\end{array}$ & $\begin{array}{l}\text { 大日如来 } \\
\text { Dainichi }\end{array}$ & $\begin{array}{l}\text { Statue d'Awashima daimyōjin 淡島大 } \\
\text { 明神 en pierre (1940). }\end{array}$ \\
\hline 05 & $\begin{array}{l}\text { 郷ノ原地葴堂 } \\
\text { Gō-no-haru } \\
\text { Jizō-dō }\end{array}$ & $\begin{array}{l}\text { 郷ノ原 } \\
\text { Gō-no- } \\
\text { haru }\end{array}$ & $\begin{array}{l}\text { 地蔵菩薩 } \\
\text { Jizōo }\end{array}$ & $\begin{array}{l}\text { Nombreuses collations offertes } \\
\text { (settai 接待). }\end{array}$ \\
\hline 06 & $\begin{array}{l}\text { 小浦薬師堂 } \\
\text { Ko.ura } \\
\text { Yakushi-dō }\end{array}$ & $\begin{array}{l}\text { 小浦 } \\
\text { Ko.ura }\end{array}$ & $\begin{array}{l}\text { 薬師如来 } \\
\text { Yakushi }\end{array}$ & $\begin{array}{l}\text { Gardien : famille Matsuo 松尾家, } \\
\text { la plus ancienne de Kido. }\end{array}$ \\
\hline 07 & $\begin{array}{l}\text { 田ノ浦阿弥陀堂 } \\
\text { Ta-no-ura } \\
\text { Amida-dō }\end{array}$ & $\begin{array}{l}\text { 田ノ浦 Ta- } \\
\text { no-ura }\end{array}$ & $\begin{array}{l}\text { 阿弥陀如来 } \\
\text { Amida }\end{array}$ & $\begin{array}{l}\text { Détruit deux fois par des incendies } \\
\text { (vengeance de voleurs d'oboles ?). }\end{array}$ \\
\hline ०8 & $\begin{array}{l}\text { 金剛の滝観音堂 } \\
\text { Kongō no taki } \\
\text { Kannon-dō }\end{array}$ & $\begin{array}{l}\text { 丸尾 } \\
\text { Maruo }\end{array}$ & $\begin{array}{l}\text { 千手観音 } \\
\text { Senju Kan- } \\
\text { non }\end{array}$ & $\begin{array}{l}\text { Cascade de Kongō : lieu de pratiques. } \\
\text { Portique d'Awashima "pour redresser } \\
\text { le dos» (Awashima koshi-nobe torii } \\
\text { 淡島腰伸べ鳥居). }\end{array}$ \\
\hline 09 & $\begin{array}{l}\text { 山王釈迦堂 } \\
\text { Sannō } \\
\text { Sahaka-dō }\end{array}$ & $\begin{array}{l}\text { 山王 } \\
\text { Sannōo }\end{array}$ & $\begin{array}{l}\text { 䣋迦如来 } \\
\text { Shaka }\end{array}$ & $\begin{array}{l}\text { Gardien : auberge. Pin du Kōya (tabu- } \\
\text { no-ki タブの木, Machilus thunbergii), } \\
\text { arbre à cire (Rbus, haze-no-ki ハゼ } \\
\text { の木). }\end{array}$ \\
\hline IO & $\begin{array}{l}\text { 切幡寺 } \\
\text { Kirihata-ji }\end{array}$ & $\begin{array}{l}\text { 丸尾 } \\
\text { Maruo }\end{array}$ & $\begin{array}{l}\text { 千手観音 } \\
\text { Senju Kan- } \\
\text { non }\end{array}$ & $\begin{array}{l}\text { Columbarium. Ancien gardien : } \\
\text { nonne. }\end{array}$ \\
\hline
\end{tabular}




\begin{tabular}{|c|c|c|c|c|}
\hline II & $\begin{array}{l}\text { 山手薬師堂 } \\
\text { Yamate } \\
\text { Yakushi-dō }\end{array}$ & $\begin{array}{l}\text { 山手 } \\
\text { Yamate }\end{array}$ & $\begin{array}{l}\text { 薬師如来 } \\
\text { Yakushi }\end{array}$ & $\begin{array}{l}\text { Gardien : descendant du maire Tō, } \\
\text { Kihachirō 藤喜八郎. }\end{array}$ \\
\hline I2 & $\begin{array}{l}\text { 千鶴寺 } \\
\text { Senkaku-ji }\end{array}$ & $\begin{array}{l}\text { 郷ノ原 } \\
\text { Gō-no- } \\
\text { haru }\end{array}$ & $\begin{array}{l}\text { 虚空蔵菩薩 } \\
\text { Kokūzō }\end{array}$ & $\begin{array}{l}\text { Cascade Chizuru 千鶴ヶ潼 : lieu de } \\
\text { pratiques. Spécialiste de la divination. } \\
\text { Lieu de pratiques affilié au shugen du } \\
\text { mont Ishizuchi (Ishizuchi-zan shugen } \\
\text { dōjō 石鈇山修験道場). Temple affilié à } \\
\text { la branche Omuro de l'École Shingon } \\
\text { 真言宗御室派. }\end{array}$ \\
\hline I3 & $\begin{array}{l}\text { 城戸大日堂 } \\
\text { Kido Dai- } \\
\text { nichi-ji }\end{array}$ & $\begin{array}{l}\text { 城戸 } \\
\text { Kido }\end{array}$ & $\begin{array}{l}\text { 十一面観音 } \\
\text { Jūichimen } \\
\text { Kannon }\end{array}$ & Gardien : restaurant. \\
\hline I4 & $\begin{array}{l}\text { 二ノ滝寺 } \\
\text { Ninotaki-ji }\end{array}$ & $\begin{array}{l}\text { 中ノ河内 } \\
\text { Nakano } \\
\text { Kōchi }\end{array}$ & $\begin{array}{l}\text { 弥勒菩薩 } \\
\text { Miroku }\end{array}$ & $\begin{array}{l}\text { Cascade : lieu de pratiques. Gardien : } \\
\text { auberge (anciennement : nonne). } \\
\text { Affilié à la branche du mont Kōya de } \\
\text { l'École Shingon 高野山真言宗. }\end{array}$ \\
\hline 15 & $\begin{array}{l}\text { 妙音寺 } \\
\text { Myōon-ji }\end{array}$ & $\begin{array}{l}\text { 金出 } \\
\text { Kana.ide }\end{array}$ & $\begin{array}{l}\text { 薬師如来 } \\
\text { Yakushi }\end{array}$ & $\begin{array}{l}\text { Affiliation : Tendai, Genseihō-ryū } \\
\text { 天台宗玄清法流. La statue principale } \\
\text { du temple est Batō Kannon 馬頭観音 } \\
\text { (Kannon à tête de cheval). }\end{array}$ \\
\hline I6 & $\begin{array}{l}\text { 呑山観音寺 } \\
\text { Nomiyama } \\
\text { Kannon-ji }\end{array}$ & $\begin{array}{l}\text { 呑山 } \\
\text { Nomiyama }\end{array}$ & $\begin{array}{l}\text { 千手観音 } \\
\text { Senju Kan- } \\
\text { non }\end{array}$ & $\begin{array}{l}\text { Commerce. Nombreux fidèles } \\
\text { femmes. Temple principal de statut } \\
\text { exceptionnel de la branche du mont } \\
\text { Kōya de l'École Shingon (Kōya-san } \\
\text { Singon-shū bekkaku honzan). }\end{array}$ \\
\hline 17 & $\begin{array}{l}\text { 山手薬師堂 } \\
\text { Yamate } \\
\text { Yakushi-dō }\end{array}$ & $\begin{array}{l}\text { 山手 } \\
\text { Yamate }\end{array}$ & $\begin{array}{l}\text { 薬師如来 } \\
\text { Yakushi }\end{array}$ & Gardien : auberge. \\
\hline I8 & $\begin{array}{l}\text { 篠栗恩山寺 } \\
\text { Sasaguri } \\
\text { Onzan-ji }\end{array}$ & $\begin{array}{l}\text { 上町 } \\
\text { Kami- } \\
\text { machi }\end{array}$ & $\begin{array}{l}\text { 薬師如来 } \\
\text { Yakushi }\end{array}$ & $\begin{array}{l}\text { Jardin. Obtint le droit de fudasho } \\
\text { après un pèlerinage aux Trois monts } \\
\text { du Dewa 出羽三山 et à Shikoku par } \\
\text { celui qui en est devenu le gardien. }\end{array}$ \\
\hline 19 & $\begin{array}{l}\text { 篠栗地蔵堂 } \\
\text { Sasaguri } \\
\text { Jizō-dō }\end{array}$ & $\begin{array}{l}\text { 上町 } \\
\text { Kami- } \\
\text { machi }\end{array}$ & $\begin{array}{l}\text { 地蔵菩薩 } \\
\text { Jizō }\end{array}$ & $\begin{array}{l}\text { Gardiens : les descendants d'Abe } \\
\text { Isuke 阿部伊助 qui était un compa- } \\
\text { gnon de Fujiki Tōsuke. }\end{array}$ \\
\hline 20 & $\begin{array}{l}\text { 鶴林寺 } \\
\text { Kakurin-ji }\end{array}$ & $\begin{array}{l}\text { 中ノ河内 } \\
\text { Nakano } \\
\text { Kōchi }\end{array}$ & $\begin{array}{l}\text { 地蔵菩薩 } \\
\text { Jizō }\end{array}$ & $\begin{array}{l}\text { En haut de la Côte du nenbutsu } \\
\text { 念仏坂. Statue de Jizō « qui ôte les } \\
\text { clous » (Kuginuki Jizō 釘抜地蔵) (1932). }\end{array}$ \\
\hline $2 I$ & $\begin{array}{l}\text { 高田虚空蔵堂 } \\
\text { Takata } \\
\text { Kokūzō-dō }\end{array}$ & $\begin{array}{l}\text { 高田 } \\
\text { Takata }\end{array}$ & $\begin{array}{l}\text { 虚空蔵菩薩 } \\
\text { Kokūzō }\end{array}$ & $\begin{array}{l}\text { Gardien : avant guerre, moine aveugle } \\
\text { pratiquant la divination. }\end{array}$ \\
\hline 22 & $\begin{array}{l}\text { 桐ノ木谷薬師堂 } \\
\text { Kirinoki-dani } \\
\text { Yakushi-do }\end{array}$ & $\begin{array}{l}\text { 桐ノ木谷 } \\
\text { Kirinoki- } \\
\text { dani }\end{array}$ & $\begin{array}{l}\text { 薬師如来 } \\
\text { Yakushi }\end{array}$ & $\begin{array}{l}\text { Jizō de la longévité (Enmei Jizō 延命 } \\
\text { 地蔵). Settai. }\end{array}$ \\
\hline
\end{tabular}




\begin{tabular}{|c|c|c|c|c|}
\hline 23 & $\begin{array}{l}\text { 山王薬師堂 } \\
\text { Sannō } \\
\text { Yakushi-dō }\end{array}$ & $\begin{array}{l}\text { 山王 } \\
\text { Sannō }\end{array}$ & $\begin{array}{l}\text { 薬師如来 } \\
\text { Yakushi }\end{array}$ & $\begin{array}{l}\text { Anciennement buvette et lieu de vente } \\
\text { de plantes médicinales. }\end{array}$ \\
\hline 24 & $\begin{array}{l}\text { 中ノ河内 } \\
\text { 虚空藏堂 } \\
\text { Nakano Kōchi } \\
\text { Kokūzō-dō }\end{array}$ & $\begin{array}{l}\text { 中ノ河内 } \\
\text { Nakano } \\
\text { Kōchi }\end{array}$ & $\begin{array}{l}\text { 虚空蔵菩薩 } \\
\text { Kokūzō }\end{array}$ & $\begin{array}{l}\text { Lieu de naissance de Fujiki Tōsuke } \\
\text { 藤木藤助. Gardien : famille d'origine } \\
\text { de Fujiki (Kanazawa 金澤家). }\end{array}$ \\
\hline 25 & $\begin{array}{l}\text { 秀善寺 } \\
\text { Shūzen-ji }\end{array}$ & $\begin{array}{l}\text { 山手 } \\
\text { Yamate }\end{array}$ & $\begin{array}{l}\text { 地蔵菩薩 } \\
\text { Jizōo }\end{array}$ & $\begin{array}{l}\text { Affilié à la branche du mont Kōya de } \\
\text { l'École Shingon. }\end{array}$ \\
\hline 26 & $\begin{array}{l}\text { 荒田大寺 } \\
\text { Arata Dai-ji }\end{array}$ & $\begin{array}{l}\text { 荒田 } \\
\text { Arata }\end{array}$ & $\begin{array}{l}\text { 薬師如来 } \\
\text { Yakushi }\end{array}$ & $\begin{array}{l}\text { Cascade de Fudō Myōō 不動明王滝 : } \\
\text { lieu de pratiques. Oratoire Karukaya } \\
\text { 荻萱堂. Gardien : auberge-buvette. } \\
\text { Vente de plantes médicinales. }\end{array}$ \\
\hline 27 & $\begin{array}{l}\text { 金出神峰寺 } \\
\text { Kana.ide } \\
\text { Kōnomine-ji }\end{array}$ & $\begin{array}{l}\text { 金出 } \\
\text { Kana.ide }\end{array}$ & $\begin{array}{l}\text { 十一面観音 } \\
\text { Jūichimen } \\
\text { Kannon }\end{array}$ & $\begin{array}{l}\text { Jardin, créé par Tō Kinsaku 藤金作. } \\
\text { Gardien : annexe de l'ancienne auberge } \\
\text { (actuellement un restaurant) Hinodeya } \\
\text { 日之出屋別館. Sur le chemin allant à } \\
\text { la cascade Ochōzu 御手水滝, bouddhas } \\
\text { de pierre des } 88 \text { étapes du pèlerinage. }\end{array}$ \\
\hline 28 & $\begin{array}{l}\text { 篠栗公畦大日寺 } \\
\text { Sasaguri kōen } \\
\text { Dainichi-ji }\end{array}$ & $\begin{array}{l}\text { 中町 } \\
\text { Naka- } \\
\text { machi }\end{array}$ & $\begin{array}{l}\text { 大日如来 } \\
\text { Dainichi }\end{array}$ & $\begin{array}{l}\text { Gardien : une lignée de nonnes. } \\
\text { Actuellement spécialiste des rites ora- } \\
\text { culaires, Shōzaki Ryōsei 庄崎良清. }\end{array}$ \\
\hline 29 & $\begin{array}{l}\text { 荒田観音堂 } \\
\text { Arata } \\
\text { Kannon-dō }\end{array}$ & $\begin{array}{l}\text { 荒田 } \\
\text { Arata }\end{array}$ & $\begin{array}{l}\text { 千手観音 } \\
\text { Senju Kan- } \\
\text { non }\end{array}$ & Gardien : auberge. \\
\hline 30 & $\begin{array}{l}\text { 田ノ浦斐玉堂 } \\
\text { Ta-no-ura } \\
\text { Higyoku-dō }\end{array}$ & $\begin{array}{l}\text { 田ノ浦 Ta- } \\
\text { no-ura }\end{array}$ & $\begin{array}{l}\text { 阿弥陀如来 } \\
\text { Amida }\end{array}$ & $\begin{array}{l}\text { Gardien : famille Hirai 平井家 } \\
\text { (ancienne auberge). }\end{array}$ \\
\hline $3 I$ & $\begin{array}{l}\text { 城戸文殊堂 } \\
\text { Kido } \\
\text { Monju-dō }\end{array}$ & $\begin{array}{l}\text { 城戸 } \\
\text { Kido }\end{array}$ & $\begin{array}{l}\text { 文殊菩薩 } \\
\text { Monju }\end{array}$ & $\begin{array}{l}\text { Dans l'enceinte du nº I. Gardien : } \\
\text { restaurant. }\end{array}$ \\
\hline 32 & $\begin{array}{l}\text { 高田十一面観 } \\
\text { 音堂 } \\
\text { Takata } \\
\text { Jū.ichimen } \\
\text { Kannon-dō }\end{array}$ & $\begin{array}{l}\text { 高田 } \\
\text { Takata }\end{array}$ & $\begin{array}{l}\text { 十一面観音 } \\
\text { Jūichimen } \\
\text { Kannon }\end{array}$ & $\begin{array}{l}\text { Gardien : le voisinage. À côté du n } \mathrm{n}^{\circ} \text { Io } \\
\text { du pèlerinage des } 33 \text { Kannon du can- } \\
\text { ton de Kasuya (Kasuya-gun sanjū-san } \\
\text { Kannon 糟屋郡三十三観音). }\end{array}$ \\
\hline 33 & $\begin{array}{l}\text { 本明院 } \\
\text { Honmyō-in }\end{array}$ & $\begin{array}{l}\text { 田中 } \\
\text { Tanaka }\end{array}$ & $\begin{array}{l}\text { 薬師如来 } \\
\text { Yakushi }\end{array}$ & $\begin{array}{l}\text { Commerce d'articles pour les pèlerins. } \\
\text { Affiliation : Tendai, Genseihō-ryū. }\end{array}$ \\
\hline 34 & $\begin{array}{l}\text { 宝山寺 } \\
\text { Hōzan-ji }\end{array}$ & $\begin{array}{l}\text { 鄉ノ原 } \\
\text { Gō-no- } \\
\text { haru }\end{array}$ & $\begin{array}{l}\text { 薬師如来 } \\
\text { Yakushi }\end{array}$ & $\begin{array}{l}\text { Innombrables Jizō pour les enfants } \\
\text { morts avant la naissance (Mizuko } \\
\text { Jizō 水子地蔵). Buvette. Roche de } \\
\text { l'or lancé (Kane maki-iwa [selon la } \\
\text { réponse de M. Nakayama n }{ }^{\circ} \text { 3] 黄金 } \\
\text { まき岩). Affilié à la branche du mont } \\
\text { Kōya de l'École Shingon. }\end{array}$ \\
\hline
\end{tabular}




\begin{tabular}{|c|c|c|c|c|}
\hline 35 & $\begin{array}{l}\text { 珠林寺薬師堂 } \\
\text { Shurin-ji } \\
\text { Yakushi-dō }\end{array}$ & $\begin{array}{l}\text { 金出 } \\
\text { Kana.ide }\end{array}$ & $\begin{array}{l}\text { 薬師如来 } \\
\text { Yakushi }\end{array}$ & $\begin{array}{l}\text { Dans l'enceinte du Shurin-ji 珠林寺. } \\
\text { Gardien : le temple. }\end{array}$ \\
\hline 36 & $\begin{array}{l}\text { 天王院 } \\
\text { Tennō-in }\end{array}$ & $\begin{array}{l}\text { 呑山 } \\
\text { Nomiyama }\end{array}$ & $\begin{array}{l}\text { 波切不動 } \\
\text { 明王 } \\
\text { Namikiri } \\
\text { Fudō myōō }\end{array}$ & $\begin{array}{l}\text { Innombrables Jizō pour les enfants } \\
\text { morts avant la naissance. Cascade : } \\
\text { lieu de pratiques. Affilié à la branche } \\
\text { du mont Kōya de l'École Shingon. }\end{array}$ \\
\hline 37 & $\begin{array}{l}\text { 高田阿弥陀堂 } \\
\text { Takata } \\
\text { Amida-dō }\end{array}$ & $\begin{array}{l}\text { 高田 } \\
\text { Takata }\end{array}$ & $\begin{array}{l}\text { 阿弥陀如来 } \\
\text { Amida }\end{array}$ & Gardien : le voisinage. \\
\hline 38 & $\begin{array}{l}\text { 丸尾観音堂 } \\
\text { Maruo } \\
\text { Kannon-dō }\end{array}$ & $\begin{array}{l}\text { 丸尾 } \\
\text { Maruo }\end{array}$ & $\begin{array}{l}\text { 千手観音 } \\
\text { Senju Kan- } \\
\text { non }\end{array}$ & $\begin{array}{l}\text { Cascade du dieu Dragon (Ryūjin no } \\
\text { taki 龍神の滝): lieu de pratiques. } \\
\text { «Eau des yeux vifs»(ikime-sui 生目水). } \\
\text { Gardien : auberge. }\end{array}$ \\
\hline 39 & $\begin{array}{l}\text { 延命寺 } \\
\text { Enmei-ji }\end{array}$ & $\begin{array}{l}\text { 上町 } \\
\text { Kami- } \\
\text { machi }\end{array}$ & $\begin{array}{l}\text { 薬師如来 } \\
\text { Yakushi }\end{array}$ & $\begin{array}{l}\text { Cascade de Fudō de la longévité } \\
\text { (Enmei Fudō no taki 延命不動の滝) : } \\
\text { lieu de pratiques. Settai. Stèle en } \\
\text { l'honneur du fondateur d'un culte théra- } \\
\text { peutique, Itō Terumī 伊藤テルミー, } \\
\text { appelé Itō Kin.ichi 伊滕金逸. }\end{array}$ \\
\hline 40 & $\begin{array}{l}\text { 一ノ滝寺 } \\
\text { Ichinotaki-ji }\end{array}$ & $\begin{array}{l}\text { 山手 } \\
\text { Yamate }\end{array}$ & $\begin{array}{l}\text { 薬師如来 } \\
\text { Yakushi }\end{array}$ & $\begin{array}{l}\text { Cascade : lieu de pratiques. Gardien : } \\
\text { anciennement nonne. Affilié à la } \\
\text { branche Daigo de l'École Shingon } \\
\text { 真言宗醍醐派. }\end{array}$ \\
\hline $4 \mathrm{I}$ & $\begin{array}{l}\text { 平原観音堂 } \\
\text { Hirabaru } \\
\text { Kannon-dō }\end{array}$ & $\begin{array}{l}\text { 平原 } \\
\text { Hirabaru }\end{array}$ & $\begin{array}{l}\text { 十一面観音 } \\
\text { Jūichimen } \\
\text { Kannon }\end{array}$ & $\begin{array}{l}\text { Cascade de Fudō : lieu de pratiques. } \\
\text { Statue du Grand Maître en pratiques } \\
\text { (Shugyō Daishi 修業大師) (1942). } \\
\text { Ancien gardien : auberge. }\end{array}$ \\
\hline 42 & $\begin{array}{l}\text { 中ノ河内仏木寺 } \\
\text { Nakanokōchi } \\
\text { Bukkoku-ji }\end{array}$ & $\begin{array}{l}\text { 中ノ河内 } \\
\text { Nakano } \\
\text { Kōchi }\end{array}$ & $\begin{array}{l}\text { 大日如来 } \\
\text { Dainichi }\end{array}$ & $\begin{array}{l}\text { Gardien : famille Kanazawa 金澤家, } \\
\text { famille d'origine de Fujiki Tōsuke. }\end{array}$ \\
\hline 43 & $\begin{array}{l}\text { 明石寺 } \\
\text { Akaishi-dera }\end{array}$ & $\begin{array}{l}\text { 鳴㴊 } \\
\text { Narubuchi }\end{array}$ & $\begin{array}{l}\text { 千手観音 } \\
\text { Senju Kan- } \\
\text { non }\end{array}$ & $\begin{array}{l}\text { Cascade : lieu de pratiques. Auberge. } \\
\text { Statues des Kannon de l'ouest du } \\
\text { pays. Affilié à la branche du Daikaku- } \\
\text { ji de l'École Shingon 真言宗大覚寺派. }\end{array}$ \\
\hline 44 & $\begin{array}{l}\text { 大宝寺 } \\
\text { Taihō-ji }\end{array}$ & $\begin{array}{l}\text { 鳴渕 } \\
\text { Narubuchi }\end{array}$ & $\begin{array}{l}\text { 十一面観音 } \\
\text { Jūichimen } \\
\text { Kannon }\end{array}$ & $\begin{array}{l}\text { Gardien : auberge. Affilié à la branche } \\
\text { du mont Kōya de l'École Shingon. }\end{array}$ \\
\hline 45 & $\begin{array}{l}\text { 城戸ノ滝不動堂 } \\
\text { Kido no taki } \\
\text { Fudō-dō }\end{array}$ & $\begin{array}{l}\text { 城戸 } \\
\text { Kido }\end{array}$ & $\begin{array}{l}\text { 不動明王 } \\
\text { Fudōō myōō }\end{array}$ & $\begin{array}{l}\text { Cascade de Fudō : lieu de pratiques. } \\
\text { Roche Heike (Heike-iwa 平家岩). } \\
\text { Dans l'enceinte du } n^{\circ} \mathrm{I} \text {. }\end{array}$ \\
\hline 46 & $\begin{array}{l}\text { 岡部薬師堂 } \\
\text { Okabe } \\
\text { Yakushi-dō }\end{array}$ & $\begin{array}{l}\text { 岡部 } \\
\text { Okabe }\end{array}$ & $\begin{array}{l}\text { 薬師如来 } \\
\text { Yakushi }\end{array}$ & $\begin{array}{l}\text { Autrefois, un raisinier de Chine } \\
\text { ou hovénie sucrée (tenpoko-nashi } \\
\text { テンポコ梨, pour kenpo nashi, Hovenia } \\
\text { dulcis) s'y trouvait. }\end{array}$ \\
\hline
\end{tabular}




\begin{tabular}{|c|c|c|c|c|}
\hline 47 & $\begin{array}{l}\text { 萩尾阿弥陀堂 } \\
\text { Haginoo } \\
\text { Amida-dō }\end{array}$ & $\begin{array}{l}\text { 萩尾 } \\
\text { Haginoo }\end{array}$ & $\begin{array}{l}\text { 阿弥陀如来 } \\
\text { Amida }\end{array}$ & $\begin{array}{l}\text { Gardien : famille Hagio 萩尾家, } \\
\text { famille résidant depuis une date } \\
\text { ancienne dans ce quartier. }\end{array}$ \\
\hline 48 & $\begin{array}{l}\text { 中ノ河内観音堂 } \\
\text { Nakano Kōchi } \\
\text { Kannon-dō }\end{array}$ & $\begin{array}{l}\text { 中ノ河内 } \\
\text { Nakano } \\
\text { Kōchi }\end{array}$ & $\begin{array}{l}\text { 十一面観音 } \\
\text { Jūichimen } \\
\text { Kannon }\end{array}$ & $\begin{array}{l}\text { Gardien : descendants de Murase } \\
\text { Shinpei 村瀬新平, un compagnon de } \\
\text { Fujiki Tōsuke. }\end{array}$ \\
\hline 49 & $\begin{array}{l}\text { 雷音寺 } \\
\text { Raion-ji }\end{array}$ & $\begin{array}{l}\text { 萩尾 } \\
\text { Haginoo }\end{array}$ & $\begin{array}{l}\text { 釈迦如来 } \\
\text { Shaka }\end{array}$ & $\begin{array}{l}\text { Affilié à la branche du mont Kōya de } \\
\text { l'École Shingon. }\end{array}$ \\
\hline 50 & $\begin{array}{l}\text { 郷ノ原薬師堂 } \\
\text { Gō-no-haru } \\
\text { Yakushi-dō }\end{array}$ & $\begin{array}{l}\text { 郷ノ原 } \\
\text { Gō-no- } \\
\text { haru }\end{array}$ & $\begin{array}{l}\text { 薬師如来 } \\
\text { Yakushi }\end{array}$ & $\begin{array}{l}\text { Nombreux ex-voto pour les maladies } \\
\text { des yeux. }\end{array}$ \\
\hline $5 \mathrm{I}$ & $\begin{array}{l}\text { 下町薬師堂 } \\
\text { Shimo-machi } \\
\text { Yakushi-dō }\end{array}$ & $\begin{array}{l}\text { 下町 } \\
\text { Shimo- } \\
\text { machi }\end{array}$ & $\begin{array}{l}\text { 薬師如来 } \\
\text { Yakushi }\end{array}$ & $\begin{array}{l}\text { Dans l'enceinte du n }{ }^{\circ} 79 \text {, Fudaraku-ji } \\
\text { 補陀落寺. Gardien : le temple. }\end{array}$ \\
\hline 52 & $\begin{array}{l}\text { 山手観音堂 } \\
\text { Yamate } \\
\text { Kannon-dō }\end{array}$ & $\begin{array}{l}\text { 山手 } \\
\text { Yamate }\end{array}$ & $\begin{array}{l}\text { 十一面観音 } \\
\text { Jūichimen } \\
\text { Kannon }\end{array}$ & $\begin{array}{l}\text { Monumentale peinture du Grand } \\
\text { Maître Kōbō en pratiques. Gardiens : } \\
\text { descendants du maire Tō Kihachirō. }\end{array}$ \\
\hline 53 & $\begin{array}{l}\text { 桐ノ木谷阿弥 } \\
\text { 陀堂 } \\
\text { Kirinoki-dani } \\
\text { Amida-dō }\end{array}$ & $\begin{array}{l}\text { 桐ノ木谷 } \\
\text { Kirinoki- } \\
\text { dani }\end{array}$ & $\begin{array}{l}\text { 阿弥陀如来 } \\
\text { Amida }\end{array}$ & Rien de particulier. \\
\hline 54 & $\begin{array}{l}\text { 中町延命寺 } \\
\text { Naka-machi } \\
\text { Enmei-ji }\end{array}$ & $\begin{array}{l}\text { 中町 } \\
\text { Naka- } \\
\text { machi }\end{array}$ & $\begin{array}{l}\text { 不動明王 } \\
\text { Fudōō myōō }\end{array}$ & Ancien gardien : auberge. \\
\hline 55 & $\begin{array}{l}\text { 桐ノ木谷大日堂 } \\
\text { Kirinoki-dani } \\
\text { Dainichi-dō }\end{array}$ & $\begin{array}{l}\text { 桐ノ木谷 } \\
\text { Kirinoki- } \\
\text { dani }\end{array}$ & $\begin{array}{l}\text { 大通智勝佛 } \\
\text { Daitsūchisho }\end{array}$ & $\begin{array}{l}\text { Anciennement buvette et lieu de vente } \\
\text { de plantes médicinales. }\end{array}$ \\
\hline 56 & $\begin{array}{l}\text { 松ヶ瀬地蔵堂 } \\
\text { Matsu-ga-se } \\
\text { Jizō-dō }\end{array}$ & $\begin{array}{l}\text { 松ヶ瀬 } \\
\text { Matsu- } \\
\text { ga-se }\end{array}$ & $\begin{array}{l}\text { 地藏菩薩 } \\
\text { Jizōo }\end{array}$ & $\begin{array}{l}\text { Tombe du yamabushi. Oratoire pour } \\
\text { les veillées (tsuya-dō 通夜堂). Nom- } \\
\text { breuses offrandes de tubes de bambou. }\end{array}$ \\
\hline 57 & $\begin{array}{l}\text { 田ノ浦栄福堂 } \\
\text { Ta-no-ura } \\
\text { Eifuku-dō }\end{array}$ & $\begin{array}{l}\text { 田ノ浦 } \\
\text { Ta-no-ura }\end{array}$ & $\begin{array}{l}\text { 阿弥陀如来 } \\
\text { Amida }\end{array}$ & $\begin{array}{l}\text { Emplacement de l'habitation de Fujiki } \\
\text { Tōsuke. Gardien : famille Fujiki } \\
\text { (ancienne auberge). }\end{array}$ \\
\hline 58 & $\begin{array}{l}\text { 大久保観音堂 } \\
\text { Ōkubo } \\
\text { Kannon-dō }\end{array}$ & $\begin{array}{l}\text { 大久保 } \\
\text { Ōkubo }\end{array}$ & $\begin{array}{l}\text { 千手観音 } \\
\text { Senju Kan- } \\
\text { non }\end{array}$ & Gardien : famille Kiryū 桐生家. \\
\hline 59 & $\begin{array}{l}\text { 田ノ浦薬師堂 } \\
\text { Ta-no-ura } \\
\text { Yakushi-dō }\end{array}$ & $\begin{array}{l}\text { 田ノ浦 } \\
\text { Ta-no-ura }\end{array}$ & $\begin{array}{l}\text { 薬師如来 } \\
\text { Yakushi }\end{array}$ & $\begin{array}{l}\text { Statue de Fujiki Tōsuke. Ancien } \\
\text { ermitage de Fujiki Tōsuke. Cascade } \\
\text { de la Lumière du Lapis-lazuli } \\
\text { (Rurikō-no-taki 瑠璃光ノ滝). }\end{array}$ \\
\hline 60 & $\begin{array}{l}\text { 神変寺 } \\
\text { Jinpen-ji }\end{array}$ & $\begin{array}{l}\text { 城戸 } \\
\text { Kido }\end{array}$ & $\begin{array}{l}\text { 大日如来 } \\
\text { Dainichi }\end{array}$ & Dans l'enceinte du $n^{\circ}$ I. \\
\hline
\end{tabular}




\begin{tabular}{|c|c|c|c|c|}
\hline 6I & $\begin{array}{l}\text { 山王寺 } \\
\text { Sannō-ji }\end{array}$ & $\begin{array}{l}\text { 山王 } \\
\text { Sannō }\end{array}$ & $\begin{array}{l}\text { 大日如来 } \\
\text { Dainichi }\end{array}$ & $\begin{array}{l}\text { Statue du Grand Maître « de la } \\
\text { Progéniture facile " (Koyasu Daishi } \\
\text { 子安大師) rapportée du no 6I du } \\
\text { Shikoku originel. Pousse-pousse dit } \\
\text { de Muhōmatsu 無法松 (héros d'un } \\
\text { roman et d'un film). Settai. Affilié à la } \\
\text { branche Omuro de l'École Shingon. }\end{array}$ \\
\hline 62 & $\begin{array}{l}\text { 遍照院 } \\
\text { Henshō-ji }\end{array}$ & $\begin{array}{l}\text { 上町 } \\
\text { Kami- } \\
\text { machi }\end{array}$ & $\begin{array}{l}\text { 十一面観音 } \\
\text { Jūichimen } \\
\text { Kannon }\end{array}$ & $\begin{array}{l}\text { Statue monumentale du Grand maître } \\
\text { en pratiques. Tour des Enfers (jigoku } \\
\text { meguri 地獄めぐり). } \mathrm{N}^{\circ} 23 \text { des } 33 \\
\text { Kannon du canton de Kasuya. }\end{array}$ \\
\hline 63 & $\begin{array}{l}\text { 天狗岩山吉祥寺 } \\
\text { Tenguiwa-san } \\
\text { Kisshō-ji }\end{array}$ & $\begin{array}{l}\text { 御田原 } \\
\text { Gotenbaru }\end{array}$ & $\begin{array}{l}\text { 昆沙門天王 } \\
\text { Bishamon }\end{array}$ & $\begin{array}{l}\text { Cascade du Tengu (Tengu-taki } \\
\text { 天狗潼) : lieu de pratiques. Gardien : } \\
\text { auberge. }\end{array}$ \\
\hline 64 & $\begin{array}{l}\text { 荒田阿弥陀堂 } \\
\text { Arata } \\
\text { Amida-dō }\end{array}$ & $\begin{array}{l}\text { 荒田 } \\
\text { Arata }\end{array}$ & $\begin{array}{l}\text { 阿弥陀如来 } \\
\text { Amida }\end{array}$ & $\begin{array}{l}\text { Gardien : auberge-entreprise de cars } \\
\text { de tourisme. }\end{array}$ \\
\hline 65 & $\begin{array}{l}\text { 三角寺 } \\
\text { Sankaku-ji }\end{array}$ & $\begin{array}{l}\text { 御田原 } \\
\text { Gotenbaru }\end{array}$ & $\begin{array}{l}\text { 十一面観音 } \\
\text { Jūichimen } \\
\text { Kannon }\end{array}$ & $\begin{array}{l}\text { Cascade du Vou pur (Seijōgan-no-taki } \\
\text { 清浄願之滝) : lieu de pratiques. Affilié } \\
\text { à la branche du mont Kōya de l'École } \\
\text { Shingon. }\end{array}$ \\
\hline 66 & $\begin{array}{l}\text { 観音坂観音堂 } \\
\text { Kannon-zaka } \\
\text { Kannon-dō }\end{array}$ & $\begin{array}{l}\text { 金出 } \\
\text { Kana.ide }\end{array}$ & $\begin{array}{l}\text { 千手観音 } \\
\text { Senju } \\
\text { Kannon }\end{array}$ & Au pied de la côte de Kannon. \\
\hline 67 & $\begin{array}{l}\text { 山王薬師堂 } \\
\text { Sannō } \\
\text { Yakushi-dō }\end{array}$ & $\begin{array}{l}\text { 山王 } \\
\text { Sannō }\end{array}$ & $\begin{array}{l}\text { 楽師如来 } \\
\text { Yakushi }\end{array}$ & Pin du Kōya (Kōya maki 高野槙). \\
\hline 68 & $\begin{array}{l}\text { 岡部神恵院 } \\
\text { Okabe } \\
\text { Jinne-in }\end{array}$ & $\begin{array}{l}\text { 岡部 } \\
\text { Okabe }\end{array}$ & $\begin{array}{l}\text { 阿弥陀如来 } \\
\text { Amida }\end{array}$ & $\begin{array}{l}\text { Ancien gardien : nonne. L'actuel } \\
\text { gardien fait des rites du Sūtra de la } \\
\text { Grande Sapience (Dai-hannya kaji } \\
\text { 大般若加持). Cascade du Paravent } \\
\text { (Byōbu-taki 屏風滝). }\end{array}$ \\
\hline 69 & $\begin{array}{l}\text { 高田観音堂 } \\
\text { Takata } \\
\text { Kannon-dō }\end{array}$ & $\begin{array}{l}\text { 高田 } \\
\text { Takata }\end{array}$ & $\begin{array}{l}\text { 聖観音 } \\
\text { Shō Kannon }\end{array}$ & $\begin{array}{l}\text { Statue de Kannon qui accorde des } \\
\text { enfants (1916). }\end{array}$ \\
\hline 70 & $\begin{array}{l}\text { 五塔ノ滝 } \\
\text { Gotō no taki }\end{array}$ & $\begin{array}{l}\text { 陣ヶ田尾 } \\
\text { Jingadao }\end{array}$ & $\begin{array}{l}\text { 馬頭観音 } \\
\text { Batō } \\
\text { Kannon }\end{array}$ & Cascade naturelle : lieu de pratiques. \\
\hline $7 \mathrm{I}$ & $\begin{array}{l}\text { 城戸千手観 } \\
\text { 音堂 } \\
\text { Kido Senju } \\
\text { Kanon-dō }\end{array}$ & $\begin{array}{l}\text { 城戸 } \\
\text { Kido }\end{array}$ & $\begin{array}{l}\text { 千手観音 } \\
\text { Senju } \\
\text { Kannon }\end{array}$ & $\begin{array}{l}\text { Anciennement dans l'enceinte du } \mathrm{n}^{\circ} \mathrm{I} \\
\text { (actuellement déplacé). Gardien : } \\
\text { auberge. }\end{array}$ \\
\hline 72 & $\begin{array}{l}\text { 田ノ浦拝師堂 } \\
\text { Ta-no-ura } \\
\text { Haishi-dō }\end{array}$ & $\begin{array}{l}\text { 田ノ浦 } \\
\text { Ta-no-ura }\end{array}$ & $\begin{array}{l}\text { 大日如来 } \\
\text { Dainichi }\end{array}$ & $\begin{array}{l}\text { Statue de Fujiki Tōsuke. Settai. Gar- } \\
\text { diens : descendants de Fujiki Tōsuke. }\end{array}$ \\
\hline
\end{tabular}




\begin{tabular}{|c|c|c|c|c|}
\hline 73 & $\begin{array}{l}\text { 山王釈迦堂 } \\
\text { Sannō } \\
\text { Shaka-dō }\end{array}$ & $\begin{array}{l}\text { 山王 } \\
\text { Sannō }\end{array}$ & $\begin{array}{l}\text { 䣋迦如来 } \\
\text { Shaka }\end{array}$ & Rien de particulier. \\
\hline 74 & $\begin{array}{l}\text { 城戸病奪り } \\
\text { 薬師堂 } \\
\text { Kido Yamaitori } \\
\text { Yakushi-dō }\end{array}$ & $\begin{array}{l}\text { 城戸 } \\
\text { Kido }\end{array}$ & $\begin{array}{l}\text { 薬師如来 } \\
\text { Yakushi }\end{array}$ & $\begin{array}{l}\text { Cascade de Fudōo (pour l'appréciation } \\
\text { esthétique). Buvette, vente de biscuits } \\
\text { du Grand Mâtre (Daishi senbei 大師 } \\
\text { せんべい). }\end{array}$ \\
\hline 75 & $\begin{array}{l}\text { 紶葉ケ滝薬 } \\
\text { 師堂 } \\
\text { Momiji-ga-daki } \\
\text { Yakushi-dō }\end{array}$ & $\begin{array}{l}\text { 鄉ノ原 } \\
\text { Gō-no- } \\
\text { haru }\end{array}$ & $\begin{array}{l}\text { 薬師如来 } \\
\text { Yakushi }\end{array}$ & $\begin{array}{l}\text { Cascade des Érables pourpres (Momiji- } \\
\text { ga-taki 紅葉ヶ滝) : lieu de pratiques. } \\
\text { Dans l'enceinte du Hōzan-ji (nº } 34) \text {. }\end{array}$ \\
\hline 76 & $\begin{array}{l}\text { 萩尾薬師堂 } \\
\text { Haginoo } \\
\text { Yakushi-dō }\end{array}$ & $\begin{array}{l}\text { 萩尾 } \\
\text { Haginoo }\end{array}$ & $\begin{array}{l}\text { 薬師如来 } \\
\text { Yakushi }\end{array}$ & $\begin{array}{l}\text { Cerisier transplanté depuis le circuit } \\
\text { du pèlerinage originel de Shikoku. }\end{array}$ \\
\hline 77 & $\begin{array}{l}\text { 山王薬師堂 } \\
\text { Sannōo } \\
\text { Yakushi-dō }\end{array}$ & $\begin{array}{l}\text { 山王 } \\
\text { Sannō }\end{array}$ & $\begin{array}{l}\text { 薬師如来 } \\
\text { Yakushi }\end{array}$ & $\begin{array}{l}\text { Gardiens : descendants de Murase } \\
\text { Tsugisaku 村瀬次作, un pèlerin du } \\
\text { vrai pèlerinage de Shikoku qui avait } \\
\text { rapporté du sable du fudasho n }{ }^{\circ} 77 \text { à } \\
\text { l'époque Meiji (probablement un } \\
\text { descendant de Murase Shinpei [ci- } \\
\left.\text { dessus, } \mathrm{n}^{\circ} 49\right] \text { ). }\end{array}$ \\
\hline 78 & $\begin{array}{l}\text { 山手阿弥陀堂 } \\
\text { Yamate } \\
\text { Amida-dō }\end{array}$ & $\begin{array}{l}\text { 山手 } \\
\text { Yamate }\end{array}$ & $\begin{array}{l}\text { 阿弥陀如来 } \\
\text { Amida }\end{array}$ & $\begin{array}{l}\text { Gardien : auberge. Pèlerinage « des } \\
\text { cent fois » à l'oratoire de Jizō « à date } \\
\text { prescrite » (Higiri Jizō 日切地蔵). }\end{array}$ \\
\hline 79 & $\begin{array}{l}\text { 補陀洛寺 } \\
\text { Fudaraku-ji }\end{array}$ & $\begin{array}{l}\text { 下町 } \\
\text { Shimo- } \\
\text { machi }\end{array}$ & $\begin{array}{l}\text { 十一面観音 } \\
\text { Jūichimen } \\
\text { Kannon }\end{array}$ & $\begin{array}{l}\text { Gardien : auberge-commerce de sou- } \\
\text { venirs et d'articles pour les pèlerins. } \\
\text { Affilié à la branche du mont Kōya de } \\
\text { l'École Shingon. }\end{array}$ \\
\hline 80 & $\begin{array}{l}\text { 田ノ浦観音堂 } \\
\text { Ta-no-Ura } \\
\text { Kannon-dō }\end{array}$ & $\begin{array}{l}\text { 田ノ浦 } \\
\text { Ta-no-Ura }\end{array}$ & $\begin{array}{l}\text { 千手観音 } \\
\text { Senju } \\
\text { Kannon }\end{array}$ & $\begin{array}{l}\text { Gardiens : famille Hirai 平井家 } \\
\text { (auberge), descendants de Hirai } \\
\text { Seishichi 平井清七 et Hirai Seiuemon } \\
\text { 平井清右衛門, compagnons de Fujiki } \\
\text { Tōsuke. Leur ancêtre Hirai Shōkō } \\
\text { 平井勝幸 a construit le tertre de sūtra } \\
\text { à Ana Kannon 穴観音 en } 1722 . \\
\text { Kannon au Trou (Ana Kannon). }\end{array}$ \\
\hline $8 \mathrm{I}$ & $\begin{array}{l}\text { 二瀬川観音堂 } \\
\text { Ninose-gawa } \\
\text { Kannon-dō }\end{array}$ & $\begin{array}{l}\text { 二瀬川 } \\
\text { Ninose- } \\
\text { gawa }\end{array}$ & $\begin{array}{l}\text { 千手観音 } \\
\text { Senju } \\
\text { Kannon }\end{array}$ & Gardien : quincaillerie. \\
\hline 82 & $\begin{array}{l}\text { 鳥越観音堂 } \\
\text { Torigoe } \\
\text { Kannon-dō }\end{array}$ & $\begin{array}{l}\text { 鳴㴊 } \\
\text { Narubuchi }\end{array}$ & $\begin{array}{l}\text { 千手観音 } \\
\text { Senju } \\
\text { Kannon }\end{array}$ & Ancien gardien : auberge. \\
\hline 83 & $\begin{array}{l}\text { 千手院 } \\
\text { Senju-in }\end{array}$ & $\begin{array}{l}\text { 御田原 } \\
\text { Gotenbaru }\end{array}$ & $\begin{array}{l}\text { 聖観音 } \\
\text { Shō Kannon }\end{array}$ & $\begin{array}{l}\text { Cascade des Huit grands rois dragons } \\
\text { (Hachi dai Ryūō no taki 八大竜王 } \\
\text { の滝) : lieu de pratiques. Cascades du } \\
\text { Senju-in 千手院漳 et du sanctuairc } \\
\text { Kushinada-hime 櫛名田姫滝. Settai. } \\
\text { Statue de la nonne Jinin 慈忍. }\end{array}$ \\
\hline
\end{tabular}




\begin{tabular}{|c|c|c|c|c|}
\hline 84 & $\begin{array}{l}\text { 中町屋島寺 } \\
\text { Naka-machi } \\
\text { Yashima-ji }\end{array}$ & $\begin{array}{l}\text { 中町 } \\
\text { Naka- } \\
\text { machi }\end{array}$ & $\begin{array}{l}\text { 千手観音 } \\
\text { Senju Kan- } \\
\text { non }\end{array}$ & $\begin{array}{l}\text { Jardin. Gardien : famille Murashima } \\
\text { 村島家 (descendants des Genji 源氏). }\end{array}$ \\
\hline 85 & $\begin{array}{l}\text { 祖聖大寺 } \\
\text { Soshōdai-ji }\end{array}$ & $\begin{array}{l}\text { 郷ノ原 } \\
\text { Gō-no- } \\
\text { haru }\end{array}$ & $\begin{array}{l}\text { 聖観音 } \\
\text { Shō Kannon }\end{array}$ & $\begin{array}{l}\text { Cascades des Cinq sabres (Go-ken no } \\
\text { taki 五剣の滝) et de Jion (Jion no taki } \\
\text { 慈恩ノ滝) : lieu de pratiques. Affilié } \\
\text { à la branche du mont Kōya de l'École } \\
\text { Shingon. }\end{array}$ \\
\hline 86 & $\begin{array}{l}\text { 金出観音堂 } \\
\text { Kanadide } \\
\text { Kannon-dō }\end{array}$ & $\begin{array}{l}\text { 金出 } \\
\text { Kana.ide }\end{array}$ & $\begin{array}{l}\text { 十一面観音 } \\
\text { Jūichimen } \\
\text { Kannon }\end{array}$ & Gardicn : lc voisinage. \\
\hline 87 & $\begin{array}{l}\text { 弘照院 } \\
\text { Kōshō-in }\end{array}$ & $\begin{array}{l}\text { 金出 } \\
\text { Kana.ide }\end{array}$ & $\begin{array}{l}\text { 聖観音 } \\
\text { Shō Kannon }\end{array}$ & $\begin{array}{l}\text { Cascade : lieu de pratiques. Pont des } \\
\text { Dix nuits (Jū-ya ga bashi 十夜ヶ橋). } \\
\text { Oratoires des } 33 \text { Kannon de l'ouest du } \\
\text { pays. Commerce. «Roche du Chas } \\
\text { de l'aiguille » (Hari no mimi iwa 針の } \\
\text { 耳岩). Statue de Kannon de l'ouest } \\
\text { du pays. Columbarium. Affiliation : } \\
\text { Tendai, Genseihō-ryū. }\end{array}$ \\
\hline 88 & $\begin{array}{l}\text { 大久保薬師堂 } \\
\text { Ōkubo } \\
\text { Yakushi-dō }\end{array}$ & $\begin{array}{l}\text { 大久保 } \\
\text { Ōkubo }\end{array}$ & $\begin{array}{l}\text { 薬師如来 } \\
\text { Yakushi }\end{array}$ & $\begin{array}{l}\text { Vente de légumes en saumure (tsuke- } \\
\text { mono 漬物) et de «l'eau de vitalité » } \\
\text { (genki-sui 元気水). Settai. Gardien : } \\
\text { famille Kiryū 桐生家. }\end{array}$ \\
\hline $\begin{array}{c}\text { Oku } \\
\text { 奥 }\end{array}$ & $\begin{array}{l}\text { 奥ノ院 } \\
\text { Oku-no-in }\end{array}$ & $\begin{array}{l}\text { 荒田 } \\
\text { Arata }\end{array}$ & $\begin{array}{l}\text { 弘法大師 } \\
\text { Kōbō daishi }\end{array}$ & $\begin{array}{l}\text { Près du sanctuaire Taiso (Taiso-gū } \\
\text { 太祖宮) au sommet du mont Waka- } \\
\text { sugi 若杉山. Eau du Vajra (Tokko } \\
\text { sui 独鈷水). «Roche qui enserre » } \\
\text { (Hasami-iwa はさみ岩). « Roche sous } \\
\text { laquelle on passe» (Kuguri-iwa くぐ } \\
\text { り岩). 《Roche fendue lors d'une lutte } \\
\text { de pouvoirs » (Seriwari-iwa 競り割岩). } \\
\text { Commerces. Gardien : Association du } \\
\text { sommet sacré de Wakasugi (Wakasugi } \\
\text { Reihō-kai 若杉霊峰会). }\end{array}$ \\
\hline $\begin{array}{c}\text { sans } \\
\text { 外 }\end{array}$ & $\begin{array}{l}\text { 珠林寺 } \\
\text { Shurin-ji }\end{array}$ & $\begin{array}{l}\text { 金出 } \\
\text { Kana.ide }\end{array}$ & $\begin{array}{l}\text { 阿弥陀如来 } \\
\text { Amida }\end{array}$ & $\begin{array}{l}\text { Fudasho } \mathrm{n}^{\circ} 25 \text { du pèlerinage des } 33 \\
\text { Kannon du canton de Kasuya. Temple } \\
\text { paroissial du secteur. Affilié à l'École } \\
\text { Jōdo, 浄土宗. Appelé aussi Kana.ide- } \\
\text { san Hōkō-in 金出山放光院. }\end{array}$ \\
\hline $\begin{array}{c}\text { sans } \\
\text { 外 }\end{array}$ & $\begin{array}{l}\text { 御手洗滝 } \\
\text { Ochōzugataki }\end{array}$ & $\begin{array}{l}\text { 金出 } \\
\text { Kana.ide }\end{array}$ & $\begin{array}{l}\text { 菩薩 } \\
\text { bodhisattva }\end{array}$ & $\begin{array}{l}\text { Cascade Ochōzu 御手水ノ滝 (du Lave- } \\
\text { ment des mains) : lieu de pratiques. } \\
\text { Ancien } \mathrm{n}^{\circ} 87 \text {. Ancien gardien : nonne } \\
\text { qui vendait des remèdes pour les yeux. }\end{array}$ \\
\hline $\begin{array}{c}\text { sans } \\
\text { 外 }\end{array}$ & $\begin{array}{l}\text { 仏舎利殿 } \\
\text { Busshari-den }\end{array}$ & $\begin{array}{l}\text { 金出 } \\
\text { Kana.ide }\end{array}$ & $\begin{array}{l}\text { 聖観音か } \\
\text { Shō Kannon } \\
\text { (?) }\end{array}$ & $\begin{array}{l}\text { À l'intérieur du parc de Kannon. } \\
\text { Columbarium. Gardien : Conseil } \\
\text { municipal d'assistance sociale (Shakai } \\
\text { fukushi kyōgi kai 社会福祉協議会). }\end{array}$ \\
\hline
\end{tabular}




\begin{tabular}{|c|c|c|c|c|}
\hline $\begin{array}{c}\text { sans } \\
\text { 外 }\end{array}$ & $\begin{array}{l}\text { 東光院 } \\
\text { Tōkō-in }\end{array}$ & $\begin{array}{l}\text { 萩尾 } \\
\text { Haginoo }\end{array}$ & $\begin{array}{l}\text { 延命地藏 } \\
\text { Enmei Jizō }\end{array}$ & Cascade : lieu de pratiques. \\
\hline $\begin{array}{c}\text { sans } \\
\text { 外 }\end{array}$ & $\begin{array}{l}\text { 慈照院 } \\
\text { Jishō-in }\end{array}$ & $\begin{array}{l}\text { 萩尾 } \\
\text { Haginoo }\end{array}$ & $\begin{array}{l}\text { 不動明王 } \\
\text { Fudōō myōō }\end{array}$ & Rien de particulier. \\
\hline $\begin{array}{c}\text { sans } \\
\text { 外 }\end{array}$ & $\begin{array}{l}\text { 三宝院 } \\
\text { Sanbō-in }\end{array}$ & $\begin{array}{l}\text { 萩尾 } \\
\text { Haginoo }\end{array}$ & $\begin{array}{l}\text { 三宝大荒神 } \\
\text { Sanbō } \\
\text { DaiKōjin }\end{array}$ & $\begin{array}{l}\text { Cascade Blanche (Shira-taki 白滝) : lieu } \\
\text { de pratiques. Ware-ishi 破石 (Roche fen- } \\
\text { due). Autrefois, se trouvait là un grand } \\
\text { pin. La statue principale a été rapportée } \\
\text { de Tateri Kōjin 立里荒神 de Nara. }\end{array}$ \\
\hline $\begin{array}{c}\text { sans } \\
\text { 外 }\end{array}$ & $\begin{array}{l}\text { 文殊院 } \\
\text { Monju-in }\end{array}$ & $\begin{array}{l}\text { 呑山 } \\
\text { Nomiyama }\end{array}$ & $\begin{array}{l}\text { 文殊菩薩 } \\
\text { Monju }\end{array}$ & $\begin{array}{l}\text { Temple des rites pour les enfants } \\
\text { morts avant la naissance. Affilié à la } \\
\text { branche Omuro de l'École Shingon. }\end{array}$ \\
\hline $\begin{array}{l}\text { sans } \\
\text { 外 }\end{array}$ & $\begin{array}{l}\text { 慈妙法院金出 } \\
\text { 道場 } \\
\text { Jimyōhō-in } \\
\text { Kana.ide dōjō }\end{array}$ & $\begin{array}{l}\text { 陣ヶ田尾 } \\
\text { Jingadao }\end{array}$ & $\begin{array}{l}\text { 不動明王 } \\
\text { Fudō myōō }\end{array}$ & $\begin{array}{l}\text { Cascade : lieu de pratiques. Gardien : } \\
\text { Jimyōhō-in 慈妙法院 de Kido. }\end{array}$ \\
\hline $\begin{array}{c}\text { sans } \\
\text { 外 }\end{array}$ & $\begin{array}{l}\text { 西国寺 } \\
\text { Saikoku-ji }\end{array}$ & $\begin{array}{l}\text { 陣ヶ田尾 } \\
\text { Jingadao }\end{array}$ & $\begin{array}{l}\text { 如意輪観音 } \\
\text { Nyoirin } \\
\text { Kannon }\end{array}$ & $\begin{array}{l}\text { Settai. Cascade. Oratoire des } 33 \\
\text { Kannon de l'ouest du pays. Est appelé } \\
\text { aussi Jūraku-zan 十楽山. Cascade? }\end{array}$ \\
\hline $\begin{array}{l}\text { sans } \\
\text { 外 }\end{array}$ & $\begin{array}{l}\text { 遍照寺 } \\
\text { Henshō-ji }\end{array}$ & $\begin{array}{l}\text { 山手 } \\
\text { Yamate }\end{array}$ & (à vérifier) & $\begin{array}{l}\text { Statue de Fudō sur laquelle on verse } \\
\text { de l'eau « merveilleuse » (Jinpen sui } \\
\text { 神変水). Affilié à la branche Daikaku-ji } \\
\text { de l'École Shingon. }\end{array}$ \\
\hline $\begin{array}{c}\text { sans } \\
\text { 外 }\end{array}$ & $\begin{array}{l}\text { 一畑薬師如来 } \\
\text { Ichibata } \\
\text { Yakushi }\end{array}$ & $\begin{array}{l}\text { 山手 } \\
\text { Yamate }\end{array}$ & $\begin{array}{l}\text { 薬師如来 } \\
\text { Yakushi }\end{array}$ & $\begin{array}{l}\text { Gardien : (probablement) confrérie } \\
\text { d'Ichibata-ji 一畑寺 (Izumo 出雲, } \\
\text { Shimane 島根). }\end{array}$ \\
\hline $\begin{array}{l}\text { sans } \\
\text { 外 }\end{array}$ & $\begin{array}{l}\text { 神代之滝不 } \\
\text { 動院 } \\
\text { Kamiyonotaki } \\
\text { Fudō-in }\end{array}$ & $\begin{array}{l}\text { 山手 } \\
\text { Yamate }\end{array}$ & $\begin{array}{l}\text { 不動明王 } \\
\text { Fudō myōō }\end{array}$ & $\begin{array}{l}\text { La statue de Yakushi d'Ichibata-ji } \\
\text { serait aussi vénérée dans cet oratoire } \\
\text { de Fudō. Soins par acupuncture et } \\
\text { moxas. Annexe du Meikan-ji 明観寺 } \\
\text { (Iizuka). Affilié à la branche Omuro } \\
\text { de l'École Shingon. Détruit par le } \\
\text { glissement de terrain de } 2009 \text {. }\end{array}$ \\
\hline $\begin{array}{c}\text { sans } \\
\text { 外 }\end{array}$ & $\begin{array}{l}\text { 玉光稲荷 } \\
\text { Gyokkō Inari }\end{array}$ & $\begin{array}{l}\text { 山手 } \\
\text { Yamate }\end{array}$ & (à vérifier) & Appelé aussi Myōhō-ji 妙法寺. \\
\hline $\begin{array}{l}\text { sans } \\
\text { 外 }\end{array}$ & $\begin{array}{l}\text { 神代之滰 } \\
\text { Kamiyonotaki }\end{array}$ & $\begin{array}{l}\text { 山手 } \\
\text { Yamate }\end{array}$ & $\begin{array}{l}\text { 不動明王 } \\
\text { Fudō myōō }\end{array}$ & $\begin{array}{l}\text { Cascade : lieu de pratiques. Lieu où se } \\
\text { déroule l'action du téléfilm Plus profond } \\
\text { que la mer (海より深き—かさぶた式 } \\
\text { 部考) d'Akimoto Matsuyo 秋元松代 } \\
\text { (1965). }\end{array}$ \\
\hline $\begin{array}{l}\text { sans } \\
\text { 外 }\end{array}$ & $\begin{array}{l}\text { 交通安全大師 } \\
\text { Kōtsū anzen } \\
\text { Daishi }\end{array}$ & $\begin{array}{l}\text { 桐ノ木谷 } \\
\text { Kirinoki- } \\
\text { dani }\end{array}$ & $\begin{array}{l}\text { 弘法大師 } \\
\text { Kōbō daishi }\end{array}$ & $\begin{array}{l}\text { Aujourd'hui disparu. Bâton à anneaux } \\
\text { monumental. }\end{array}$ \\
\hline
\end{tabular}




\begin{tabular}{|c|c|c|c|c|}
\hline $\begin{array}{l}\text { sans } \\
\text { 外 }\end{array}$ & $\begin{array}{l}\text { 地蔵寺 } \\
\text { Jizō-ji }\end{array}$ & $\begin{array}{l}\text { 桐ノ木谷 } \\
\text { Kirinoki- } \\
\text { dani }\end{array}$ & $\begin{array}{l}\text { 地蔵菩薩 } \\
\text { Jizō }\end{array}$ & $\begin{array}{l}\text { Settai. Oratoire de la famille Miura } \\
\text { 三浦家 (originellement l'autel boudd- } \\
\text { hique domestique de cette famille). } \\
\text { Fabriquait et vendait des bâtons de } \\
\text { pèlerins. }\end{array}$ \\
\hline $\begin{array}{l}\text { sans } \\
\text { 外 }\end{array}$ & $\begin{array}{l}\text { 立岩 } \\
\text { Tateiwa }\end{array}$ & $\begin{array}{l}\text { 桐ノ木谷 } \\
\text { Kirinoki- } \\
\text { dani }\end{array}$ & $\begin{array}{l}\text { 不動明王 } \\
\text { Fudōō myōō }\end{array}$ & $\begin{array}{l}\text { Sculpture rupestre d'un Fudō myōō } \\
\text { monumental (vers i860). }\end{array}$ \\
\hline $\begin{array}{l}\text { sans } \\
\text { 外 }\end{array}$ & $\begin{array}{l}\text { 子授観音 } \\
\text { Kosazuke } \\
\text { Kannon }\end{array}$ & $\begin{array}{l}\text { 桐ノ木谷 } \\
\text { Kirinoki- } \\
\text { dani }\end{array}$ & $\begin{array}{l}\text { 子授観音 } \\
\text { Kosazuke } \\
\text { Kannon }\end{array}$ & $\begin{array}{l}\text { En face de Tateiwa 立岩. Bien qu'il } \\
\text { s'agisse d'un oratoire, il y a un } \\
\text { supérieur. Nombreuses offrandes de } \\
\text { représentations des parties génitales } \\
\text { masculines et féminines. }\end{array}$ \\
\hline $\begin{array}{l}\text { sans } \\
\text { 外 }\end{array}$ & $\begin{array}{l}\text { 子安観音 } \\
\text { Koyasu Kan- } \\
\text { non }\end{array}$ & $\begin{array}{l}\text { 桐ノ木谷 } \\
\text { Kirinoki- } \\
\text { dani }\end{array}$ & $\begin{array}{l}\text { 子安観音 } \\
\text { Koyasu } \\
\text { Kannon }\end{array}$ & $\begin{array}{l}\text { Grand nombre de poupées déposées } \\
\text { en offrandes. Célèbre pour son grand } \\
\text { cerisier. }\end{array}$ \\
\hline $\begin{array}{l}\text { sans } \\
\text { 外 }\end{array}$ & $\begin{array}{l}\text { 聖法院 } \\
\text { Shōbō-in }\end{array}$ & $\begin{array}{l}\text { 鄉ノ原 } \\
\text { Gō-no- } \\
\text { haru }\end{array}$ & $\begin{array}{l}\text { 大日如来 } \\
\text { Dainichi }\end{array}$ & $\begin{array}{l}\text { Statues de pierre des } 88 \text { statues princi- } \\
\text { pales des fudasho. Appelé aussi Hōkan- } \\
\text { zan 宝巻山. Affilié au Manji-kyōdan } \\
\text { de l'École Shingon 真言宗论教団 (une } \\
\text { branche dérivée de l'École Shingon). }\end{array}$ \\
\hline $\begin{array}{l}\text { sans } \\
\text { 外 }\end{array}$ & $\begin{array}{l}\text { 十一峰寺 } \\
\text { Jūichibu-ji }\end{array}$ & $\begin{array}{l}\text { 郷ノ原 } \\
\text { Gō-no- } \\
\text { haru }\end{array}$ & (à vérifier) & Grand bouddha de béton. \\
\hline $\begin{array}{l}\text { sans } \\
\text { 外 }\end{array}$ & $\begin{array}{l}\text { 聖徳寺 } \\
\text { Shōtoku-ji }\end{array}$ & $\begin{array}{l}\text { 郷ノ原 } \\
\text { Go-no- } \\
\text { haru }\end{array}$ & (à vérifier) & $\begin{array}{l}\text { Gère le «Parc des âmes » (Shōtoku- } \\
\text { byō 聖徳廟霊園). Gardien : entreprise } \\
\text { de pierre à bâtir de Sasaguri. Affilié } \\
\text { à la branche Kibe de l’École Jōdo- } \\
\text { shin 浄土真宗木辺派 (anciennement } \\
\text { Shōtoku-shū 聖徳宗, une école dérivée } \\
\text { du Hossō-shū 法相宗). }\end{array}$ \\
\hline $\begin{array}{l}\text { sans } \\
\text { 外 }\end{array}$ & $\begin{array}{l}\text { 不動明王 } \\
\text { Fudōō myōō }\end{array}$ & $\begin{array}{l}\text { 小浦 } \\
\text { Ko.ura }\end{array}$ & $\begin{array}{l}\text { 不動明王 } \\
\text { Fudō myōō }\end{array}$ & $\begin{array}{l}\text { Gardien : confrérie de Narita Fudō } \\
\text { 成田不動講. }\end{array}$ \\
\hline $\begin{array}{l}\text { sans } \\
\text { 外 }\end{array}$ & $\begin{array}{l}\text { 正蓮院 } \\
\text { Shōren-in }\end{array}$ & $\begin{array}{l}\text { 城戸 } \\
\text { Kido }\end{array}$ & $\begin{array}{l}\text { 聖観音 } \\
\text { Shō Kannon }\end{array}$ & $\begin{array}{l}\text { Supérieur : disciple du Nanzō-in. } \\
\text { Affilié à la branche du mont Kōya de } \\
\text { l'École Shingon. }\end{array}$ \\
\hline $\begin{array}{l}\text { sans } \\
\text { 外 }\end{array}$ & $\begin{array}{l}\text { 慈妙法院 } \\
\text { Jimyōhō-in }\end{array}$ & $\begin{array}{l}\text { 城戸 } \\
\text { Kido }\end{array}$ & $\begin{array}{l}\text { 不動明王 } \\
\text { Fudō myōō }\end{array}$ & $\begin{array}{l}\text { Supérieur : spécialiste de rites oracu- } \\
\text { laires. Affilié à la branche Daikaku-ji } \\
\text { de l'École Shingon, et au groupe } \\
\text { shintō dérivé de la confrérie shugen du } \\
\text { mont Ishizuchi (Shikoku), Ishizuchi } \\
\text { honkyō 石鏈本教. }\end{array}$ \\
\hline $\begin{array}{l}\text { sans } \\
\text { 外 }\end{array}$ & $\begin{array}{l}\text { 薬王寺 } \\
\text { Yakuō-ji }\end{array}$ & $\begin{array}{l}\text { 城戸 } \\
\text { Kido }\end{array}$ & $\begin{array}{l}\text { 薬師如来 } \\
\text { Yakushi }\end{array}$ & $\begin{array}{l}\text { Supérieur : spécialiste de rites oracu- } \\
\text { laires. }\end{array}$ \\
\hline $\begin{array}{l}\text { sans } \\
\text { 外 }\end{array}$ & $\begin{array}{l}\text { 善通寺 } \\
\text { Zentsū-ji }\end{array}$ & $\begin{array}{l}\text { 荒田 } \\
\text { Arata }\end{array}$ & & $\begin{array}{l}\text { Cascade : lieu de pratiques. Affilié à } \\
\text { la branche du mont Kōya de l’École } \\
\text { Shingon. }\end{array}$ \\
\hline
\end{tabular}




\begin{tabular}{|c|c|c|c|c|}
\hline $\begin{array}{c}\text { sans } \\
\text { 外 }\end{array}$ & $\begin{array}{l}\text { 金剛頂院 } \\
\text { Kongōchō-in }\end{array}$ & $\begin{array}{l}\text { 若杉 } \\
\text { Wakasugi }\end{array}$ & $\begin{array}{l}\text { 大日如来 } \\
\text { Dainichi }\end{array}$ & $\begin{array}{l}\text { Supérieur : Usaka Kōnin 羽坂孔忍 } \\
\text { (à la tête des temples Shingon de } \\
\text { Kyūshū). Étape surnuméraire du } \\
\text { pèlerinage des } 88 \text { lieux saints de } \\
\text { Kyūshū. Statue de Fudō myōō datant } \\
\text { de l'époque Muromachi. }\end{array}$ \\
\hline $\begin{array}{c}\text { sans } \\
\text { 外 }\end{array}$ & $\begin{array}{l}\text { 䇥老ノ滝 } \\
\text { Yōrōnotaki }\end{array}$ & $\begin{array}{l}\text { 若杉 } \\
\text { Wakasugi }\end{array}$ & $\begin{array}{l}\text { 不動明王 } \\
\text { Fudō myōō }\end{array}$ & $\begin{array}{l}\text { Dans cette enceinte se trouvent le } \\
\text { Myōō-in 明王院 (faisant partie du } \\
\text { groupe des temples de l'École Shingon } \\
\text { de Kyūshū), qui est le } n^{\circ} 9 \text { des } 88 \text { lieux } \\
\text { saints du pèlerinage de Shikoku à } \\
\text { Kyūshū, et le Monju-in 文殊院 (affilié } \\
\text { à la branche du mont Kōya de l'École } \\
\text { Shingon), qui est le n⿳亠 } 24 \text { du pèlerinage } \\
\text { des } 24 \text { Jizō de Kyūshū (les deux temples } \\
\text { sont gérés par le même supérieur). }\end{array}$ \\
\hline $\begin{array}{l}\text { sans } \\
\text { 外 }\end{array}$ & $\begin{array}{l}\text { 妙福寺 } \\
\text { Myōfuku-ji }\end{array}$ & $\begin{array}{l}\text { 中町 } \\
\text { Naka- } \\
\text { machi }\end{array}$ & $\begin{array}{l}\text { 阿弥陀如来 } \\
\text { Amida }\end{array}$ & $\begin{array}{l}\text { Temple paroissial du secteur. Appelé } \\
\text { aussi Sasaguri-zan 篠栗山. Affilié à la } \\
\text { branche Nishi-Hongan-ji de l'École } \\
\text { Jōdo shin 浄土真宗西本願寺派. }\end{array}$ \\
\hline $\begin{array}{c}\text { sans } \\
\text { 外 }\end{array}$ & $\begin{array}{l}\text { 天浄一念寺 } \\
\text { Tenjōichinen-ji }\end{array}$ & $\begin{array}{l}\text { 中町 } \\
\text { Naka- } \\
\text { machi }\end{array}$ & (à vérifier) & $\begin{array}{l}\text { Affilié au Tenjô-shū 天浄宗. Fudōo } \\
\text { myōō et Benzaiten 弁財天. }\end{array}$ \\
\hline
\end{tabular}

Tableau 2 : Historique des transformations du pèlerinage de Sasaguri

\begin{tabular}{|c|c|}
\hline Année & Événement \\
\hline 1899 & $\begin{array}{l}\text { Le Nanzō-in 南藏院 du mont Kōya est transféré à Sasaguri, où il devient } \\
\text { le } \mathrm{n}^{\circ} \text { I du circuit de pèlerinage. Hayashi Kakuun 林覚運 ( } 25 \text { ans) en } \\
\text { devient le supérieur. }\end{array}$ \\
\hline 1900 & Le $\mathrm{n}^{\circ} 62$ devient un temple affilié au Shingon. \\
\hline I9OI & $\begin{array}{l}\text { Démarrage de la fonderie nationale Yawata dans le village Yawata 八幡村 } \\
\text { (Fukuoka). }\end{array}$ \\
\hline 1902 & Kido Chiryō 城戸智亮 (2I ans) entre dans le fudasho $\mathrm{n}^{\circ} 87$. \\
\hline 1904 & $\begin{array}{l}\text { Ouverture de la gare de Sasaguri et de la ligne Yoshizuka 吉塚— Sasaguri } \\
\text { par les chemins de fer de Kyūshū 九州鉄道. Le gardien de l'oratoire de } \\
\left.\text { Yakushi de Yamate ( }{ }^{\circ} \text { II }\right) \text {, Tō Kihachirō 藤喜八郎, devient maire de } \\
\text { Sasaguri (jusqu'en I9o8). Composition des « Hymnes-guides pour le } \\
\text { pèlerinage de Shikoku à Sasaguri » (Sasaguri Shikoku michibiki wasan } \\
\text { 篠栗四国導き和讃) par Kusaba Chiyokichi 草場千代吉. }\end{array}$ \\
\hline 1905 & $\begin{array}{l}\text { Ouverture de la ligne entre Sasaguri et Hakata 博多 (ville de Fukuoka). } \\
\text { Édification de la grande stèle de pierre indiquant «Chemin de } \\
\text { Shikoku » à la bifurcation de Jin-ga-dao 陣ヶ田尾. }\end{array}$ \\
\hline 1906 & $\begin{array}{l}\text { Wakako ワカコ, geisha de Hakata, devient nonne au Nanzō-in }\left(n^{\circ} \mathrm{I}\right) \text {, et } \\
\text { prend le nom d'Eryō 恵良. }\end{array}$ \\
\hline
\end{tabular}




\begin{tabular}{|c|c|}
\hline I9II & $\begin{array}{l}\text { La poétesse Yanagiwara Byakuren 柳原白蓮 (I885-1967) épouse le roi des } \\
\text { houillières du nord de Kyūshū, Itō Den.uemon 伊藤伝右衛門 (I86I-1947). }\end{array}$ \\
\hline I9I4 & $\begin{array}{l}\text { Avec l'entrée dans la première guerre mondiale, l'industrie sidérurgique } \\
\text { connaît une période de prospérité et la demande en charbon augmente. } \\
\text { Kihara Kizō 木原喜造 (I842-192I) fait dresser une stèle indiquant le che- } \\
\text { min de pèlerinage à l'entrée de l'Ichinotaki-ji一J潼寺 (n }{ }^{\circ} \text { 40) et à partir } \\
\text { de cette date, ne cesse d'investir des fonds dans le pèlerinage de Sasaguri. } \\
\text { Le temple Eifuku-in 永福院 de Shingū 新宮町 (Fukuoka) organise un } \\
\text { groupe de mille pèlerins et restaure tous les pèlerinages des } 88 \text { lieux saints } \\
\text { du nord du canton de Kasuya 糟屋 (Sasaguri, Shingū-chō et Koga-shi } \\
\text { 古賀市). }\end{array}$ \\
\hline 1915 & $\begin{array}{l}\text { Un disciple du Nanzō-in ( } \mathrm{n}^{\circ} \text { I) (originaire du département de Saga) } \\
\text { devient gardien du fudasho } \mathrm{n}^{\circ} 44 \text {, Taihō-ji 大宝寺. Shinkō 真光, ancienne } \\
\text { prostituée de Hakata, qui était devenue nonne au Nanzō-in, devient } \\
\text { gardienne du } n^{\circ} 28 \text {, Sasaguri kōen Dainichi-ji 篠栗公園大日寺. }\end{array}$ \\
\hline 1916 & $\begin{array}{l}\text { Des fidèles de Hakata font don de la statue principale dorée de l’oratoire } \\
\text { de Kannon de Takata 高田観音堂 }\left(\mathrm{n}^{\circ} 69\right) \text {. Le } \mathrm{n}^{\circ} 79 \text {, Yamate Amida-dō } \\
\text { 山手阿弥陀堂, est transféré à l'auberge Ebisuya 惠比須屋. }\end{array}$ \\
\hline vers 1918 & $\begin{array}{l}\text { Jikō 慈光, qui était devenue nonne au Nanzō-in, devient gardienne du } \\
n^{\circ} \text { I4, Ninotaki-ji 二ノ滝寺. }\end{array}$ \\
\hline 1919 & $\begin{array}{l}\text { Période de prospérité exceptionnelle à Fukuoka. Tous les jours ont lieu } \\
\text { des banquets regroupant ceux qui se sont enrichis avec les houillières } \\
\text { (jusqu'en 1920). }\end{array}$ \\
\hline 1920 & $\begin{array}{l}\text { Des fidèles de Hakata font don de la statue principale dorée du n }{ }^{\circ} 67 \text {, } \\
\text { Sannō Yakushi-dō 山王薬師堂, et de celle du Grand Mâttre peinte. }\end{array}$ \\
\hline I92I & $\begin{array}{l}\text { Le } n^{\circ} 62 \text {, Henshō-in 遍照院, dresse la plus grande statue du Japon du } \\
\text { Grand Maître en pratiques (bronze, } 13 \mathrm{~m}, 23 \text { tonnes). }\end{array}$ \\
\hline 1922 & $\begin{array}{l}\text { Édification à Yamate de la statue de bronze de Kihara Kizō 木原喜造 et } \\
\text { de la stèle en son honneur. }\end{array}$ \\
\hline 1923 & 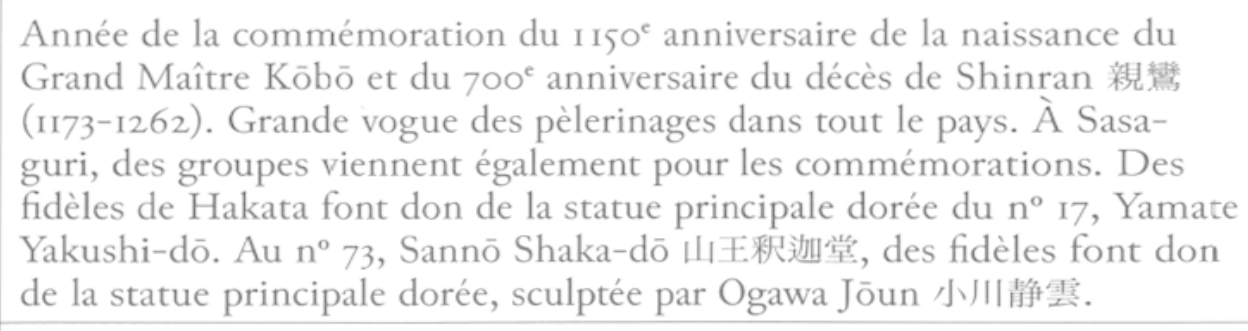 \\
\hline 1924 & $\begin{array}{l}\text { Publication du "Guide des sites célèbres et des lieux saints de Sasaguri » } \\
\text { (Sasaguri meisho reijo annai 篠栗名所霊場案内) (texte de Kaneko Jōkō } \\
\text { 金子常光, Tō Kiyoshi 藤清, éd.). Des fidèles font don de la statue princi- } \\
\text { pale dorée du n }{ }^{\circ} 57 \text {, Ta-no-ura Eifuku-dō 田ノ浦栄福堂. }\end{array}$ \\
\hline 1926 & $\begin{array}{l}\text { Début des hymnes du Kongō-ryū (Kongō-ryū go-eika 金剛流御詠歌) au } \\
\text { mont Kōya. Â l'oratoire de Kannon de Takata }\left(n^{\circ} 69\right) \text {, des fidèles font } \\
\text { don d'une seconde statue principale dorée. }\end{array}$ \\
\hline 1927 & $\begin{array}{l}\text { Des fidèles de Hakata font don de la statue principale dorée du } \mathrm{n}^{\circ}{ }_{53} \text {, } \\
\text { Kiri-no-dani Amida-dō 桐) 谷阿弥陀堂, de ses deux parèdres et d'un } \\
\text { oratoire aux Treize Bouddhas. }\end{array}$ \\
\hline
\end{tabular}




\begin{tabular}{|c|c|}
\hline 1930 & $\begin{array}{l}\text { À l'oratoire de Kanon de Takata }\left(\mathrm{n}^{\circ} 69\right) \text {, des fidèles font don d'une sta- } \\
\text { tue dorée de Kannon qui accorde des enfants. Création au mont Kōya du } \\
\text { bureau pour l'organisation de la commémoration du IIOo anniversaire } \\
\text { du décès du Grand Maître Kōbō. }\end{array}$ \\
\hline 1932 & $\begin{array}{l}\text { Matsuo Kimie 松尾キミア, membre de la confrérie du Grand Maître du } \\
\text { mont Kōya, fait le pèlerinage de Sasaguri. Des fidèles de Hakata font } \\
\text { don de la statue principale dorée du } n^{\circ} 65 \text {, Sankaku-ji 三角寺. }\end{array}$ \\
\hline I933 & $\begin{array}{l}\text { Mise en application des « Règles des } 88 \text { lieux saints du nouveau Shikoku } \\
\text { de Sasaguri et règlements de leur comité »(Sasaguri Shin-Shikoku } \\
\text { bacbijū bakka-sho reijō kisoku oyobi iinkai kitei 篠栗新四国八十八ヶ所霊 } \\
\text { 場規則及委員会規定). Une confrérie de fidèles de Hakata fait don du } \\
\text { bâtiment principal du } n^{\circ}{ }^{3} \text {, Honmyō-in 本明院. }\end{array}$ \\
\hline I934 & $\begin{array}{l}\text { Commémoration du I Iоo anniversaire du décès du Grand Maître Kōbō. } \\
\text { Grande vogue des nouveaux pèlerinages de Shikoku dans tout le pays. }\end{array}$ \\
\hline 1935 & 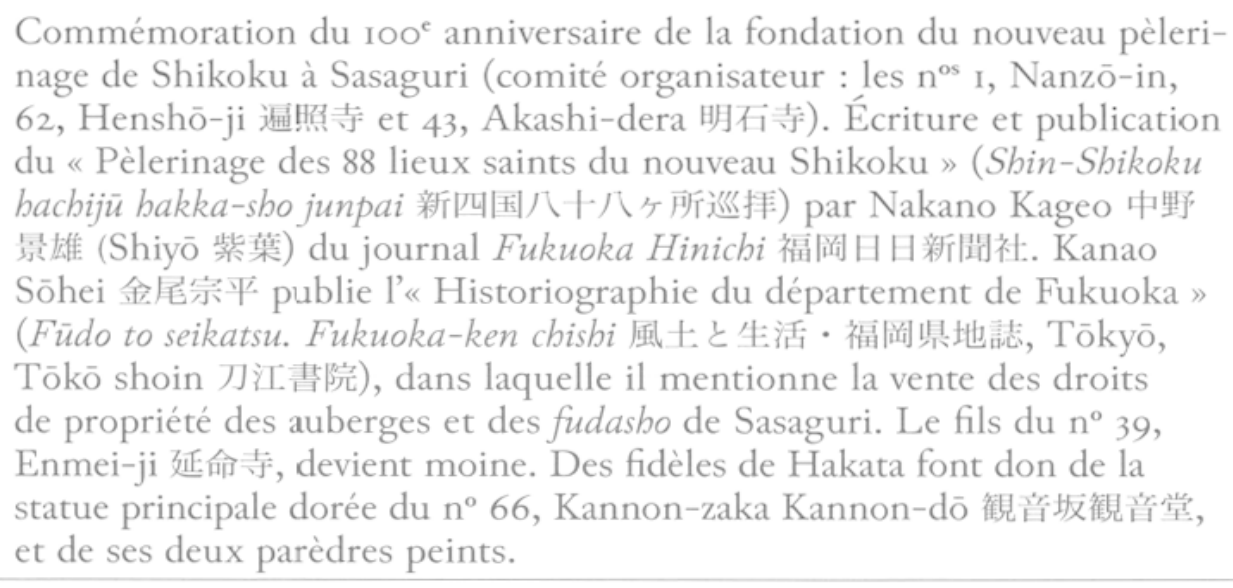 \\
\hline 1936 & $\begin{array}{l}\text { Rédaction de la « Liste des gardiens d'oratoire. Pour les membres du } \\
\text { comité »(Shudōsha meibo. Iinchō-yō 守堂者名簿 委員長用) (Archives de } \\
\text { la famille Kiryū 桐生家文書). }\end{array}$ \\
\hline vers 1937 & $\begin{array}{l}\text { Publication des « Hymnes du pèlerinage du Shikoku à Sasaguri » (Sasa- } \\
\text { guri Shikoku junpai wasan 篠栗四国巡洋和讃). }\end{array}$ \\
\hline I940 & $\begin{array}{l}\text { Installation dans l'oratoire de Kannon de Torigoe 鳥越観音堂 ( } \mathrm{n}^{\circ} 82 \text { ) } \\
\text { de la statue principale sculptée par le supérieur du Hongyô-in 本行院 } \\
\text { (canton de Chikushi 筑紫郡). }\end{array}$ \\
\hline 1942 & 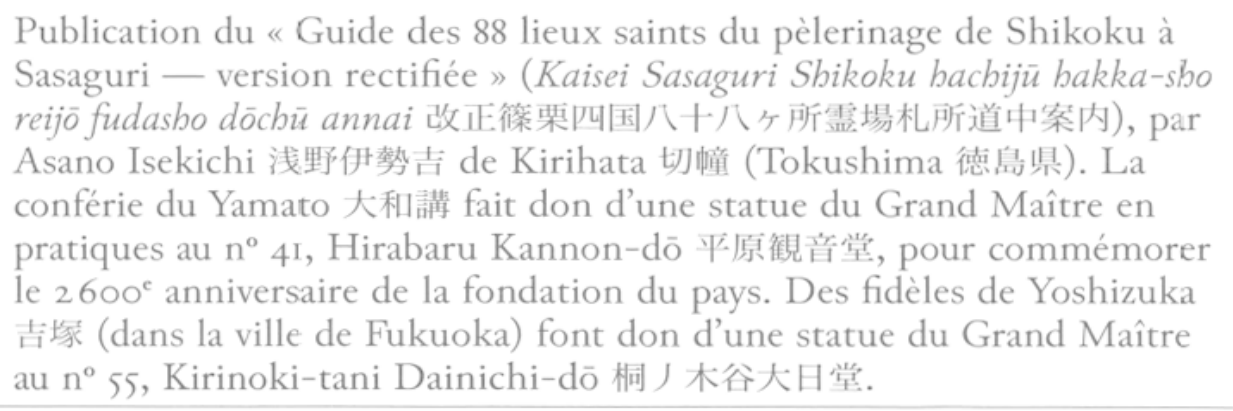 \\
\hline I943 & $\begin{array}{l}\text { Des fidèles de Wakamatsu construisent un oratoire du Grand Maître au } \\
n^{\circ} 53 \text {. }\end{array}$ \\
\hline 1945 & $\begin{array}{l}\text { Le Sanbō-in 三宝院 du mont Kōya décerne le nom de Sankaku-ji 三角寺 } \\
\text { au n }{ }^{\circ} 65 \text {. }\end{array}$ \\
\hline
\end{tabular}




\begin{tabular}{|c|c|}
\hline vers 1947 & La nonne Eryō 惠良 fonde le Kirihata-ji 切幢寺 ( $n^{\circ}$ IO). \\
\hline I948 & $\begin{array}{l}\text { Hayashi Kakuga 林覚雅, supérieur du Nanzō-in }\left(\mathrm{n}^{\circ} \mathrm{I}\right) \text {, termine ses } \\
\text { études à l'universitè du mont Kōya et devient instituteur à l'école pri- } \\
\text { maire de Sasaguri. }\end{array}$ \\
\hline 1950 & $\begin{array}{l}\text { Reconstruction de la statue de Fujiki Tōsuke 藤木藤助. Publication de la } \\
\text { «Carte simplifiée du pèlerinage de Sasaguri » (Junpai ryakuzu Sasaguri } \\
\text { reijō meguri 巡拝略図・篠栗雲場巡り) par Asano Isekichi 浅野伊勢吉. Le } \\
\mathrm{n}^{\circ} 70 \text { est transféré à la cascade de Gotō 五塔ノ滝. }\end{array}$ \\
\hline $195 \mathrm{I}$ & $\begin{array}{l}\text { Publication du « Guide des beaux sites de Sasaguri » (Sasaguri meisho } \\
\text { annai. Sasaguri 篠栗名所案内・篠慗). }\end{array}$ \\
\hline 1952 & $\begin{array}{l}\text { Mōri Jundō 毛利純堂 fait don d'une peinture monumentale du Grand } \\
\text { Maître au } n^{\circ} 52 \text {, Yamate Kannon-dō 山手観音堂. }\end{array}$ \\
\hline 1953 & $\begin{array}{l}\text { Les pluies violentes provoquent } 6 \text { décès à Sasaguri. Don d'une stèle en } \\
\text { l'honneur de Fujiki Tōsuke au n }{ }^{\circ} 24 \text {, Nakano Kōchi Kokūzō-dō 中ノ河 } \\
\text { 内虚空藏堂, par des fidèles (Kanazawa Nagisa 金澤渚, et d'autres) pour } \\
\text { commémorer le } 120^{\mathrm{e}} \text { anniversaire de la fondation du pèlerinage de Sasa- } \\
\text { guri. Le no }{ }^{\circ} 87 \text { devient un temple, le Kōshō-in 弘照院 (affilié au Shingon } \\
\text { du mont Kōya). }\end{array}$ \\
\hline 1954 & $\begin{array}{l}\text { Publication des « Règlements des lieux saints de Shikoku à Sasaguri » } \\
\text { (Sasaguri Shikoku reijō kisoku 篠栗四国霊場規則). }\end{array}$ \\
\hline 1955 & $\begin{array}{l}\text { Publication de la «Carte du pèlerinage des lieux saints de Sasaguri » } \\
\text { (Sasaguri reijō junpai-zu 篠栗霊場巡拝図) par l'office du tourisme } \\
\text { municipal de Sasaguri. Un supérieur venu du mont Kōya entre au no }{ }^{\circ} \text { I } 4 \text {, } \\
\text { Ninotaki-ji. Le nº } 39 \text {, Enmei-ji, devient un temple affilié au Shingon du } \\
\text { mont Kōya. }\end{array}$ \\
\hline 1957 & $\begin{array}{l}\text { Le } \mathrm{n}^{\circ} \text { 26, Arata Dai-ji 荒田大寺, est transféré à la buvette Chika-michi } \\
\text { 近道茶屋. Vol de la statue principale de l'oratoire d'Amida de Yamate } \\
\text { 山手阿弥陀堂 }\left(\mathrm{n}^{\circ} 78\right) \text { qui est vendue à un antiquaire. }\end{array}$ \\
\hline 1959 & $\begin{array}{l}\text { Stèle érigée en l'honneur du fondateur du pèlerinage de Sasaguri, Fujiki } \\
\text { Tōsuke, et de I9 autres de ses collaborateurs. }\end{array}$ \\
\hline 1960 & $\begin{array}{l}\text { Le } \mathrm{n}^{\circ} 25 \text { est transféré au Shūzen-ji 秀善寺. Le } \mathrm{n}^{\circ} 60 \text { est transféré depuis } \\
\text { l'auberge-buvette Yoshino-ya 吉野屋 au } \mathrm{n}^{\circ} \text { I2, la cascade de Chizuru 千鶴 } \\
\text { ケ潼, où s'est installée une nonne, disciple du supérieur de ce même } \\
\text { temple. }\end{array}$ \\
\hline I96I & 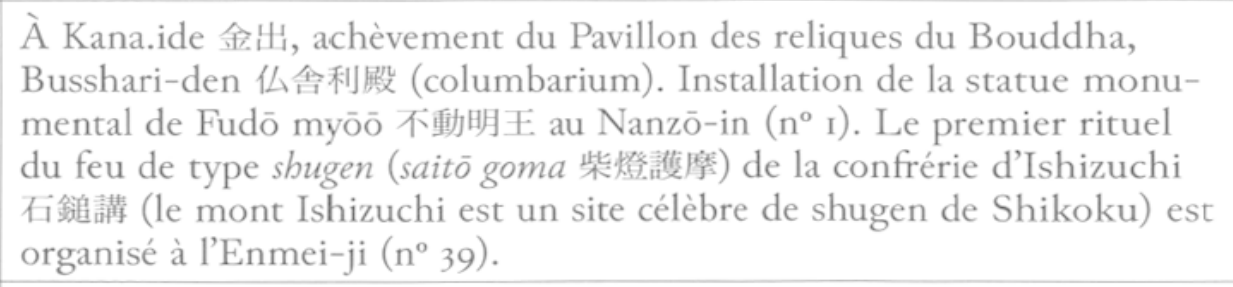 \\
\hline 1962 & $\begin{array}{l}\text { Le } n^{\circ} \text { I4 devient un temple, le Ninotaki-ji 二ノ潼寺. Le } \mathrm{n}^{\circ} \text { I2 est trans- } \\
\text { féré au centre de pratiques de la cascade de Chizuru affilié au shugen du } \\
\text { mont Ishizuchi. A l'Enmei-ji 延命寺 }\left(\mathrm{n}^{\circ} 39\right) \text {, est créée, comme lieu de } \\
\text { pratiques, la cascade de Fudō. Des fidèles de la commune Ukiha 浮羽町 } \\
\text { (département de Fukuoka) font don d'un oratoire du Grand Maître et } \\
\text { d'une statue de celui-ci. }\end{array}$ \\
\hline
\end{tabular}




\begin{tabular}{|c|c|}
\hline 1965 & $\begin{array}{l}\text { Diffusion par la chaîne TBS du téléfilm Plus profond que la mer (海より } \\
\text { 深き—かさぶた式部考) d'Akimoto Matsuyo 秋元松代 qui a pour décor le } \\
\text { pèlerinage de Sasaguri, dans lequel l'actrice Minamida Yōko 南田洋子 joue } \\
\text { le rôle de la nonne Chishū 智修. Tō Kiyoshi et Hayashi Kakuga lancent } \\
\text { l'aménagement de la pruneraie Keikō-en 敬光園梅林. Entrée d'un supé- } \\
\text { rieur venant du mont Kōya au no I6 qui devient un temple, le Kannon-ji } \\
\text { de Nomiyama 呑山観音寺. }\end{array}$ \\
\hline 1966 & $\begin{array}{l}\text { Grande commémoration du } 130^{\mathrm{e}} \text { anniversaire de la fondation du pèle- } \\
\text { rinage des lieux saints de Shikoku à Sasaguri. Publication du «Manuel } \\
\text { simplifié de l'histoire de Sasaguri » (Sasaguri shōshi benran 篠栗小史便覧) } \\
\text { par la Société des amis de la protection des sites historiques (Shiseki } \\
\text { hozon dōkō-kai 史跡保存同好会), entreprise soutenue par le supérieur du } \\
\text { Nanzō-in, Hayashi Kakuga 林覚雅, alors président du comité municipal } \\
\text { d'éducation. }\end{array}$ \\
\hline 1968 & $\begin{array}{l}\text { Pour commémorer le } \text { Ioo }^{\mathrm{e}} \text { anniversaire de l'ère Meiji, ouverture de la } \\
\text { prolongation de la ligne de Sasaguri jusqu'à la gare de Katsuragawa } \\
\text { 桂川駅. Les locomotives à vapeur sont remplacées par des machines diesels. } \\
\text { Ouverture de la gare de Kido, Kido Nanzō-in mae 城戸南蔵院前駅. } \\
\text { Augmentation du nombre de pèlerins qui commencent le circuit de } \\
\text { pèlerinage par le Nanzō-in }\left(n^{\circ}{ }_{1}\right) \text {. }\end{array}$ \\
\hline vers 1969 & $\begin{array}{l}\text { Le Kannon-ji de Nomiyama ( }{ }^{\circ} \text { i6) transfère au no } 36 \text { le temple } \\
\text { Tennō-in 天王院 du mont Kōya. }\end{array}$ \\
\hline 1970 & $\begin{array}{l}\text { Le célèbre auteur de manga Tsuge Yoshiharu つげ義春 (né en 1937) } \\
\text { fait le pèlerinage de Sasaguri pour la revue photographique Asabi } \\
\text { Gurafủ アサグラフ, et publie des photos de Sasaguri. Le supérieur du } \\
\text { Nanzō-in, Hayashi Kakuga, devient président de l'annexe du Shingon du } \\
\text { mont Kōya à Fukuoka (jusqu'en 1977). }\end{array}$ \\
\hline I97I & $\begin{array}{l}\text { Plantation de } 600 \text { camélias à la cascade de Gotō par Tō Kiyoshi, Hayashi } \\
\text { Kakuga et le maire Nagasawa 長澤町長. }\end{array}$ \\
\hline 1972 & $\begin{array}{l}\text { Publication de la «Carte touristique des lieux saints de Sasaguri » (Sasa- } \\
\text { guri reijō kankō annai-zu 篠栗霊場観光案内図). }\end{array}$ \\
\hline 1973 & $\begin{array}{l}\text { Le supérieur du Nanzō-in, Hayashi Kakuga, reçoit le prix du mérite pour } \\
\text { l'éducation et la culture du département de Fukuoka. Début de la série } \\
\text { d'articles «Le bâton et le chapeau (de pèlerin)» (Tsue to kasa 杖と笠) par } \\
\text { Yamamoto Hōryū 山本宝隆, supérieur du Hōzan-ji 宝山寺 ( }{ }^{\circ} \text { 34), dans le } \\
\text { Bulletin municipal de Sasaguri (Sasaguri-chō kōhō 花栗町広報). De violentes } \\
\text { pluies provoquent } 6 \text { décès à Sasaguri. }\end{array}$ \\
\hline vers 1975 & $\begin{array}{l}\text { Miyake Myōshū 三宅妙秀 (ordonnée au mont Ishizuchi) devient gardienne } \\
\text { du n } 28 \text {, Sasaguri kōen Dainichi-ji. }\end{array}$ \\
\hline 1976 & $\begin{array}{l}\text { Publication du « Circuit des } 88 \text { stations de Sasaguri, lieux saints de } \\
\text { Chikuzen " (Sasaguri hachijü hakka-sho. Chikuzen no reijō meguri 篠栗八 } \\
\text { 十八力所・筑前の霊場めぐり) par Hirahata Ryōyū 平幡良雄 (de l'Iinuma } \\
\text { Kannon 飯沼観音, } \mathrm{n}^{\circ} 27 \text { du pèlerinage du Bandō 坂東三十三観音, dépar- } \\
\text { tement de Chiba 千葉県). Le } \mathrm{n}^{\circ} 83 \text { est transféré de Kido au Senju-in } \\
\text { 千手院 d'Ondawara 御田原. }\end{array}$ \\
\hline I977 & $\begin{array}{l}\text { Commémoration du } 150^{\mathrm{c}} \text { anniversaire de la fondation du pèlerinage de } \\
\text { Shikoku à Sasaguri. } 50^{\mathrm{c}} \text { anniversaire de la création de la municipalité de } \\
\text { Sasaguri. }\end{array}$ \\
\hline
\end{tabular}




\begin{tabular}{|c|c|}
\hline 1980 & $\begin{array}{l}\text { Publication de la «Carte touristique des lieux saints de Shikoku à Sasa- } \\
\text { guri » (Sasaguri Shikoku reijō annai-zu 篠栗四国霊場観光案内図). }\end{array}$ \\
\hline I98I & $\begin{array}{l}\text { Achèvement du «parcours d'orientation de Kido » (オリエンテーリング } \\
\text { 城戸コース). }\end{array}$ \\
\hline 1982 & $\begin{array}{l}\text { Édification d'une statue monumentale du Grand Maître au Sannō-ji } \\
\text { 山王寺 }\left(n^{\circ} \text { 6I). }\right.\end{array}$ \\
\hline 1983 & $\begin{array}{l}\text { Le } n^{\circ} 74 \text {, Kido Yamaitori Yakushi-dō 城戸病奪り薬師堂, est transféré et } \\
\text { cédé à la buvette des Biscuits du Grand Maitre, Daishi senbei chaya 大師 } \\
\text { せんべい茶屋. }\end{array}$ \\
\hline I984 & $\begin{array}{l}\text { I I } 50^{\mathrm{c}} \text { anniversaire de la mort du Grand Maître Kōbō. Grande vogue des } \\
\text { nouveaux pèlerinages de Shikoku dans tout le pays. Plusieurs temples du } \\
\text { pèlerinage de Sasaguri adhèrent puis se retirent aussitôt de l'organisation } \\
\text { des } 88 \text { lieux saints de Kyūshū (Kyūshū hachijū hakka-sho reijō 九州八 } \\
\text { 十八ヶ所霊場, présidée par le supérieur du Ninna-ji 仁和寺 de Kyōto). } \\
\text { Entrée au no }{ }^{\circ} \text {, Sasaguri kōen Dainichi-ji, de Shōzaki Ryōsei 泩崎良清, } \\
\text { ordonnée au Nanzō-in. Le fils de l'oratoire de Yakushi d'Arata (nº 26) } \\
\text { devient moine au mont Kōya. Le no }{ }^{\circ} 60 \text {, Jinpen-ji 神変寺, devient une } \\
\text { annexe du Nanzō-in. }\end{array}$ \\
\hline 1985 & $\begin{array}{l}\text { Ouverture de la déviation de la nationale 2or par le mont Yagi 八木山. } \\
\text { Achèvement de «Kannon des fleurs 》 (Hana Kannnon 花観音), une image } \\
\text { du bodhisattva Kannon faite avec des arbres florifères. Un disciple du } \\
\text { Nanzō-in devient supérieur du Raion-ji 雷音寺 }\left(n^{\circ} \text { 49). Le no } 85 \text { devient }\right. \\
\text { un temple, le Soshōdai-ji 祖聖大寺 (affilié au Shingon du mont Kōya). }\end{array}$ \\
\hline I986 & 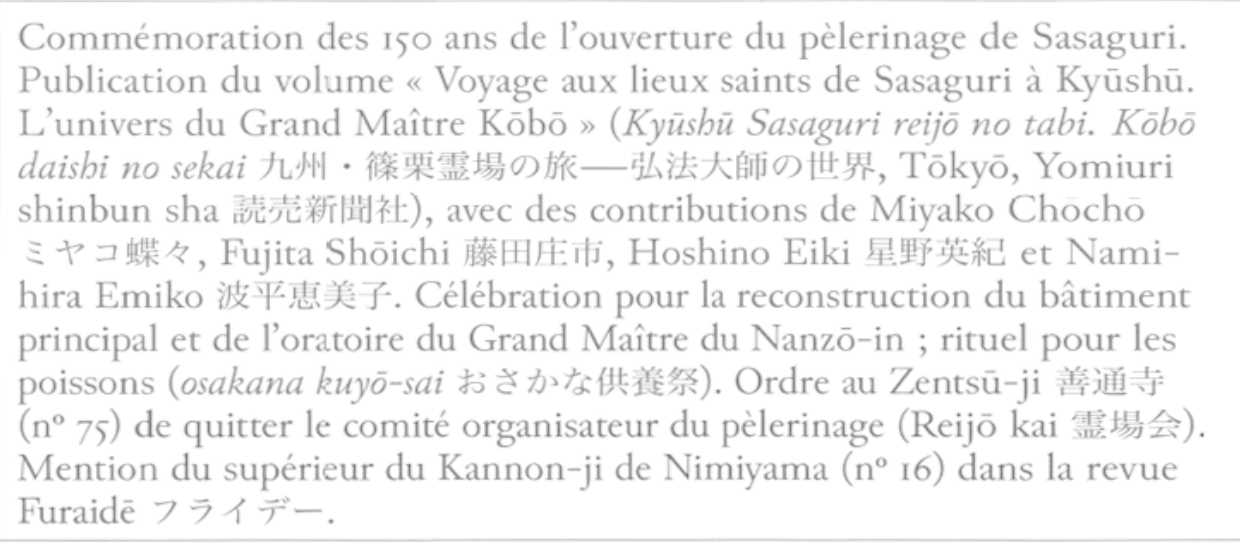 \\
\hline 1987 & $\begin{array}{l}\text { Le supérieur du Zentsū-ji 善通寺 }\left(\mathrm{n}^{\circ} 75\right) \text {, Nomiyama Kakuō 野見山覚応, } \\
\text { intente un procès au comité organisateur du pèlerinage devant le tribunal } \\
\text { de première instance de Fukuoka. }\end{array}$ \\
\hline 1988 & $\begin{array}{l}\text { Don au Nanzō-in de reliques de Shakyamuni, d'Anan 阿難 (Ānanda) } \\
\text { et de Mokuren 目蓮 (Maudgalyayana) par un dignitaire bouddhique du } \\
\text { Myanmar. Le } n^{\circ} 79 \text { devient un temple, le Fudaraku-ji 補陀洛寺 (affilié } \\
\text { au Shingon du mont Kōya). }\end{array}$ \\
\hline 1989 & $\begin{array}{l}\text { Décès de Hayashi Kakuga, second supérieur du Nanzō-in. Le Kannon-ji } \\
\text { de Nomiyama est nommé «Centre votif général du pèlerinage " (Reijō } \\
\text { sō-kigan-sho 霊場総祈願所) dans le journal Nishi Nippon sbinbun 西日本 } \\
\text { 新聞. }\end{array}$ \\
\hline 1992 & $\begin{array}{l}\text { Achèvement d'un columbarium d'une capacité de rooooo urnes au } \\
\text { Nanzō-in. }\end{array}$ \\
\hline
\end{tabular}




\begin{tabular}{|c|c|}
\hline 1993 & $\begin{array}{l}\text { Publication de «Pèlerinage des } 88 \text { lieux saints de Sasaguri » (Sasaguri } \\
\text { bachijū hakka-sho reijō meguri 篠栗八十八力所霊場めぐり) par Ino.ue } \\
\text { Masaru 井上優 et «Le pèlerinage de Sasaguri » (Sasaguri henro 篠栗遍路) } \\
\text { par Hirahata Ryōyū 平幡良雄. Le } \mathrm{n}^{\circ} 75 \text {, Zentsū-ji, fait appel auprès de la } \\
\text { Cour suprême. }\end{array}$ \\
\hline 1994 & $\begin{array}{l}\text { Révision des règlements du comité organisateur (Reijō-kai) du pèleri- } \\
\text { nage de Sasaguri (en vigueur à partir de I995). }\end{array}$ \\
\hline 1995 & $\begin{array}{l}\text { Après l'affaire du gaz sarin lancé dans le métro de Tōkyō par la secte } \\
\text { Aum, renforcement de la méfiance et du rejet religieux dans la popu- } \\
\text { lation. Clôture du procès du } \mathrm{n}^{\circ} 75 \text {, Zentsū-ji ; l'existence de deux } \mathrm{n}^{\circ} 75 \\
\text { sur le circuit est acceptée. Achèvement de la statue du monumental } \\
\text { Bouddha couché au Nanzō-in et cérémonie des mille moines. Le } \\
\text { supérieur gagne } 130 \text { millions de yens à la loterie. Transfert du n } \mathrm{n}^{\circ} \text { I5 au } \\
\text { Myōon-ji 妙音寺 et du n } \mathrm{n}^{\circ} 60 \text {, Jinpen-ji, au Nanzō-in. }\end{array}$ \\
\hline 1996 & $\begin{array}{l}\text { Sur les indications du Hōman-dō 宝満堂 de Sue 須恵町 (département } \\
\text { de Fukuoka) (représenté par Yamashita Yōmiko 山下陽美子), l'《 eau de } \\
\text { Yakushi » (Yakushi-sui 薬師水) de l'oratoire de Yakushi d'Ōkubo 大久保 } \\
\text { 薬師堂 est nommée 《e eau de vitalité » (genki-sui 元気水). }\end{array}$ \\
\hline 1997 & $\begin{array}{l}\text { Le comité organisateur du pèlerinage installe un nouvel oratoire } \mathrm{n}^{\circ} 75 \text { à } \\
\text { la cascade des Érables pourpres, Momiji-ga-taki 紅葉ヶ滝 }\left(\text { ancien } n^{\circ} 34\right) \\
\text { dans l'enceinte du Hōzan-ji 宝山寺 à Gō-no-haru 郷/原 }\left(\text { actuel n }{ }^{\circ} 34\right) \text {. }\end{array}$ \\
\hline 1998 & Le $n^{\circ}{ }_{51}$ est transféré au Fudaraku-ji 補陀落寺 $\left(n^{\circ} 79\right)$. \\
\hline 1999 & $\begin{array}{l}\text { Production de la vidéo “Sasaguri, lieux saints 》 (Reijō Sasaguri. Ikit- } \\
\text { eyuku koto, ikasareru koto 霊場篠栗—生きてゆくこと 生かされること) } \\
\text { (Kurume 久留米市). }\end{array}$ \\
\hline 2000 & $\begin{array}{l}\text { Publication de «Bouddhas. Les trois grands nouveaux (pèlerinages de) } \\
\text { Shikoku du Japon. L’univers des bouddhas dans les } 88 \text { lieux saints de } \\
\text { Sasaguri » (Busson. Nibon san-dai Shin-Shikoku. Sasaguri reijō bachijū } \\
\text { hakka-sho ni miru Busson no sekai 仏尊—日本三大新四国 篠栗霊場八十 } \\
\text { 八ヶ所に見る仏尊の世界, Fukuoka, Tōka shobō 櫂歌書房), vendu avec la } \\
\text { vidéo précédente. }\end{array}$ \\
\hline vers 2002 & Kirihata-ji $\left(n^{\circ}\right.$ IO) transforme sa tour reliquaire en columbarium. \\
\hline 2003 & Le $\mathrm{n}^{\circ} 8$ est transféré à la cascade Kongō 金剛の滝観音堂. \\
\hline 2005 & $\begin{array}{l}\text { Commémoration du } 170^{\mathrm{e}} \text { anniversaire de la fondation du pèlerinage de } \\
\text { Shikoku à Sasaguri et du } 20^{\mathrm{e}} \text { anniversaire de la formation de l'Associa- } \\
\text { tion Hōsei-kai 法青会. }\end{array}$ \\
\hline 2006 & $\begin{array}{l}\text { Célébration du I } 200^{\mathrm{e}} \text { anniversaire de la venue du Grand Mâitre Kōbō } \\
\text { sur le mont Wakasugi 若杉山 par l'Association Wakasugi Reihō-kai 若杉 } \\
\text { 霊峰会. Cérémonie pour l'inauguration de la statue de Fujiki Tōsuke. } \\
\text { Grand rite du feu (saitō dai-goma ku 柴燈大護摩供) pour célébrer le } 170^{\mathrm{e}} \\
\text { anniversaire de la fondation du pèlerinage de Shikoku à Sasaguri. Après } \\
\text { la fermeture de l'auberge et l'ouverture d'un restaurant, l'oratoire de } \\
\text { Kannon de Kido 城戸千手観音堂 }\left(\mathrm{n}^{\circ} 7 \mathrm{I} \text { ) est transféré. }\right.\end{array}$ \\
\hline
\end{tabular}


Document I : L'origine du pèlerinage : inscription gravée sur la stèle de pierre de la roche Heike (oratoire de Fudó à la cascade de Kido $n^{\circ} 45$ )

(竿石部分の銘)

南無弘法大師遍照金剛

南

\section{抑新四國八十八ヶ所}

(台座部分の銘)

石碑建立世話

桐生源四郎

同 権七

井上儀平

松尾善二郎

吉富次三郎

桐生利七

印作次郎

藤野甚平

井上伊作

桐生安次郎

井上仁三郎

長濱彦三郎

印清右ㄱ門

桐生利三郎

江良德平

藤原善六

藤原善藏

藤野隈太郎

松尾文右卫門

藤原善助

藤野甚五郎

印助次郎

畑江又助

大谷次七

藤野甚四郎

葉山兵次郎

井上儀右卫門

藤 儀八

古屋藤七

藤 丈七

吉富与四郎

桐生茂吉

西 久次郎

江良新藏

同 平藏

桐生利吉

嘉永七年

當村話

松尾善吉 十

井上直平

藤木藤助

村瀬新平 年

甲寅閏七月吉日

有隅文助

高城天順

安楽寺住職

石工

月浦茂吉 


\section{Document 2 : Historique de l'édification de la stèle de la roche Heike, par Kiryū Genshirōo (archive de la famille Kiryū no ${ }^{\circ}$ )}

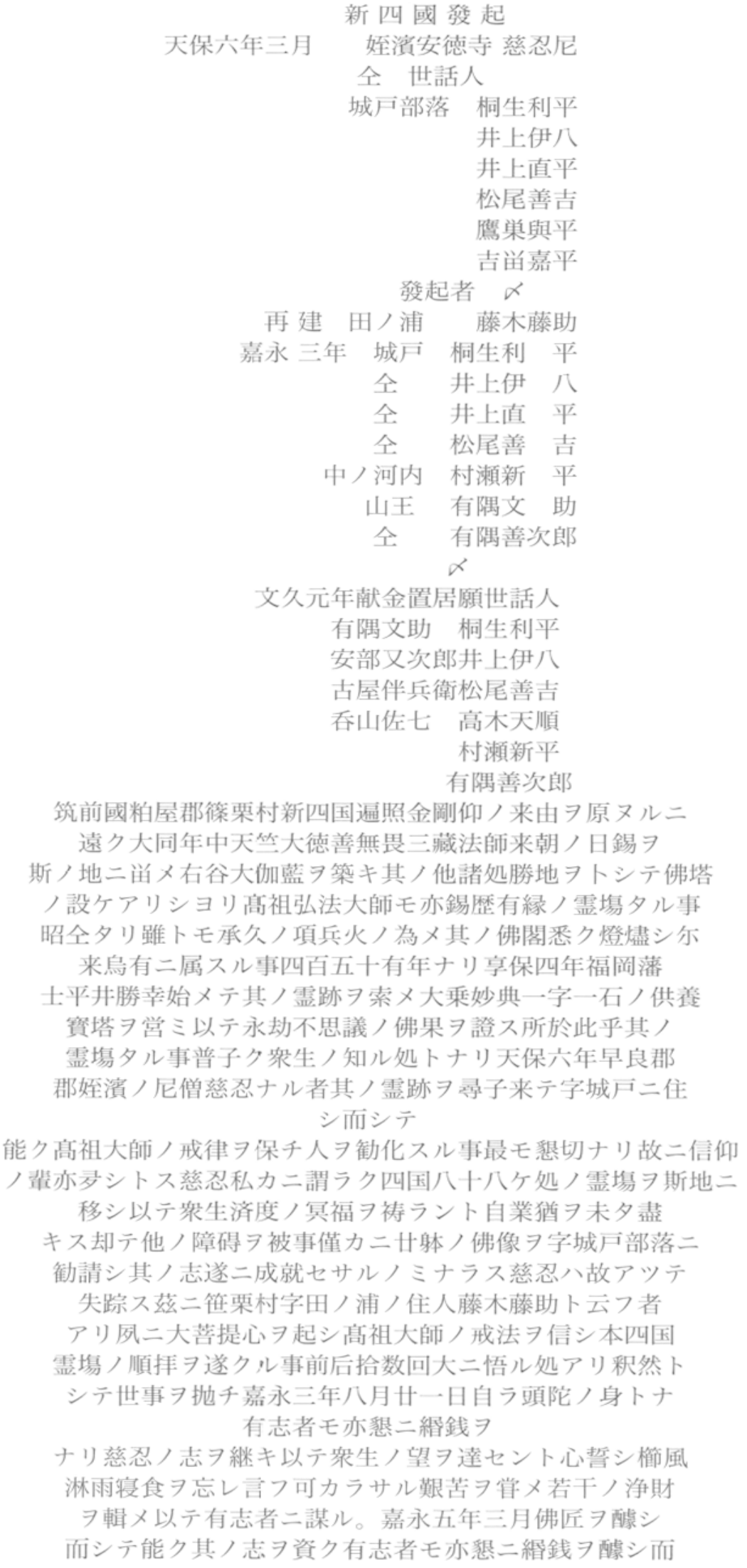

$$
\text { シ而シテ }
$$

能ク高祖大師ノ戒律 保チ人 ノ輩亦寻シトス慈忍私力二謂ラク四国八十八ケ処ノ霊堛

移シ以テ鼻生済度ノ冥福习䘠ラント自業猶习未夕盡 キス却テ他ノ障碍ヨ被事僅力二廿躭ノ佛像 勧請シ其ノ志遂二成就七サルノミナラス慈忍ハ故アッテ

失踪又茲二笹栗村字田ノ浦ノ住人藤木藤助卜云つ者

アリ夙二大菩提心 $\exists$ 起シ高祖大師ノ戒法 7 信シ本四国 霊場ノ順拝 シテ世事习抛千嘉永三年八月廿一日自ラ頭陀ノ身トナ 有志者モ亦留二悢銭

ナリ慈忍ノ志ヨ継キ以テ衆生ノ望习達セント心誓シ櫛風

淋雨寝食ヨ忘レ言フ可カラサル艱苦ヨ嘗メ若干ノ浄財

ヨ輯メ以テ有志者二謀ル。嘉永五年三月佛匠 $ᄏ$ 醵シ

而シテ能ク其ノ志 $习$ 資ク有志者乇亦懇二䋎銭 7 醵シ而 
シテ能ク其ノ志习資ク嘉永五年三月佛匠ヨ雇テ彫工ヨ 起シ安政二年二月二至り殆卜三年星霜习閲シ其ノ成効

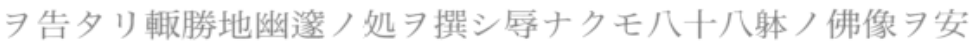

置スル事 $习$ 得藤助外有志者ノ勧喜又力加ヘシ乎時二藤 助路命七還暦 7 起千超へ気剛尚ホ撓マス同年五月十七日満願 成就ノ意 以テ本四國霊塲最終ノ順拝ヨ遂ケン事

期ス又夕随喜ヨ求ムル者アリ則平井清右門古屋藤三萩 尾與平阿部又次郎萩尾仁平ノ五子ニシテ是皆当 時有志者トシテ専ラ週旋ノ労习煩ハシタル者ナリ藤 助大二力 7 得欣然與俱二起千弘誓ノ舟 $习$ 棹シ彼国二 航ヌルヤ順次八十八ヶ処ノ霊塲二詣テ輙千霊土ヨ請シテ 之レヨ布囊二納レ全年七月三日恙ナク的航ス全十六日 請持夕ル処霊土 $习$ 我篠栗村新四國八十八之金剛 佛躱中二恭シク安置シ全十八日ニ終ル是ニヨリ霊験 日二著シク今二至ツテ猶ホ轉展随ノ信者八無量ノ 数 加へ賽客本四国二譲ラス是ノ繁昌能ク人ノ知 ル処ナリ矣鳴呼始又藤助ノ此ノ志 $习$ 起シ永劫中興開 基ノ声譽习得夕ル以前ノモノ八或夜夢二異人二逢つ 異人告テ曰汝ノ身二災厄アリ運命己二薄ル須ラク金 剛佛ヨ的命シテ其ノ難ヨ避クヘシト夢覺メテ心事尚ホ 恍惚諸佛ノ身ヨ圍繞セラレ殺気ノ以テ侵ス能ハサル

観シ感泣己レ 忘レ突然佛恩報謝ノ意 体

习体一念發起シテ止マス身 7 難行八門二寄七願 望成就ス卜雖モ其ノ命終ニ久シカラス安政六年七月 十一日卒ス行年六十四湓シテ得忍卜号ス維年明治廿六 年七月有志者相謀リ藤助ノ碩徳 7 追遠シ

茲二石 樹テ粗ホ其ノ来由习録シ以テ紀念卜為ス 卜云是辞二日

得忍佛性永福的冥昭々事蹟 悠々心霊 一世求道 萬劫残銘 内川愛道撰 


\section{Document 3 : Inscription de la stèle commémorant l'ouvre de Fujiki Tōsuke}

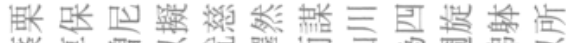

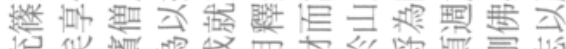

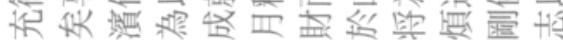

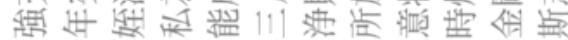

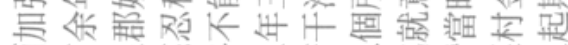

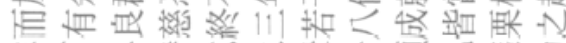

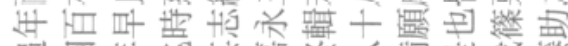

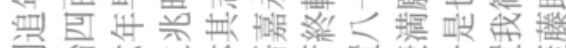

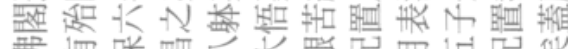

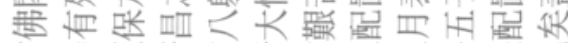

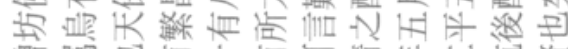

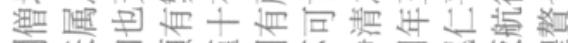

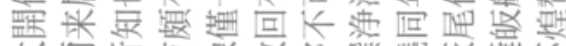

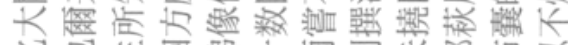

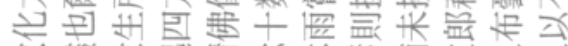

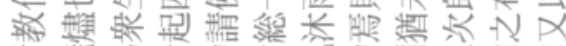

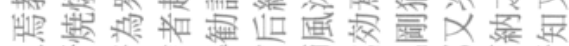

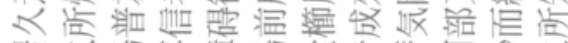

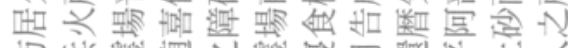

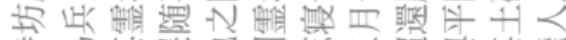

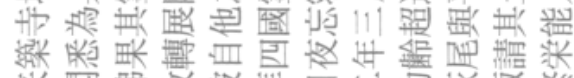

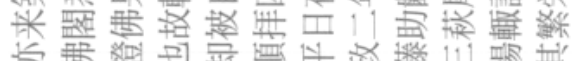

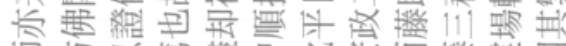

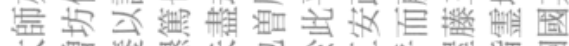

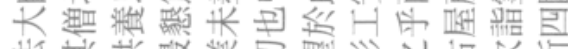

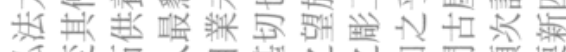

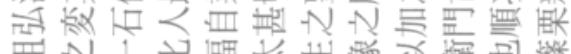

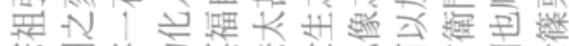

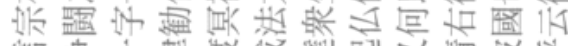

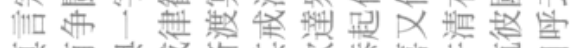

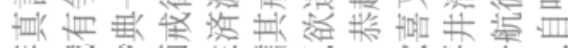

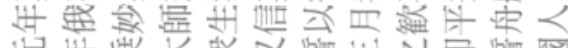

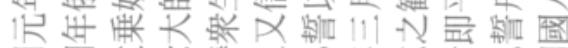

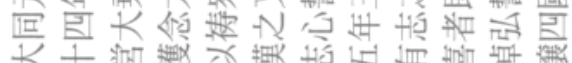

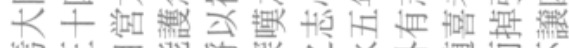

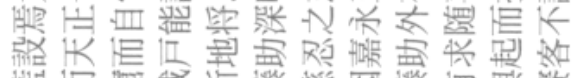

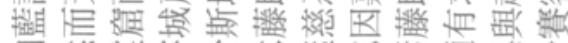

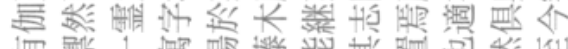

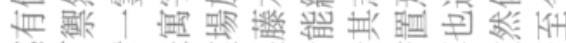

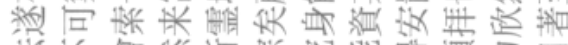

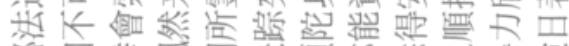

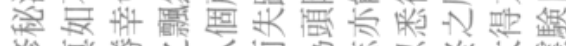

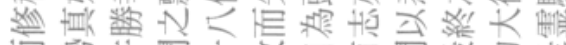

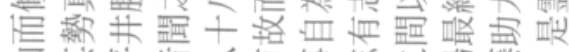

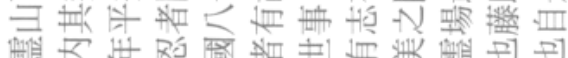

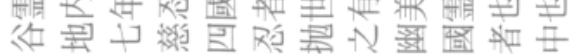

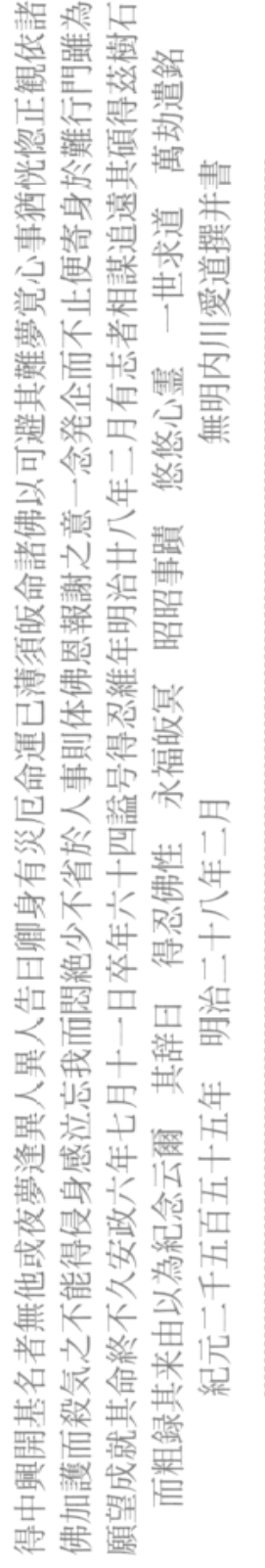

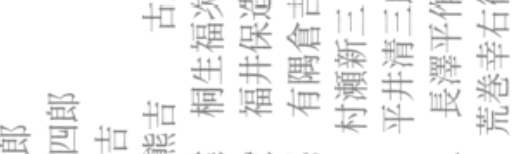

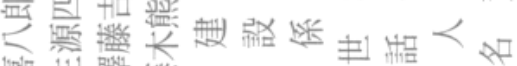

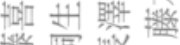

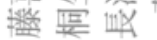

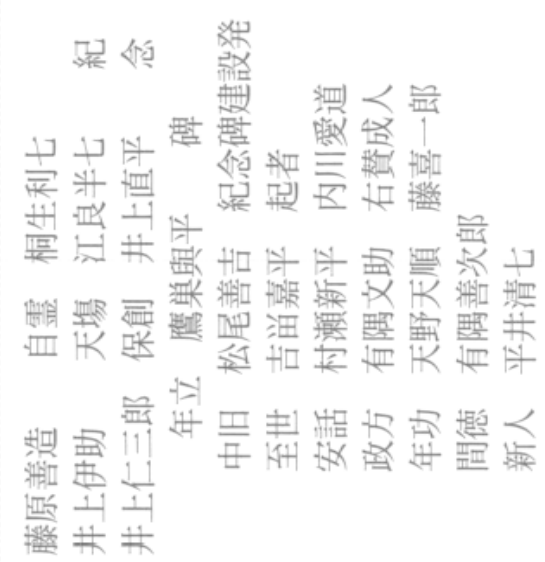

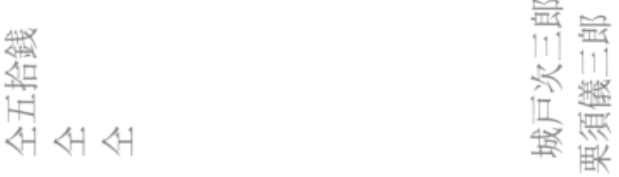

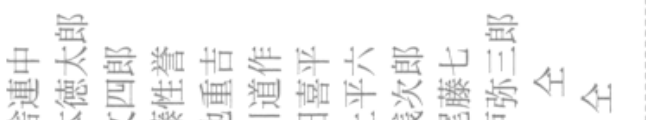

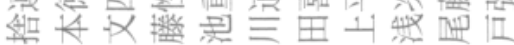

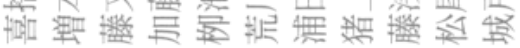

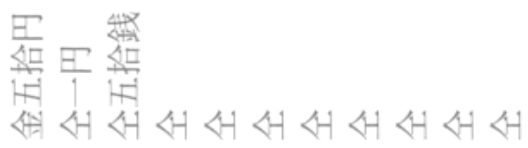
柏究 $\prec \notin$ 慢许 

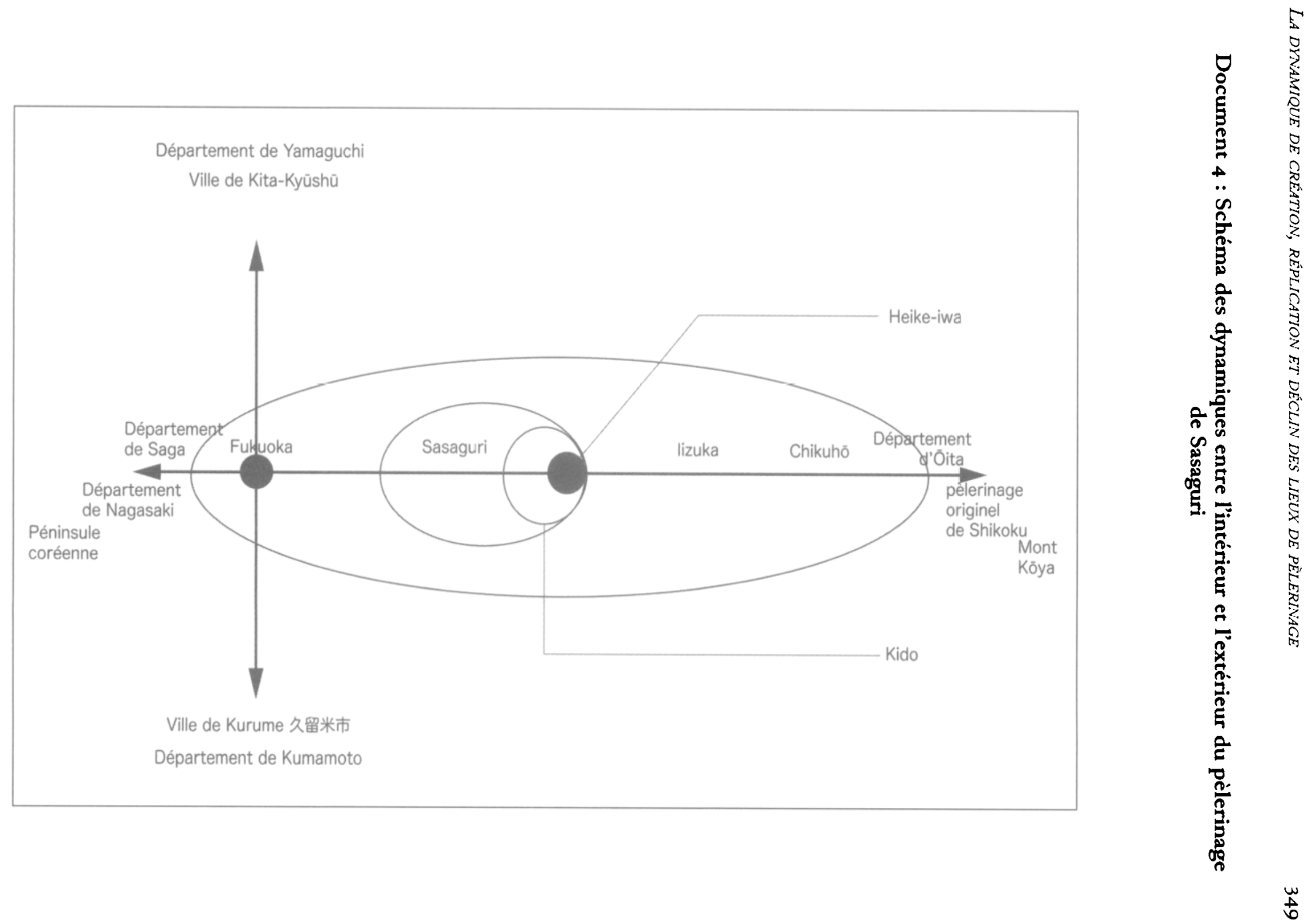


\section{Résumé en japonais/月本衙要旨}

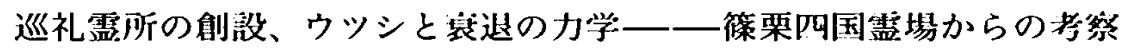

簙栗新四国需場を例に巡礼のウチとソトの力学を検討した。その結果、(1巡礼地が発牛す る力学 (㓣設の力学)、(2)巡礼者が発生する力学（受容の力学）、(3)巡礼地が巡礼者を変え る力学 (作用の力学) 、(4)巡礼者が巡礼地を変える力学（再㓱没の力学）の作用が明らかと なった。(1)と(4)は巡礼地の力学（巡礼地㓣設論）、(2)と(3)は巡礼者の力学（巡礼地利用論） である。これらの学で㩆著なのはウッシ（年/移/遷/映）の力学であった。ソトに ある慧力や威力の资源を摸做することで、少ない労力と知力で効果的に文化を構成してい た。力夕を流用する手法には創造性があり、社会・文化を回転させる動力となっていた。

巡礼には人を変えろ力があるが、篠栗霊場では巡礼者のみならず、被巡礼老、すなわち 巡礼対象を管理したり巡礼者を州話したりする人々の意識や経済状洗が人きく装化させ、 巡礼地と巡礼対象には次々と変化か加えられている。 